\title{
The Mind-Body Connection
}

How Physical Activity

and Physical Fitness

Affect Academic Performance

Vedrana Sember

\section{Shawnda A. Morrison}



The Mind-Body Connection 


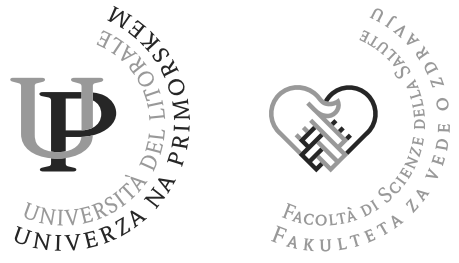




\section{The Mind-Body Connection}

How Physical Activity

and Physical Fitness

Affect Academic Performance

\section{Vedrana Sember} Shawnda A. Morrison

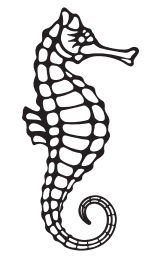


The Mind-Body Connection:

How Physical Activity and Physical Fitness

Affect Academic Performance

Vedrana Sember

Shawnda A. Morrison

Reviewers · Jose Carlos Ribeiro and Janko Strel

Photographs. Shutterstock

Published by · University of Primorska Press

Titov trg 4, 6000 Koper

www.hippocampus.si

Editor in Chief · Jonatan Vinkler

Managing Editor · Alen Ježovnik

Koper $\cdot 2018$

(C) 2018 Vedrana Sember and Shawnda A. Morrison

http://www.hippocampus.si/ISBN/978-961-7055-30-6.pdf

http://www.hippocampus.si/ISBN/978-961-7055-31-3/index.html

https://doi.org/10.26493/978-961-7055-30-6

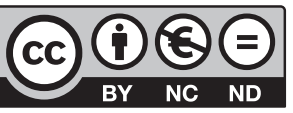

Kataložni zapis o publikaciji (CIP) pripravili

v Narodni in univerzitetni knjižnici v Ljubljani

COBISS.SI-ID $=298153728$

ISBN 978-961-7055-30-6 (pdf)

ISBN 978-961-7055-31-3 (html) 


\section{Contents}

Seznam preglednic $\cdot 7$

Preface $\cdot 9$

\section{Physical Activity 11}

Health-Mind Connection $\cdot 13$

Health Effects $\cdot 13$

Cognition Effects $\cdot 20$

2 Physical Activity Recommendations $\cdot 23$

Europe $\cdot 23$

United States of America $\cdot 25$

Canada $\cdot 28$

Slovenia $\cdot 28$

Adult Physical Activity Guidelines Comparisons · 31

3 Physical Activity: Growth, Maturation and Development • 33

4 Physical Education • 35

Education System $\cdot 35$

Physical Education $\cdot 36$

Europe $\cdot 37$

Slovenia $\cdot 38$

United States of America $\cdot 40$

5 Physical Activity Research - 43

Quantifying Physical Activity · 43

Physical Activity in Numbers $\cdot 52$ 


\section{Contents}

6 Physical Fitness - 67

Quantifying Physical Fitness · 68

Physical Fitness in Numbers · 71

7 Body-Mind Connection $\cdot 73$

Summary $\cdot 79$

References $\cdot 81$

Reviews 109 


\section{List of Tables}

2.1 Comparison of National Physical Activity Recommendations from European Countries for Children (5-18 Years Old) and Younger People $\cdot 26$

2.2 Selected Objectives for Increasing Physical Activity for Children and Adolescents, Healthy People $2010 \cdot 27$

2.3 Comparison between the US (2013), EU (2008), Canadian (2011), and Slovenian (2007) Recommendations on Physical Activity for Adults $\cdot 30$

4.1 Recommended minimum annual taught time for physical education as compulsory subject, $2011 / 2012 \cdot 38$

4.2 Number of Hours of Physical Education (Year) and Physical Activity in Slovenian Primary School Curriculum 40

6.1 Chosen Fitness Test and Associated Physical Fitness Indicator, Test Label and Units in Which Physical Fitness Indicator is Expressed · 70 



\section{Preface}

In modern thinking, there is quite a sharp distinction between mental and physical activities. In addition to separating between mental and physical activities, thinking of the superiority of the language, logic, mathematics, and academics compared to physical activity is also present. Physical activity is any activity that raises heart rate and can be implemented in the form of sports, playing with friends, family, walking to school, dancing or other daily physical activities (Roberts, Tynjälä, \& Komkov, 2004). From the physiological point of view each event produced by contraction of skeletal muscles, which requires consumption of energy (Bouchard et al., 1990) is physical activity.

Physical activity has a positive impact on child's development, but only if it is frequent, of sufficient quality, intensity and duration. Several studies examined the relationship between physical activities, motor and physical development of a child. Since physical activity is an integrative part of every child's development (Grissom, 2005), which combines physical and mental processes, it can be considered an important but not the only factor influencing children's academic performance.

Academic performance is one of the most critical areas in the development of a child, especially in late childhood (Papalia, Olds, \& Feldman 2003). Despite continued dramatic increases in children's health risks, physical education programs are being cut more than ever to make room for more academic time (Shannonhouse, 2012). This negative trend continues despite the evident positive influence 
of physical activity on academic performance. The widest research question of the doctoral dissertation is whether physical activity affects the intellectual development or academic performance of the child and how academic performance of elementary schoolchildren changes through a different quantity of physical activity and time. The following sections review the benefits of physical education and related physical activity on physical fitness and academic performance. A detailed examination of physical activity is discussed next. 


\section{Physical Activity}

Physical activity is a behavior influenced by many factors. These factors work on four levels: physiological, psychological, sociocultural, and ecological (Lindquist, Reynolds, \& Goran, 1999). Physiological level of physical activity in children is determined by age, gender, and ethnicity (Reynolds et al., 1990; Hudson, 2008). It has been found that girls are less active than boys, older children less active than younger and black girls less active than white girls (Ogden et al., 2006; Robinson \& Killen, 1995; Zakarian, Hovell, Hofstetter, Sallis, \& Keating, 1994; Centers for Disease Control, 1997). Psychological determinants of physical activity are self-efficacy (Dishman et al., 2004), a perception of physical competence (Sallis, Prochaska, \& Taylor, 2000), positive attitude (Trost et al., 1997), enjoyment of physical activity (Dishman et al., 2005) and perceiving benefits from engaging in physical activity (Zakarian et al., 1994). Sociocultural factor includes support for participation in activity from peers and siblings, parental level of physical activity (Sallis, Pattersen, Buono, Atkins, \& Nader, 1988; Adkins, Sherwood, Story, \& Davis, 2004), parental support (Sallis \& Saelens, 2000) and parental income. Ecological determinants include facilities, availability of equipment and transportation to activities (Sallis et al., 1992).

Quantity, intensity, frequency and types of physical activity differ by gender and age (Telford, Salmon, Timperio, \& Crawford, 2005). After the second year of life, children begin experimenting with their bodies and various other movements. By the age of 4 are children 


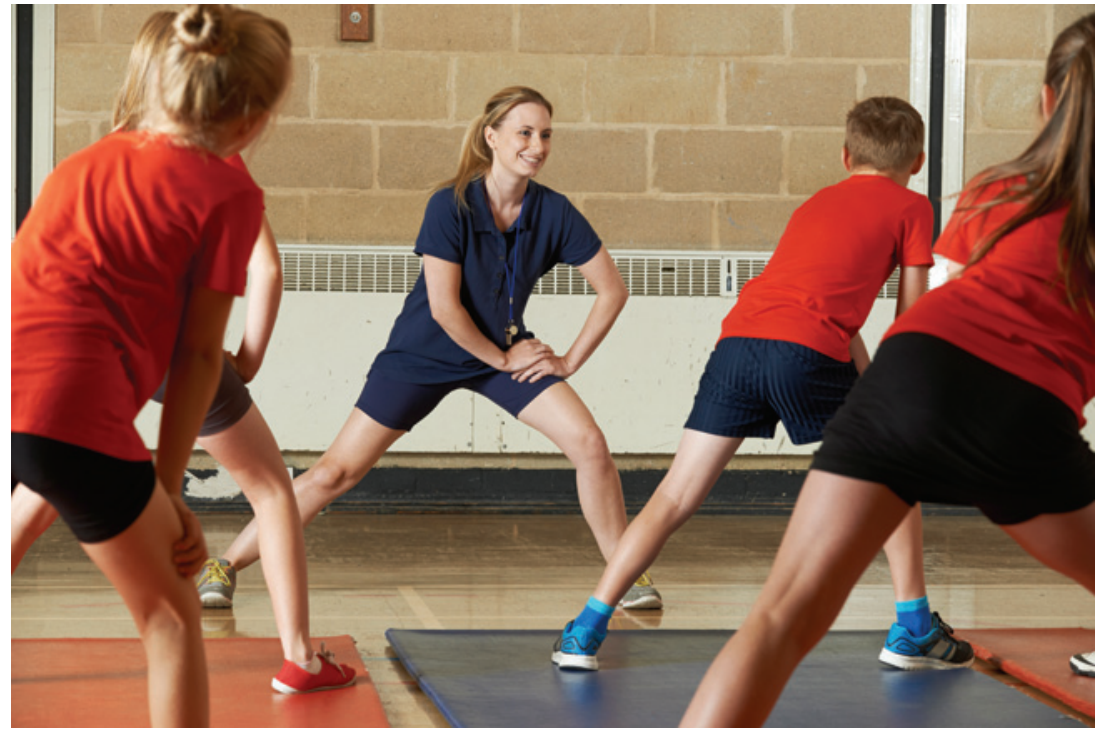

usually proficient in patterns of natural movements, such as running, jumping, throwing and catching and standing or moving on one leg (Škof, 2007). After the age of 7, movement and physical activity becomes more accurate, easy, efficient and useful in different situations. Younger children move more than older, and boys are moving more than girls (Riddoch et al., 2007), and children are physically less active than a decade before (Strel et al., 2003).

Physical activity is any bodily movement, produced by skeletal muscles and resulting in energy expenditure. It can be measured in kilocalories and can be classified into occupational, sports, conditioning, household and other activities. It is a complex behavior, including sports and non-sports activities (Caspersen, Powell, \& Christenson, 1985; Gabriel, Morrow, \& Woolsey, 2012), so also measuring it is complicated. Sports and movement are often planned, structured and repetitive, whereas non-sport activities are occupational and not planned. The difficult nature of physical activity makes it challenging to precisely measure (Plasqui \& Westerterp, 2006) all of its aspects and outcome parameters, such as energy expenditure. Different measuring techniques can be grouped into five categories: behavioral observation, self-report, physiological mark- 
ers, motion sensors and indirect calorimetry (Plasqui \& Westerterp, 2007).

\section{Health-Mind Connection}

Physical activity has positive effects on physical, psychological/social, and cognitive health on school-aged children and youth (Janssen \& LeBlanc, 2010). Evidence showed that physical activity improved body composition and the prevention of overweight and obesity, improved skeletal (Gunter, Almstedt, \& Janz, 2012), metabolic (Janssen \& LeBlanc, 2010) and cardiovascular health (Fernhall \& Agiovlasitis, 2008). Despite biological benefits on biological health, physical activity also affects psychosocial health, such as reduction of symptoms of depression, stress, anxiety and improvements in self-confidence and self-esteem (Biddle \& Asate, 2011).

\section{Health Effects}

It is widely known that physical activity has benefits on psychosocial health, functional ability and overall quality of life (Powell \& Pratt, 1996). The prevalence of childhood obesity and healthconcerned factors is increasing and is anticipated to increase (Zaninotto, Wardle, Stamatakis, Mindell, \& Head, 2006). Promotion of physical activity in children and adolescents has become a key focus to promote health (Lobstein, Baur, \& Uauy, 2004). It has been shown that physical activity reduces blood pressure and certain types of cancer (Batty \& Thune, 2000). Physical activity reduces the risk of coronary heart disease (Batty \& Lee, 2004) and raises cardio respiratory function (Strauss, Rodzilsky, Burack \& Collin, 2001), improves muscular fitness and reduces the risk of falls (World Health Organisation, 1997). Physical activity engages directly on weight reduction and allows better control of fat in blood (Leon \& Sanchez, 2001), reduces the amount of body fat (Kromhout, Bloember, Seidell, Nissinen, \& Menotti, 2011), raises the level of protective cholesterol (HDL), reduces the level of harmful cholesterol (LDL) (Sasaki, Shindo, Tanaka, Ando, \& Arakawa, 1987) and increases bone density (Centres for Disease Control and Prevention, 1997). Low physical activity has been identified as major risk factor for cardiovascular 
disease (Sandvik et al., 1993; Yusuf et al., 2004), which is the leading cause of death for men and women (World Health Organisation, 2010). Elevated body mass index (BMI) represents a greater risk for cardiovascular disease (CVS) as adults (Haque et al., 2008). Physical activity in childhood significantly affects healthy lifestyle and health status in adulthood (Gillander \& Hammarstrom, 2002), since positive linear connections have been established between increased physical activity and positive health outcomes (Pate, 1993).

It has been reported that relations between physical activity of children and benefits on health are hard to find in children (Riddoch, 1998). Following a systematic review of the health benefits of physical activity and fitness in school-aged children (Janssen \& LeBlanc, 2010), authors limited their research on seven health associated indicators. These indicators are high blood cholesterol, hypertension, the metabolic syndrome, obesity, low bone density, depression, and injuries.

It has been reported that relations between physical activity of children and benefits on health are hard to find in children (Riddoch, 1998). Following a systematic review of the health benefits of physical activity and fitness in school-aged children (Janssen \& LeBlanc, 2010), authors limited their research on seven health associated indicators. These indicators are high blood cholesterol, hypertension, the metabolic syndrome, obesity, low bone density, depression, and injuries.

\section{Cardiovascular Disease}

Development of cardiovascular disease becomes evident in middleage, but the beginning of development of cardiovascular disease starts in childhood and adolescence (McGill et al., 2002), especially elevated blood cholesterol and blood pressure. It has been demonstrated that physical activity has a beneficial effect on lipids, lipoproteins (Kraus et al., 2002) and blood pressure (Whelton, Chin, Xin, \& He, 2002) in adults. Armstrong and Simons-Morton (1994) reported minimal, but beneficial effect of physical activity on lipids and lipoproteins in children and adolescents. Aerobic training had only weak relationship with blood pressure, but that kind of 
exercise reduced systolic and diastolic blood pressure in adolescents. After a thorough review of literature, Riddoch (1998) reported that six studies found no beneficial associations (Al-Hazzaa, Sulaiman, Al-Matar, \& Al-Mobaireek, 1994; de Visser et al., 1994; Dwyer \& Gibbons, 1994; Harrell et al., 1996; Rowland, Mattel, Vanderburgh, Manos, \& Charkoudium, 1996) between physical activity and lipids and lipoproteins, whereas another six showed a limited association (Suter \& Hawes, 1993; Bistritzer et al., 1995; Craig, Bandini, Lichtenstein, Schaefer, \& Dietz, 1996; Gutin, Cucuzzo, Islam, Smith, \& Stachura, 1996; Twisk, Kemper, Mellenbergh, Van Mechelen, \& Post, 1996; Boreham, Twisk, Savage, Cran, \& Strain, 1997). 12-year old boys $(n=1005)$ from two Moscow districts were divided into reference group and intervention group participated for three years in a 3-year intervention study. The intervention group received counseling for children and their parents on a diet, physical activity and smoking hazards. Follow up were carried out after 1 and three years, following baseline measures. Examinations at 1-year showed greater reduction cholesterol level, triglycerides, systolic blood pressure in the intervention group (Alexandrov, Maslenikova, Kulikov, Propirnu, \& Perova, 1992). DuBose, McKune, Brophy, Geyer, and Hickner (2015) reported lower systolic blood pressure values related to higher physical activity levels in children $(n=72)$, aged $9.5+1.2$ years. Despite the strong links between physical activity and cardiovascular fitness and coronary heart disease risk in children and adolescents, it appears to be mostly mediated by fatness (Boreham \& Riddoch, 2001).

\section{Metabolic syndrome}

Metabolic syndrome is characterized by hyperinsulinemia, low glucose tolerance, hyperlipidemia, hypertension, and obesity (Brage et al., 2004). Metabolic syndrome has been present in adults (34.4\%), adolescents (8.6\%), and children (5\%) (DuBose, Addy, Ainsworth, Hand, \& Durstine, 2005; Ford, Li, \& Zhao, 2010; Johnson et al., 2009). Obese children and adolescents have higher prevalence of metabolic syndrome compared to non-obese peers (Cook, Weitzman, Auinger, Nguyen, \& Dietz, 2003) and obesity may be a primary risk 
factor for development of metabolic syndrome in youth (Goodman, Dolan, Morrison, \& Daniels, 2005). Physical activity has been negatively associated with development of metabolic syndrome in adults and adolescents and total physical participation seems not to be associated with metabolic syndrome in children (Brage et al., 2004; Ekelund et al., 2007). DuBose et al.(2015) examined the relationship between physical activity and the metabolic syndrome Score in 72 children, aged $9.5+1.2$ years. Metabolic syndrome score was created from blood pressure, waist circumference, high-densitylipoprotein, triglyceride, and glucose values; physical activity was assessed with an accelerometer. Time spent in different levels of physical activity were not related to metabolic syndrome after controlling for confounders. Jiménez-Pavón et al. (2013) report that odds for having metabolic syndrome were higher for boys (6-9year-olds) in the lowest physical activity quartile, compared to children in highest physical activity quantile. Several studies suggest negative associations between metabolic syndrome, physical activity intensity and metabolic syndrome Score (Martínez-Gómez et al., 2009; Ekelund et al., 2007). Martínez-Gómez et al. (2009) reported an interaction between metabolic syndrome score, cardiorespiratory fitness metabolic syndrome score. Children with high physical activity levels and physical fitness had lower metabolic syndrome score than those with low physical activity levels and physical fitness levels. Vigorous physical activity may be substantial for determination the metabolic syndrome score (DuBose et al., 2015).

\section{Obesity}

Obesity is a multifactorial disease which is dependent on many factors and multiple interactions between genes and environment (Maffeis, 2000). Obesity in youth is associated with conditions such as dyslipidemia (Stensel, Lin, Ho, \& Aw, 2001) and an increased risk of type II diabetes mellitus (Sinha et al., 2002). Obesity is defined as excess body fat, which is mostly defined by body mass index (BMI) (Flodmark, Lissau, Moreno, Pietrobelli, \& Wilham, 2004). BMI is a value derived from weight and height of an individual (expressed in units $\mathrm{kg} / \mathrm{m}^{2}$ ). The overweight equivalent in children and adoles- 
cents corresponds to the cut-off points of BMI at or above 25.0 and obesity equivalent corresponds to the cut-off points of BMI at or above 30.0. Children's and adolescents' obesity around the world is a significant health problem and showed an increased prevalence of pediatric and adolescent obesity in Europe (Caroli, 2003), USA (Ogden, Flegal, Carol, \& Johnson, 2002) and in other less developed countries (Ebbeling, Pawlak, \& Ludwik, 2002). Since 1980 the percentage of obese children in the United States aged from 6 to 11 has doubled and the proportion of obese adolescents aged from 12 to 19 has tripled (Centers for Disease Control, 2013). The highest prevalence of overweight children in Europe was found in children and adolescents from Finland, Ireland and Greece (expressed as 85th centile BMI) (Flodmark et al., 2004). In the USA prevalence was higher than in Europe (expressed as 95th centile BMI) (Lissau et al., 2004). More accurate comparisons between American and European children and adolescents cannot be made, since the same method and the same reference values for definition of obesity were not available (Troiano \& Flegal, 1998). The two countries with the highest prevalence of overweight and obese youth participated in Health Behaviour in School-Aged Children Study, were Malta (33.3\%) and United States (31.9\%). Countries with the lowest prevalence of overweight youth were Lithuania $(5.5 \%)$ and Latvia (6.4\%) (Janssen et al., 2005). Children of obese parents have a higher risk of becoming obese compared to children of non-obese parents (Garn \& Clark, 1976). Obesity in childhood and adolescence in $30 \%$ to $60 \%$ of cases continues to obesity in adulthood (Serdula et al., 1993). The risk of obesity is reduced when children and adolescents engage in recommended levels of physical activity daily (Pate et al., 2015).

The rise of childhood obesity became the global trend and is increasingly prominent; $21.4 \%$ of children, aged from 5 to 17 years were considered overweight or obese (OECD, 2012), which represents a double proportion of the comparison in relation to the previous decades. In 1978 and 1979 in Canada 15\% of youth, aged 5 to 17 years were overweight or obese; in 2009-2011 31.5\% of Canadian youth were overweight or obese (Roberts, Shields, de Groh, 
Aziz, \& Gilbert, 2012). To stop the negative trend of obesity among adolescents and children, all children should follow physical activity guidelines within the school premises, since the schools have the maximum control on children's behavior.

\section{Bone Density}

The overall amount of bone during the development and growing years of children represents a major determinant of the risk of fractures in later life. Childhood and adolescence have been identified as the most critical periods of mineralization (Slemenda et al., 1994). The residual bone mass is under environmental influences, which appear to be body mass, diet - calcium intake (Heaney et al., 2000) and the amount and type of physical activity in child and adolescent period (Bailey, Faulkner, \& McKay, 1996). Slemenda et al. (1994) reported 4-7\% increase in bone mineral density for prepubertal children in the highest physical activity quartile. Researchers from the University of Saskatchewan were investigating the influence of physical activity on bone mineral accrual during adolescent years. Children and adolescents in the highest activity quartile had greater peak bone mineral accrual rate and a greater bone mineral accumulation (Bailey, McKay, Mirwald, Crocker, \& Faulkner, 1999). In 10 months, high impact, strength-building exercise program $(n=$ 71) in 9-10 years old girls were investigating positive effects of physical activity on bone and lean mass. At the end of the intervention, there were no differences in height and total body mass, pubertal development or external physical activity. More lean mass, less body fat content, greater shoulder, knee and grip strength and greater total body (control 1.2\%; exercise 3.5\%), lumbar spine (control $1.2 \%$; exercise $4.8 \%$ ), proximal femur (control $1.3 \%$; exercise $4.5 \%$ ) and femoral neck (control 1.7\%; exercise 12.0\%) and bone mineral density (Morris, Naughton, Gibbs, Carlson, \& Wark, 1997) was found. In research, if moderate exercise during growth in prepubertal boys increase areal bone mineral density, twenty boys (mean age 10.4 years) were participating in 8 -months of 30 -minute sessions, three times per week of weight-bearing physical education. The increase in areal bone mineral density in the exercise group was 
twice as in the control group and volumetric bone mineral density increased by $1.14+0.33 \%$ per month $(p<0.05)$ (Bradney et al., 1998).

Physical activity, especially weight-bearing physical activity during childhood is a significant predictor of bone mineral density, while non-weight-bearing activity, such as swimming or cycling is not (Grimston, Willows, \& Hanley, 1993). Longitudinal and interventional studies have shown that increased physical activity in prepubertal children stimulates bone mineral accrual (Bailey et al., 1999; McKay et al., 2000; Fuchs, Bauer, \& Snow, 2001). Overall, physical activity is the stimulus for bone structure and has potential to increase peak bone mass notwithstanding genetics, hormonal and nutritional influences (Boreham \& Riddoch, 2001).

\section{Depression}

Evidence from studies demonstrates that physical activity in adults is inversely associated with depression (North, McCullagh, \& Tran, 1990). Kanner (1990) compared the effects of two levels of exercise in childhood and adolescence depression. Subjects were children and adolescents $(n=68)$ between age 8 and 18 from Psychiatric Treatment Center in California. Children were randomly divided into two groups; high-level exercise treatment and low exercise treatment. Both groups demonstrated a better reduction in depression compared to pre-test but no statistically significant differences between groups in depression outcome score. McPhie and Rawana (2015) examined the influence of physical activity on a trajectory of depression from adolescence through adulthood. They reported lower levels of depression during mid-adolescence in adolescents with engaging in higher levels of physical activity. Biddle and Asate (2011) synthesized reviews investigating physical activity and depression, anxiety, self-esteem and cognitive functioning in children and adolescents.

Four review articles reported evidence concerning depression (Craft \& Landers, 1998; North et al., 1990), which summarized that physical activity over no intervention seemed to be potentially beneficial for reduced depression in children and adolescents. All reviewed articles had certain limitations, such as inclusion in inter- 
ventions with mild depression over a short time frame and bad specification of frequency, duration, and type of activity; therefore all interpretations of articles should be taken with vigilance. Authors summarized that physical activity has positive psychosocial outcomes in young people and higher levels of sedentary behavior are associated with worse mental health.

\section{Injuries}

Despite all the positive features and benefits of physical activity on health in children, every engagement in physical activity can lead toward injuries. Among young elite athletes, 40 injuries per 100 children in lyear incidence rate occurred (Baxter-Jones, Maffulli, \& Helms, 1993). All activities carry an increased risk of acute injuries, physical activity in any competitive form of sports can result in the additional risk for fracture (Van Mechelen, 1997). Injuries sustained during physical activity engagement have been established as a leading cause of injuries in children and adolescents (Brudvik \& Hove, 2003; Finch, Valuri, \& Ozzane-Smith, 1998). Jespersen et al. (2015) described the epidemiology of diagnosed musculoskeletal extremity injuries and incidence rates about different settings, body regions and injury types in children, aged 6-12 years. Overall, the total of 1259 injuries were diagnosed, with an overall rate of 1.59 injuries per 1000 physical activity units.

To ensure positive effects of physical activity on children's health, all activities need to be under the watchful eye of teachers and parents, because injuries can lead to absenteeism in school, sport and the occurrence of incipient depression. Injuries may result in locomotors inactivity, weakening of the locomotors system, obesity, high blood cholesterol and bad habits of children and adolescents in the most critical period of development.

\section{Cognition Effects}

Physical inactivity influences not only the health of children but also cognitive and brain health (Chaddox, Pontifex, Hillman, \& Kramer 2011). Low levels of activity and aerobic fitness are associated with declines in academic achievement (Chaddock, Pontifex, Hillman, \& 
Kramer, 2011), brain structure, cognitive abilities and brain function (Sibley \& Etnier, 2003; Castelli, Hillman, Buck, \& Erwin, 2007; Chaddock et al., 2010).

Research findings in aging population studies showed that exercise and physical activity are protective against cognitive decline, especially working memory and executive planning (Kramer et al., 1999; Van Boxtel et al., 1997). Physical activity may increase oxygen saturation (Kramer et al., 1999) and angiogenesis (Kleim, Cooper, \& VandenBerg, 2002) in brain area responsible for task performance. Several studies have demonstrated a positive relationship between aerobic fitness and cognition (Colcombe \& Kramer, 2003; Chaddock et al., 2010). The prefrontal cortex and the hippocampus are the focus of many human studies of activity and neurocognition; molecular architecture and behavior of basal ganglia may be influenced by physical activity (Chaddock et al., 2010). The prefrontal cortex is the cerebral cortex in the front part of the lobe, containing Brodmann areas 9, 10, 11, 12, 46 and 47 (Finger, 2001). The functions carried out in prefrontal cortex are executive functions, such as planning complex cognitive behavior, personality expression, decision making, and moderating social behavior (Yang \& Raine, 2009). The hippocampus is located in the temporal lobe of each cerebral cortex. Humans have two hippocampi, one in the left part of the temporal lobe and the other in the right part of the temporal lobe. As part of the limbic system, the hippocampus plays a major role in memory, spatial memory, and navigation. Basal ganglia are situated at the base of the forebrain. Principal components of the basal ganglia are the dorsal striatum, ventral striatum, globus pallidus, ventral pallidum, substantia nigra and subthalamic nucleus. The basal ganglia are primarily responsible for motor control, motor learning, executive functions and emotion (Lanciego, Luquin, \& Obeso, 2012).

Chaddock et al. (2010) reported that exercise influences the striatum by increasing dopamine signaling and angiogenesis. Children with higher aerobic fitness levels showed less behavioral interference to misleading and irrelevant flanking cues (Chaddock et al., 2010). Their results supported that dorsal striatum is involved in cognitive control, motor integration and response resolution (Aron, 
Poldrack, \&Wise, 2009). Welk, Morrow and Falls (2002) reported that lower levels of aerobic fitness were associated with longer reaction time in youth and decreased response accuracy; children in higher levels of aerobic fitness were not behaviorally different. ChaddockHeyman et al. (2014) reported that children with higher aerobic fitness levels had greater white matter integrity and subcortical structures than children in lower aerobic fitness levels. White matter and subcortical structures are critical for learning and memory. They were the first to demonstrate that aerobic fitness in children is positively associated with brain and cognitive health, using diffusion tensor imaging. Researchers showed that higher fit children show greater fractional anisotropy in sections of the corpus callosum, corona radiata, and superior longitudinal fasciculus, compared to lower fit children. 


\section{Physical Activity Recommendations}

Physical inactivity is identified as the fourth leading (6\% of deaths globally) risk factor for global mortality (World Health Organisation, 2010). Physical inactivity, non-communicable diseases (NCDs) and general health problems of the population are rising worldwide. Following recommendations from World Health Organization (2010), all children aged 5-17 years should be participating in a variety of physical activities that support natural development, are enjoyable and safe. Recommendations include play, games and sports, active transportation, recreation, physical education, planned exercise, school and community activities.

Children aged 5-17 years should accumulate at least 60 minutes of moderate- to vigorous-intensity (MVPA) physical activity per day, what is more than 60 minutes provides additional health benefits. Most of the physical activities should be aerobic (World Health Organisation, 2010). Examples of MVPA include basketball, racquet sports, soccer, dance, swimming laps, skating, brisk walking, jogging, stair climbing, strength training, cross-country skiing and cycling.

\section{Europe}

The European recommendations are based primarily on the recommendations of the World Health Organisation (World Health Organisation, 2002), which are not completely adequate for the European population since $40-60 \%$ of the people of Europe lead a sedentary life (EUPAG, 2008). Many of State Members of the European Uni- 


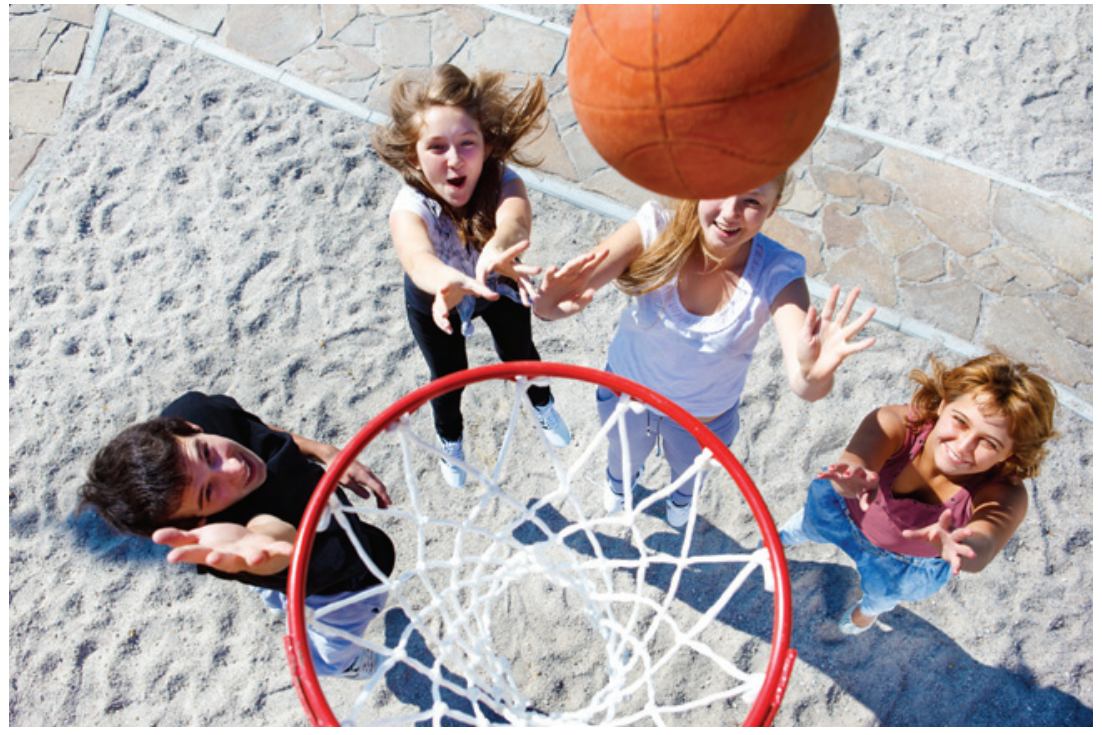

on have national guidelines for physical activity which help health agencies and private institutions to promote the importance of physical activity. The EU Working Group 'Sport \& Health' (2008) made recommendations that would promote increased physical activity in the European Union. These recommendations are addressed primarily to policy makers as inspiration for a formulation of national physical activity guidelines. The first guideline is based on World Health Recommendation. European Union recommended a minimum of 60 minutes of daily moderate-intensity for children and youth and at least of 30 minutes of daily moderateintensity physical activity for adults and seniors (EUPAG, 2008). European guidelines were divided into sections sport; health; education; transport, environment, urban planning and public safety; working environment and services for senior citizens.

Kahlmeier et al. (2015) reviewed and systematically analyzed physical activity recommendations of the World Health Organisation for the European region. Review of the research article contains information on national recommendations and guidelines for physical activity. Information about national physical activity recommendations were found only in 37 countries $(\sim 70 \%)$. Only 
21 countries developed recommendations including frequency, intensity, and duration of activity ( $\sim 40 \%)$. Recommendations for children (Table 1) have been developed only in 14 European countries $(\sim 26 \%)$ and for older adults only in 6 countries $(\sim 11 \%)$. Countries with developed physical recommendations in Europe for all age groups are Austria (Titze et al., 2010), Iceland (Public Health Institute, 2008), Ireland (Department of Health and Children, 2009), Netherlands (Ministry of Health, Welfare and Sport, 2005) and United Kingdom (Department of Health, 2011).

According to review article of Kahlmeier et al. (2015), physical activity recommendations were available only for about onethird of countries, mostly from central and eastern part of Europe. Around $40 \%$ of countries in the European Union did not develop national recommendations till 2015.

\section{United States of America}

Healthy People Organisation provides science-based objectives for improving health in the United States of America. The organisation developed new goals and objectives for health and disease prevention in States every 10-years for the past 30 years (US Department of Health and Human Services, 2014). Healthy People 2010 ranked physical activity as leading health indicator and developed goals to increase physical activity levels among adults, children, and adolescents and to reduce sedentary behavior among adolescents (US Department of Health and Human Services, 2000). Two most important objectives in Healthy People 2010 (US Department of Health and Human Services, 2000) are to increase the amount of moderateto-vigorous physical activity among all population subgroups and increase opportunities and facilities where people can be physically active. Objectives for increasing physical activity for children and adolescents are seen in Table 2.

Committee on Physical Activity and Physical Education in the School Environment from Institute of Medicine of the National Academies, Washington (2013) formulated recommendations for physical activity and divided them into six areas: whole-of-school approach, considering physical activity in all schools related policy 
Table 2.1 Comparison of National Physical Activity Recommendations from European Countries for Children (5-18 Years Old) and Younger People

\begin{tabular}{|c|c|c|c|c|}
\hline Country/Org. & Inactivity & Duration & Intensity & Frequency \\
\hline $\begin{array}{l}\text { World Health } \\
\text { Organisation }\end{array}$ & & $\begin{array}{l}\text { At least } 60 \\
\text { minutes. }\end{array}$ & $\begin{array}{l}\text { Moderate-to- } \\
\text { vigorous. }\end{array}$ & Every day. \\
\hline Austria & $\begin{array}{l}\text { Sitting more } \\
\text { than } 60 \\
\text { minutes. }\end{array}$ & 60 minutes. & $\begin{array}{l}\text { At least mod- } \\
\text { erate. }\end{array}$ & Every day. \\
\hline Belgium & & 60 minutes. & Moderate. & Every day. \\
\hline Denmark & & $\begin{array}{l}\text { At least } 60 \\
\text { minutes. }\end{array}$ & Moderate. & Every day. \\
\hline $\begin{array}{l}\text { Finland (for } \\
\text { children 7-18 } \\
\text { years old). }\end{array}$ & $\begin{array}{l}\text { Sitting more } \\
\text { than } 120 \\
\text { minutes. }\end{array}$ & $\begin{array}{l}60-120 \\
\text { minutes. }\end{array}$ & $\begin{array}{l}\text { All-round } \\
\text { activity. }\end{array}$ & Every day. \\
\hline France & & 60 minutes. & $\begin{array}{l}\text { Moderate-to- } \\
\text { vigorous. }\end{array}$ & Every day. \\
\hline Iceland & $\begin{array}{l}\text { More than } 120 \\
\text { minutes. }\end{array}$ & 60 minutes. & & Every day. \\
\hline Ireland & & 60 minutes. & $\begin{array}{l}\text { Moderate-to- } \\
\text { vigorous. }\end{array}$ & Every day. \\
\hline Luxembourg & & 60 minutes. & Moderate. & Every day. \\
\hline Malta & & 30-60 minutes. & $\begin{array}{l}\text { Moderate-to- } \\
\text { vigorous. }\end{array}$ & Every day. \\
\hline Netherlands & & 60 minutes. & Moderate & Every day. \\
\hline Norway & & 60 minutes. & $\begin{array}{l}\text { Moderate-to- } \\
\text { vigorous. }\end{array}$ & Every day. \\
\hline Sweden & & 60 minutes. & $\begin{array}{l}\text { Moderate-to- } \\
\text { vigorous. }\end{array}$ & Every day. \\
\hline Switzerland & $\begin{array}{l}\text { More than } 120 \\
\text { minutes. }\end{array}$ & 60 minutes. & $\begin{array}{l}\text { Equivalent to } \\
\text { brisk walking } \\
\text { or cycling. }\end{array}$ & Every day. \\
\hline $\begin{array}{l}\text { United King- } \\
\text { dom }\end{array}$ & & $\begin{array}{l}\text { At least } 60 \\
\text { minutes. }\end{array}$ & $\begin{array}{l}\text { Moderate-to- } \\
\text { vigorous. }\end{array}$ & Every day. \\
\hline
\end{tabular}

decisions, designating physical education as a core subject, monitoring physical education and opportunities for physical education. Whole-of-school approach advocates for 60 minutes of physical activity daily and at least 30 minutes in moderate to vigorous level of physical activity in the school time in elementary school. 
Table 2.2 Selected Objectives for Increasing Physical Activity for Children and Adolescents, Healthy People 2010

\begin{tabular}{llll}
\hline Objective & Population & Baseline 2010 objective \\
\hline $\begin{array}{l}\text { At least } 30 \text { minutes of moderate } \\
\text { physical activity }>5 \text { of previous } 7 \\
\text { days }\end{array}$ & adolescents & $27 \%$ & Increase to 35\% \\
\hline $\begin{array}{l}\text { Vigorous physical activity that } \\
\text { promotes the development and } \\
\text { maintenance of cardiorespirat- } \\
\text { ory fitness }>3 \text { days per week for } 20 \\
\text { minutes }\end{array}$ & Adolescents & $65 \%$ & Increase to 85\% \\
\hline Daily school physical education & Adolescents & $29 \%$ & Increase to 50\% \\
\hline $\begin{array}{l}\text { Walking to school }<1 \text { mile } \\
\text { Bicycling to school }<2 \text { miles }\end{array}$ & $\begin{array}{l}\text { Children and ad- } \\
\text { olescents }\end{array}$ & $31 \%$ & Increase to 50\% \\
& Children and ad- & $2.4 \%$ & Increase to 5\% \\
\hline
\end{tabular}

For easier understanding, this is equivalent to 150 minutes per week. Students should engage in additional physical activities during recess, dedicated physical activity time and other opportunities (Committee on Physical Activity and Physical Education in the School Environment, 2013). With recommendation Physical Activity in All School-Related Policy Decisions scientists advocate for regular access for physical activity in the school environment as a contributing factor in children's health, development and improving academic performance. In implementation, this refers to after-school programming, participation in sports, active transport to and from school, agreements between schools and community sports objects to share places to be physically active after schooltime. School Physical Education is the only opportunity for some children to make something for their health, be physically active and excess negative energy. Despite negative tendencies of daily physical activity and growing concern about physical inactivity in the United States, physical education is not treated as a core subject. United States Department of Education and health agencies need to find innovative applications of physical education as a core subject, to measure and highlight outcomes. In the fourth recom- 
mendation the committee states that all education, health and government agencies should develop data systems to monitor policies and behaviors to provide a foundation for planning, developing and implementing physical activity in schools. Next recommendation, Providing Preservice Training and Professional Development for teachers, is based on educating physical education and classroom teachers to be more professional from the field sport and physical activity and to promote physical activity across the curriculum. The last recommendation is Enduring Equity in access to Physical Activity and Physical Education, which should pursue equal access to facilities and opportunities for physical activity.

\section{Canada}

Canada's first physical activity guidelines were introduced in 2002 (Health Canada, 2002). Two sets of guidelines were published, separately for children aged 6 to 9 years and youth aged 10 to 14 years (Health Canada, 2002). Canada launched new guidelines for physical activity for children, youth, adults and older adults in January 2011. The process of updating Canadian Physical Activity Guidelines lasted from November 2006 till the launch day to Canadians in January 2011. Canadian guidelines are relevant to all healthy children (aged 5-11 years) and youth (12-17 years). Children and youth should be physically active as a part of play, games, transportation, recreation, physical education or planned exercise. For health benefits, they should accumulate at least 60 minutes of moderate- to vigorous physical intensity per day and should include vigorous-intensity and activities that strengthen muscles and bones at least three times per week. Adults (18-64 years) should accumulate at least 150 minutes of moderate- to vigorous-intensity physical activity per week, which can be in sessions of at least 10 minutes. Physical activity should include activities that strengthen muscles and bones at least two days per week (Tremblay et al., 2011).

\section{Slovenia}

Slovenia made directives and recommendations for physical activity, but only for adults. Recommendations for physical activity in 


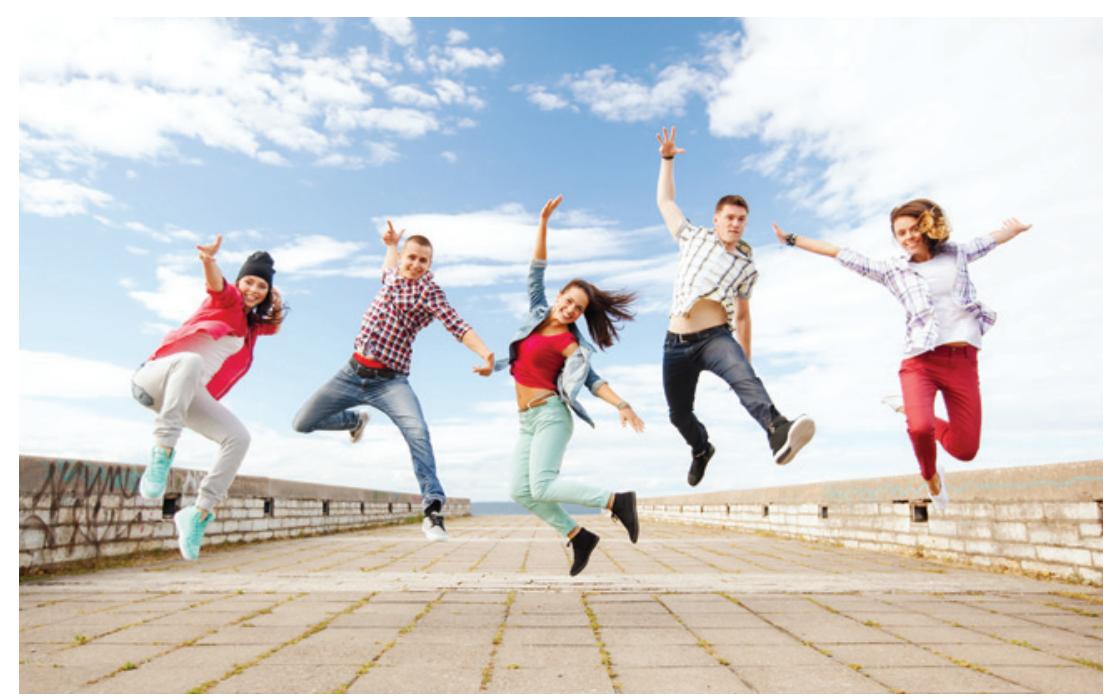

Slovenia are divided into four sectors: type, intensity, frequency and duration of physical activity (Fras \& Poličnik, 2007). Traditional recommendations advise aerobic activities, which require the use of large muscle groups and are continuous (brisk walking, jogging, cycling, swimming, ice skating, cross-country skiing). Newer guidelines recommend walking or any activities which can be carried out daily with every-day intensity, such as moderately intense housework (such as lifting or carrying devices), moderately heavy gardening, ball games and other games with children, moderately intense swimming, slow jogging (about $7 \mathrm{~km} / \mathrm{h}$ ). It is important that the physical activity in relation to the type of activity is balanced. Activity should be partitioned into 50\% aerobic activities, $25 \%$ flexibility exercises and $25 \%$ of exercises to strengthen the muscles.

Intensity of physical activity should range between $50-85 \%$ of maximum aerobic capacity (oxygen consumption) or moderate physical activity of energy consumption of 3 to 6 MET or 4 to $7 \mathrm{kc}$ $\mathrm{al} / \mathrm{min}$. Daily or 5 times/week. Duration of physical activity should range between 30 and 60 minutes; newer recommendations allow intermittent exercise in several daily sessions with shorter or longer intervals if activity cannot be carried continuously. Duration of each session should not be shorter than 10 minutes, and all 
Table 2.3 Comparison between the US (2013), EU (2008), Canadian (2011), and Slovenian (2007) Recommendations on Physical Activity for Adults

\begin{tabular}{|c|c|c|c|}
\hline $\begin{array}{l}\text { European Union } \\
\text { recommendations } \\
\text { (EUPAG, 2008). }\end{array}$ & $\begin{array}{l}\text { United States re- } \\
\text { commendations } \\
\text { (US Department of } \\
\text { Health and Human } \\
\text { Services (2008). }\end{array}$ & $\begin{array}{l}\text { Canadian } \\
\text { guidelines } \\
\text { (Tremblay et al., } \\
\text { 2011). }\end{array}$ & $\begin{array}{l}\text { Slovenian recom- } \\
\text { mendations (Fras } \\
\text { \& Poličnik, 2007). }\end{array}$ \\
\hline $\begin{array}{l}\text { At least } 150 \\
\text { minutes/week } \\
\text { of moderate- } \\
\text { intensity phys- } \\
\text { ical activity or at } \\
\text { least } 60 \text { minutes of } \\
\text { vigorous-intensity } \\
\text { physical activity }\end{array}$ & $\begin{array}{l}\text { At least } 150 \\
\text { minutes/week of } \\
\text { moderate-intensity } \\
\text { physical activity } \\
\text { or } 75 \text { minutes of } \\
\text { vigorous-intensity } \\
\text { aerobic activ- } \\
\text { ity/week }\end{array}$ & $\begin{array}{l}\text { At least } 150 \\
\text { minutes/week } \\
\text { of moderate- to } \\
\text { vigorous-intensity } \\
\text { physical activity }\end{array}$ & $\begin{array}{l}\text { At least } 150- \\
210 \text { minutes of } \\
\text { moderate-intensity } \\
\text { physical activ- } \\
\text { ity/week }\end{array}$ \\
\hline $\begin{array}{l}\text { Activity can be } \\
\text { accumulated in } \\
\text { blocks of at least } 10 \\
\text { minutes. }\end{array}$ & $\begin{array}{l}\text { Activity should } \\
\text { be in episodes } \\
\text { of at least } 10 \\
\text { minutes and } \\
\text { spread throughout } \\
\text { the week. }\end{array}$ & $\begin{array}{l}\text { Activity can be } \\
\text { accumulated in } \\
\text { blocks of at least } 10 \\
\text { minutes. }\end{array}$ & $\begin{array}{l}\text { Activity could be } \\
\text { in sessions, which } \\
\text { could not be short- } \\
\text { er than } 10 \text { minutes } \\
\text { and all sessions to- } \\
\text { gether at least } 30 \\
\text { minutes. }\end{array}$ \\
\hline \multirow[t]{2}{*}{$\begin{array}{l}\text { Activities to in- } \\
\text { crease muscular } \\
\text { strength and en- } \\
\text { durance should be } \\
\text { added } 2 \text { to } 3 \text { days } \\
\text { per week. }\end{array}$} & $\begin{array}{l}\text { Adults should } \\
\text { also do muscle- } \\
\text { strengthening } \\
\text { activities of mod- } \\
\text { erate or high in- } \\
\text { tensity and involve } \\
\text { all major muscle } \\
\text { groups on } 2 \text { or } \\
\text { more days. }\end{array}$ & $\begin{array}{l}\text { Activities to in- } \\
\text { crease muscular } \\
\text { strength and en- } \\
\text { durance should be } \\
\text { added } 2 \text { days per } \\
\text { week. }\end{array}$ & \\
\hline & $\begin{array}{l}\text { Adults should in- } \\
\text { crease their aer- } \\
\text { obic activity to } \\
300 \text { minutes per } \\
\text { week of moder- } \\
\text { ate intensity or } 150 \\
\text { minutes of vigor- } \\
\text { ous intensity. }\end{array}$ & & $\begin{array}{l}\text { All physical activ- } \\
\text { ity should be por- } \\
\text { tioned: } 50 \% \text { aer- } \\
\text { obic activities, } 25 \% \\
\text { flexibility exercises } \\
\text { and } 25 \% \text { of exer- } \\
\text { cises to strengthen } \\
\text { the muscles. }\end{array}$ \\
\hline
\end{tabular}

sessions should sum at least 30 minutes altogether. Bratina et al. (2013) published a scientific review article in Slovenian language 
with guidelines for physical activity for Slovenian children, aged 2-18 years. Authors concluded that children should accumulate at least 60 minutes of moderate- to vigorous physical activity daily and to heat before exercise and calm and relax after physical activity.

\section{Adult Physical Activity Guidelines Comparisons}

European recommendations are based on World Health Organisation recommendations (World Health Organisation, 2002) for physical activity. American recommendations are based primarily on policy changes and actions to increase physical activity. This approach also includes sport, health, education, environment, safety, work and services for the elderly and active transport (US Department of Health and Human Services, 2008). Canadian guidelines are based on observation and systematic process of forming new guidelines for physical activity. Canadian and American recommendations provided recommendations for all age groups but in Europe only six countries of 53 (Kahlmeier et al., 2015). Irrespective of different policy in countries, all recommendations are very similar, almost identical and follow recommendations of World Health Organisation (2002). Many guidelines recommend that children and youth spend minimum of 60 minutes of moderate- to vigorousintensity physical activity (MVPA). The importance of MVPA is crucial and could not be overstated, all intensities of physical activity may be substantial for health promotion and disease prevention (Carson et al., 2013). There are currently no recommendations that include light-intensity physical activity (LPA), which may be due to the historical focus on MVPA (Marshall and Ramirez, 2011). 



\section{Physical Activity: Growth, Maturation and Development}

In physical activity research, pedagogy, pediatrics, human biology and biological anthropology terms like growth and maturation are often in the center of attention. Both processes are often mentioned in the same sentence. Nevertheless, each refers to particular biological activity. Natural growth and maturation of children and adolescents have been studied for more than 150 years (Malina, Bouchard, \& Bar-Or, 2004). Growth is linked to maturation (Hermanussen, 2010). Processes growth and maturation are very important to understand the children's and adolescents' biological variability in the phase of development. Growth and maturation are often used in conjunction with term development (Bose, 2007). Development is a widely used term, which refers to biological, psychological and emotional changes between birth and the end of adolescence.

Growth is an increase in size, cell number or hyperplasia, cell size or hypertrophy and intercellular substance or accretion. As children grow, they become taller, heavier; they increase in lean and fat mass and their organs increase in size (Malina et al., 2004). Maturation is often described as the process of becoming mature and refers to the timing and tempo toward the mature biological state. Timing refers to when some specific events occur, e.g. appearance of pubic hair and tempo refers the rate at which maturation progress youngster is. Timing and tempo of maturation are different in children at the same age and the same size. Since maturation and growth are closely related, they must be viewed as dynamic. 


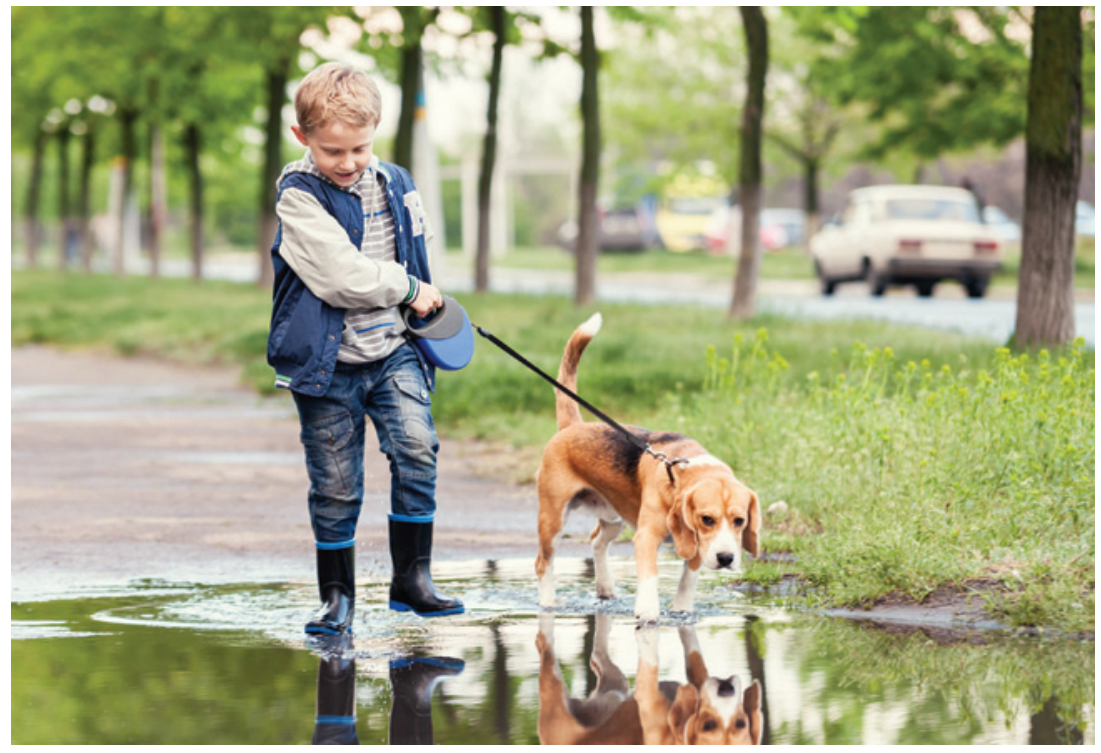

In the transition from childhood to adolescence children undergo many changes. Puberty occurs in girls earlier than in boys. Nowadays puberty occurs earlier than in previous years, especially in overweight children (Cheng et al., 2012). There are various methods for determining the degree of maturity. The most accurate estimate is by the skeletal maturity but is not widely used because of the risks associated with x-ray. The maturity of the child can also be determined through the development of the teeth and on the development of secondary sexual characteristics. Often used is also the method for determining the maximum height increments, where the maximum height increase determine the ratio between the length of the legs and body (Mirawald, Baxter-Jones, Bailey, \& Beunen, 2002). 


\section{4}

\section{Physical Education}

\section{Education System}

Education system in European Union is classified by International Standard Classification of Education - ISCED 2011 (UNESCO Institute for Statistics, 2012). ISCED provides framework for presenting national education data in comparable manner - internationally agreed categories (Eurydice, 2014): Early Childhood Education (ISCED 0), Primary education (ISCED 1), Lower secondary education (ISCED 2), Upper secondary education (ISCED 3), Postsecondary non-tertiary education (ISCED 4), Short-cycle tertiary education (ISCED 5), Bachelors' or equivalent level (ISCED 6) and Master's or equivalent level (ISCED 7). Fort-two education systems are included covering 37 countries from Europe continent (28 Member States, Bosnia and Herzegovina, Switzerland, Iceland, Liechtenstein, Montenegro, former Yugoslav Republic of Macedonia, Norway, Serbia and Turkey).

Main organisational models in Europe are divided into Early childhood education and care (ECEC) and Compulsory education (EURYDICE, 2015). In ECEC structure, two main forms can be distinguished (EURYDICE, 2015): unitary system (programmes and settings are provided for whole pre-school range and services and educational guidelines cover entire ECEC range) and split system (children are divided in settings for younger and older pre-school children, where educational guidelines are only provided for older children). Compulsory education consists of three main models of organisation in European countries (EURYDICE, 2015): Single 
structure (general education is provided for all pupils from the beginning till the end of compulsory schooling), Common core curriculum provision (after finishing ISCED 1 all students progress to ISCED 2, where they follow same general common curriculum) and Differentiated lower secondary education (after completing primary education students follow specific types of schooling at the beginning or during lower secondary education).

ISCED 0 finishes at children's age of 6 or 7 years. ISCED 0 normally finishes at 6 or 7 years of age, where ISCED 1 begins and continues till children's age of 9.5 (FRYM, Turkey), 10 (Croatia, Germany, Hungary, Austria, Slovakia, Bosnia and Herzegovina), 10.5 (Serbia), 11 (UK (except Scotland), France, Liechtenstein, Montenegro, Czech Republic, Bulgaria, Romania, Slovenia, Italy, Lithuania, Malta), 11.5 (Cyprus), 12 (Switzerland, Spain, Greece, Ireland, Belgium, Luxembourg, Netherlands, Poland, Portugal, Scotland) and 13 years old (Iceland, Estonia, Denmark, Latvia, Finland, Norway, Sweden) (EURYDICE, 2015). Education system in Slovenia is mainly organised as public service, where public schools are secular and school environment autonomous. Italian and Hungarian ethnic minorities have the right to Study in Slovenian educational system in their own language. Slovenian education system in organised in several levels of education: Pre-school education (optional in Slovenia, funded and financed by municipalities), Compulsory basic education (single structure nine-year basic school, funded and financed by municipality and state), Upper secondary education (takes 2-5 years, funded and financed by state) and Tertiary education (short-cycle higher education and higher education; see https://webgate.ec.europa.eu/fpfis/mwikis/eurydice/index.php).

\section{Physical Education}

Often there is a misunderstanding with terms physical activity and physical education. Physical activity is behaviour and physical education is curriculum area that educates about physical activity. Main goal for quality physical education is to develop physically educated children who have the knowledge and confidence to enjoy being physically active for a lifetime. Physical education as a school 
subject is teaching school-aged children methods and science of health, sport, physical fitness and gross motor skills (Robinson, 2011). Physical education uses comprehensive, but physically active approach, who involves teaching social, cognitive and physically active approach. Physical education is education through the physical (Siedentop, 2009).

School physical education accounts for a large proportion of children's physical activity and has positive effect on the development of motor abilities (EUPAG, 2008). When comparing the pupils attending sports classes to those who do not have any extra hours of physical education, there are significant and noticeable positive changes, especially in terms of better physical fitness dimensions from Slovenian's sports classes (Jurak, Kovač, \& Strel, 2007). Longitudinal data have shown that normal weight adolescents participated in physical education, the odds of becoming overweight in adulthood decreased by $5 \%$ (Menschik, 2008).

\section{Europe}

Physical education in Europe is not limited only to the training in physical abilities and has more than just recreational character. By participating in many physical activities come knowledge and insights focused on the principles of the game, such as honest, respect, tactical and physical consciousness and social awareness related to personal interaction and teamwork in many sports. Health, social integration and good personal development of children give extra weight to its importance in the school curriculum. All European countries recognize importance of physical education, which is part of core curriculums and is compulsory in primary and lower secondary education in Europe. Physical education in European primary schools is taught by generalist or specialist teachers, who need to have bachelor's degree. At lower secondary education, physical education is normally taught by specialist, with bachelors or masters degree. Almost all European countries assess formative and summative personal progress in the field of physical education. Grading system at physical education is usually the same as at the other compulsory subjects. National test of physical 
Table 4.1 Recommended minimum annual taught time for physical education as compulsory subject, 2011/2012

\begin{tabular}{lrlr}
\hline Country & $(1)$ & Country & $(1)$ \\
\hline Germany & $56-85$ & Netherlands & Flexible timetable \\
Estonia & $53-70$ & Austria & $60-120(90)$ \\
Ireland & $37-45$ & Poland & $73-113$ \\
Greece & $45-68$ & Portugal & 81 \\
Spain & $35-53$ & Romania & $30-59$ \\
Belgium & $61-91$ & Slovenia & $67-98$ \\
Bulgaria & $36-64$ & Slovakia & 56 \\
France & $108-144$ & Finland & 57 \\
Czech & 59 & Sweden & 500 hours (2) \\
Denmark & $30-90$ & England and Wales Flexible timetable \\
Italy & 66 & Northern Ireland & Flexible timetable \\
Cyprus & $46-81$ & Scotland & 76 \\
Latvia & $45-49(46)$ & Croatia & $53-79$ \\
Lithuania & $54-72$ & Iceland & 72 \\
Luxembourg & $68-108$ & Turkey & $24-48$ \\
Hungary & $69-83$ & Liechenstein & $59-117$ (88) \\
Malta & $22-64$ & Norway & $68-76$ \\
\hline
\end{tabular}

О Р Ом В Е (1) Average number of hours per year, (2) in 9 years.

education was carried out only in Slovenia in 2009 (European Commission, 2013). Recommended minimum taught time for physical education as compulsory subject is different from country to country (Table 4).

\section{Slovenia}

School physical education in Slovenia is a continuous process of enriching knowledge, developing skills and motor abilities and important tool for formatting personality and relationships between individuals. Regular and quality physical education in Slovenia contributes to the harmonious development of the bio psychosocial development with neutralization of the negative effects of long hours sitting and other unhealthy habits. Healthy lifestyle is also responsible for welfare, health, vitality and life optimism (Ministrstvo za šolstvo in šport, 2011). 


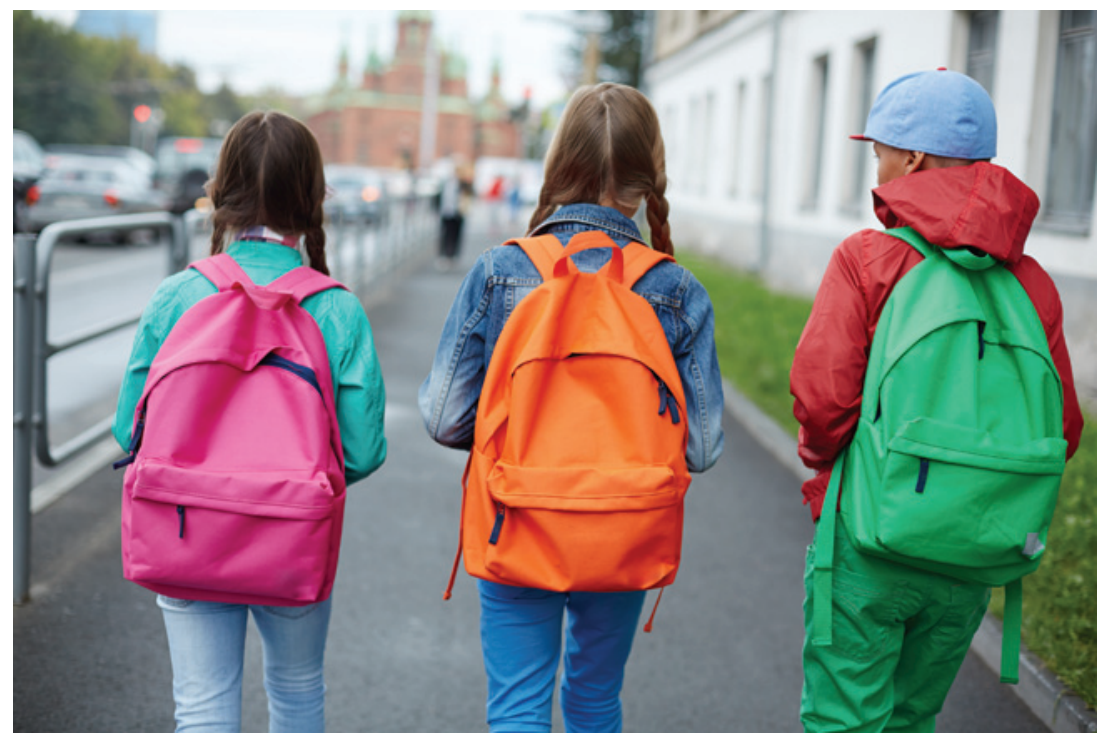

Physical activity classes are in Slovenia divided into: physical education classes and extracurricular program, which is different from school to school. Slovenia have also extracurricular program called Healthy lifestyle, where approximately 150 schools are part of it. Children who are part of Healthy Lifestyle program have 2 extra physical activity hours per week. Physical education in Slovenia is required for every school-aged child.

From 1st to 6th grade in Primary school, children have 105 school hours of physical education per year ( 3 hours/week), 70 hours in 7th and 8th grade ( 2 hours/week) and 64 hours in 9th grade (2 hours/week). One school hour lasts 45 minutes (Kovač, Jurak, Starc, $\&$ Strel, 2011). Pupils from 7th to 9th grade can also choose elective courses. Slovenia offers 6 courses from the field physical activity and sport. These classes are: dance, folklore dances, old and social dances, sport for health, sport for release and selected sports (volleyball, soccer, basketball). Pupils have 1 additional physical education hour per week and 35 hours per year. Students can select one course only once in primary education and maximum 2 courses from field physical activity (Zakon o osnovni šoli, 2006). Combining all physical education and physical activity hours in Slovenian 
Table 4.2 Number of Hours of Physical Education (Year) and Physical Activity in Slovenian Primary School Curriculum

\begin{tabular}{|c|c|c|c|c|}
\hline Grade & Teacher & (1) & $(2)$ & (3) \\
\hline $1 \mathrm{st}$ & \multirow{5}{*}{$\begin{array}{l}\text { Classrom teacher } \\
\text { and physical educa- } \\
\text { tion teacher - special- } \\
\text { ist }\end{array}$} & 105 & & 70 \\
\hline 2nd & & & & \\
\hline 3rd & & & & \\
\hline 4 th & & & & \\
\hline 5 th & & & & \\
\hline 6 th & \multirow{4}{*}{$\begin{array}{l}\text { Classrom teacher } \\
\text { and physical educa- } \\
\text { tion teacher - special- } \\
\text { ist }\end{array}$} & & & \\
\hline 7th & & 70 & 35 & 70 \\
\hline 8th & & & & \\
\hline 9th & & 64 & 35 & 70 \\
\hline
\end{tabular}

о Ромв (1) Hours (year), (2) elective, (3) extracurricular.

curriculum, pupils can achieve up to 6 school hours of physical activity and physical education during school day. Physical education, elective courses and extracurricular program is taught by physical education specialist and classroom teacher (with cooperation with PE teacher first 5 years in primary school). Table 5 shows all the hours of physical education and physical activity, including extracurricular sports activities (not obligatory) and elective sport courses (not obligatory) in Slovenian primary school curriculum.

\section{United States of America}

Physical education became one of subjects in United States schools at the beginning of 19th century, but was presented in forms of German and Swedish gymnastics (Hackensmith, 1966). In early 20th century, learning about personal hygiene and exercise became part of school physical education. Educator Thomas Wood (1913) criticized schools' physical education as being to narrow towards health and hygiene, so physical education was transformed to more holistic approach in terms of physical skills and sport games. During last two decades, physical education became more science, health and body-movement directed subject in school curriculum with goals that facilitate holistic development of children (National Association for Sport and Physical Education, 2004). United States don't 
operate with centralized curriculum; all curriculums are made locally by school districts or individually by schools, what gave physical education in USA great diversity (National Association for Sport and Physical Education, 2010). Physical education in United States is taught in many different forms and structures. Different curriculum models are present, including movement education, sport education and fitness education. Main goal in fitness education curricula is to increase class-physical activity, in sport education and movement education is physical activity only a basis for students to learn skills or knowledge. In sport education students are educated to become sportpersons and they tried roles of coaches, players, captains, referees, statisticians, manager ... Fitness education is teaching children the science behind why they need to be physical active in their lives. The main goal of fitness education curricula for children is to understand fitness concepts, principles, and strategies, to participate in a health-enhancing level of fitness (Kohl \& Cook, 2013). Children in United States of America in primary school receive 150 minutes per week of physical education and 225 minutes per week in secondary school. Physical education classes are taught by classroom teacher (generalist) and physical education teacher specialist; $68 \%$ of elementary schools allow classroom teacher and $82 \%$ and $90 \%$ of states (National Association for Sport and Physical Education, 2010) requires physical education teacher specialist in middle/junior high school and high school. 



\section{5 \\ Physical Activity Research}

\section{Quantifying Physical Activity}

Physical activity can be quantified according to frequency (how often?), intensity (how hard?), duration (how long?), and mode (what type?) (Chen \& Bassett, 2005). If the habitual physical activity is required, some variation should be taken into account, because a regular physical activity is a behavior which can occur only as a result of skeletal muscle activity that is supported by energy expenditure (Armstrong \& Welsman, 2006).

Determining physical activity needs to be socially accepted, should not burden the children with major equipment and should only minimally interfere physical activity of the child (Armstrong \& Welsman, 2006; Livingstone, Robson, Wallace, \& McKinley, 2003). Researchers in the last decade developed a series of methods for identifying and measuring physical activity for children. Based on the literature review the most commonly used scientific methods for determining physical activity are: direct observation or objectively assessed physical activity and indirect or subjectively assessed physical activity (Kohl, Fulton, \& Caspersen, 2000; Welk, Corbin, \& Dale, 2000).

The subjective measure is less reliable than objective and is more easily administered to a population of groups. Subjective methods possess various limitations regarding their reliability and validity and are most commonly used to increase validity and reliability of individual instruments (Shephard, 2003). Direct measures are believed to remove many of the issues of recall and response bias 


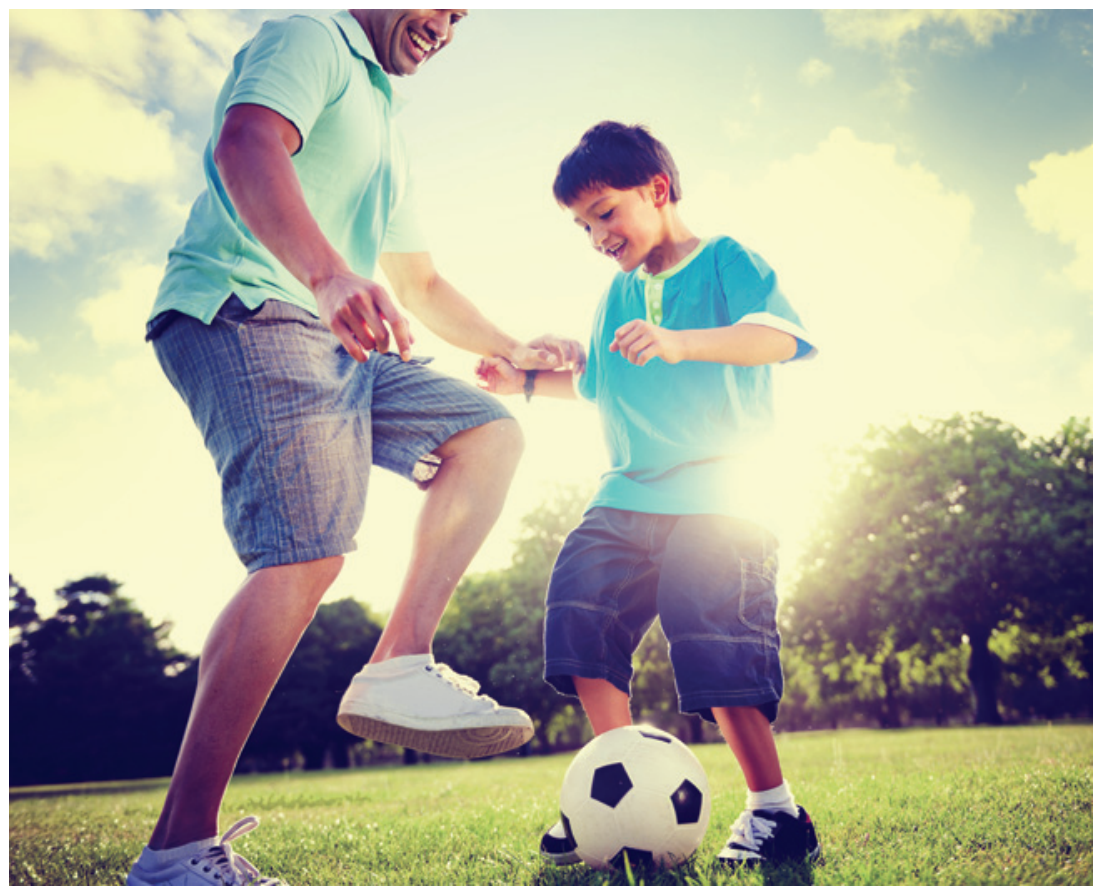

(Prince et al., 2008), but they are time and cost intensive and difficult to apply to large epidemiologic settings. Objective measures also require specialized training, the physical proximity of participants and there is no "gold standard" for measuring physical activity (Dishman, Washburn, \& Schoeller, 2001), since there is a lot of measuring equipment in the market these days.

The appropriate method for measuring physical activity depends on different aspects, such as the number of participants in the study, commercial availability and period of needed measurement.

\section{Objective Methods}

Objective measures of physical activity rely on information presented by another person through direct observation, measuring the temperature of the body or from measurement device like heartrate monitor, accelerometer or pedometer. Objective measures of physical activity are used to predict energy expenditure, which is crucial in terms of decreasing obesity and other diseases related to

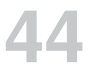


physical activity. Objective measures remove disadvantages associated with subjective measures, are more reliable, involve quantitative analysis of numerical data.

Objective methods can be expensive and are suitable for individuals or smaller groups. With direct (systematic) observation we directly monitor and record children's physical activity at the same time. We can use video and special software for automatic detection of movement patterns. In the past this method was widely spread, however today it is somewhat neglected, although it has many advantages. Observation procedures are flexible, accurate, detailed and offer many descriptions of observed events (environment, equipment, conditions, behavioral ...) (Trost, 2007). It was an important tool in assessment of physical activity, because it uses an objective method and provides rich data, especially in researches studying children, cognitive-behavior and effects of physical and social environments on physical activity (McKenzie, 2001).

Measuring of physical activity is nowadays increasingly directed towards measuring devices, which provide physiologically and mechanically more accurate and reliable data, compared to other techniques (Westerterp, 2009). Measuring devices referred to as 'activity trackers' or 'fitness trackers' are nowadays very popular for personal PA monitoring. Their popularity has risen as they became affordable, unobtrusive and useful in their application (Evenson, Goto, \& Furberg, 2015). Activity trackers can provide feedback and offer recommendations for individual's physical activity, but they are not reliable for scientific purpose to the same extent as accelerometers, pedometers and multiple-sensor devices. Unfortunately, there are no gold standards for measuring physical activity with wearable monitors (Freedson, Bowles, Troiano, \& Haskell, 2012). The choice of measuring device is left to the researcher and depends on several factors: interest, target population, cost and precision of measurement (Ainsworh, Cahalin, Buman, \& Ross, 2015).

Accelerometers are small wearable motion sensors which detect body accelerations in gravitational units (Freedson et al., 2012). The core of accelerometer is a sensor from piezoelectric material, which 
produces voltage as a function of geometric deformation (Chen \& Bassett, 2005). Accelerations are then transferred to a lower resolution called epoch. Epoch is calibrated to a known criterion measure (e.g., oxygen consumption, doubly-labelled water). Most of existing calibration studies are then presented in unitless intensity metric called 'counts' (Freedson et al., 2012). When we have physical activity in counts, we can modify this unitless intensity to different levels of physical activity and energy expenditure. Acceleration is change in velocity over given period of time; therefore, intensity, frequency and duration of measured physical activity can be assessed (Ridgers \& Fairclough, 2011). Compared to measures of oxygen consumption and METs most of accelerometer show a wide range of correlations ( $r=0.45$ to 0.93 ) (Trost, McLever, \& Pate, 2005), which corresponds to a number of protocol-related variations such as accelerometer placement (hip, wrist, wrinkle, trunk) and investigation activities (ambulatory, non-ambulatory).

There are uni-, bi-, and triaxial accelerometers. Uniaxial accelerometer measure accelerations in one direction, biaxial in vertical and horizontal directin and triaxial in three directions: anteroposterior, mediolateral and vertical direction. Triaxial accelerometers provide more information and show the best relationship to activity-related energy expenditure (Bouten, Westerterp, Verduin, \& Janssen, 1994). In physical activity research the most commonly used accelerometer is uniaxial. Researchers found comparable results between uniaxial, biaxial and triaxial accelerometers, because physical activity research prevails in vertical acceleration and this type of accelerometer is cheaper and easier for data processing (Kumahara, Tanaka, \& Schutz, 2004).

Accelerometers can be placed on different body parts: ankle, thigh, chest, wrist, upper or lower back, hips or belly button. In terms of reliability and validity of the data, literature encourages wearing accelerometer on the hips or in the lower back because of the proximity of the center of gravity of the body (Ekelund et al., 2000).

Accelerometer collects and stores data in intervals called epochs, which is usually possible to adjust on $5,15,30,45$ and 60 s or cus- 
tomized to one second or less. Shorter intervals, such as 15s epoch is more suitable for shorter and more intensive movement, because longer interval may not detect a short-lasting movement. Use of a longer epoch does not give an accurate assessment of high intensity activity, but longer epoch ensures longer data collection and storage up to three weeks or more (Nilson, Ekelund, Yngve, \& Sjostrom, 2002). The majority of the studies in children and adolescents used a 60s epoch (66\%) and 15s epoch in preschoolers (42.9\%) (Cain, Sallis, Conway, Van Dyck, \& Calhoon, 2013).

A valid day is one of the conditions we need to take in consideration when measuring with accelerometers. The valid day is defined by a minimum number of wearing hours. Rule $70 / 80$ provides that $70 \%$ of the sample subjects wear an accelerometer for at least $80 \%$ of the daily observation time (Catellier et al., 2005). Minimum number of wearing accelerometer ranges from 3-10 days (Mattocks et al., 2008), 7 days should be reasonable standard for all ages (Ward, Evenson, Vaughn, Rodgers, \& Troiano, 2005). One of these days needs to be weekend day (Rowlands, 2007).

When measuring physical activity with accelerometers, we need to define non-wear time within a day, which is normally identified with summing consecutive zero counts per minute (cpm) and wear time is computed by decreasing the non-wear time from cumulative possible time. It is very important to differentiate between wearing accelerometer but being sedentary and not wearing accelerometer because of sleep time or swimming (Cain et al., 2013).

Pedometer is probably the oldest technique to assess physical activity and was designed by Leonardo da Vinci 500 years ago (Montoye, Kemper, Saris, \& Washburn, 1996). The pedometer records acceleration and deceleration of movement in one direction (Saris \& Binkhorst, 1977). Pedometers provide measure of the number of steps taken during a given period of time (Kohl et al., 2000). Pedometers have been used for measuring physical activity for the last two decades. Advantage of pedometers is low-cost, effectiveness (Buckworth, Lee, Regan, Schneider, \& DiClemente, 2007) and usefulness particularly in the epidemiological studies (Volmut, 2014). Disad- 
vantage of pedometer is that we cannot assess intensity of movement and identify how many steps have been done in the specified intensity and the results assessed from pedometer are poorly associated with accelerometer outcome in everyday living conditions with children (Treuth et al., 2003). Pedometer step count is more inaccurate at speed $<60 \mathrm{~m} / \mathrm{min}$ (Abel et al., 2011), therefore it is not suitable for older people and if the subject is walking faster than normally, pedometer may underestimate total distance, since step count of pedometer is influenced by stride length and speed of walking (Abel et al., 2009).

Heart-rate monitors. Heart rate is an indirect measurement of physical activity and it measures the physiological response of the body. Physical activity rate assessed with heart-rate monitor is closely related to oxygen consumption $\left(\mathrm{VO}_{2}\right)$, thus power consumption at different intensities of physical activity (McArdle, Katch, \& Katch, 2006). Heart-rate monitors record participant's heart rate at given intervals during the period of observation. They gather information about responses of the heart during exercise and physical activity, which could be interpreted as a proxy measure of acute physical activity (Kohl et al., 2000). Minute by minute information from heart-rate monitor gives us information about intensity, frequency and duration of free-living physical activity (Schutz, Weinsier, \& Hunter, 2001). Estimation of energy expenditure accessed via heart-rate monitor is popular, inexpensive, non-invasive and versatile; however, there are various sources in the assessment of physical activity by heart rate because factors other than exercise affect heart rate. Factors such as high ambient temperature, high humidity, and emotional stress will cause an increase of heart rate (Freedson \& Miller, 2000). Beside pedometers and accelerometers heart-rate monitors are major examples of objective measurement (Sirard \& Pate, 2001).

Doubly-Labelled Water (DLW) appears to be a gold standard for validating other methods to measure daily physical activity in freeliving individuals (Starling, Matthews, Ades, \& Poehlman, 1999) and is one of the most accurate assessments of energy consumption in 
the implementation of activities in daily living environment. The method assesses the energy consumption with an accuracy of 1-3\% depending on the results of calorimetry (Speakman, Nair, \& Goran, 1993) and variability of the measurement is between $4-10 \%$ (Speakman, 1998). DLW is noncalorimetric technique for measuring total energy expenditure (TEE) using an oral dose of water which contains nonradioactive isotopes of hydrogen $(2 \mathrm{H})$ and oxygen (18O). Derived CO2, as a product of physical activity, and indirect calorimetry formulas are used to calculate energy expenditure. Physical activity energy expenditure can be calculated knowing total daily energy expenditure (TEE) measured by DLW, resting energy expenditure (REE) and thermic effect of consumed food (TEF), measured by indirect calorimetry (Starling et al., 1999; Plasqui \& Westerterp, 2007). Measurement period normally runs from 1-3 weeks. Samples isotopes may be sampled from all body fluids, but is the most commonly used urine (Volmut, 2014).

AEE (kcal/day) = TEE (kcal/day) - REE ( kcal/day).

Disadvantage of DLW technique is high cost, because of the relatively high price of the oxygen-18 water, mass spectrometer instrumentation and specific technical expertise in sample preparation and measurement (Starling et al., 1999). Despite being the criterion for gold standard, DLW does not provide specific information about daily physical activity, such as activity type, intensity and duration. Taken into consideration all these limitations, DLW is used in scientific manner to validate other techniques and approaches for the quantification of free-living energy expenditure (Westerterp, 2009).

Multi-Sensor Devices. Measuring all aspects of physical activity under free-living conditions is complex; the use of multiple methods of assessing physical activity simultaneously is recommended. Accelerometer and heart-rate monitor together make a powerful tool for assessing energy expenditure. Accelerometer counts verify that elevations in heart-rate are because of increased physical activity or vice versa. Technology has moved on, so new wearable devices are produced. Actiheart (CamNtech Ltd, Cambridge, UK) combines heart-rate and accelerometry (Zakeri, Adolph, Puyau, Vohra, 


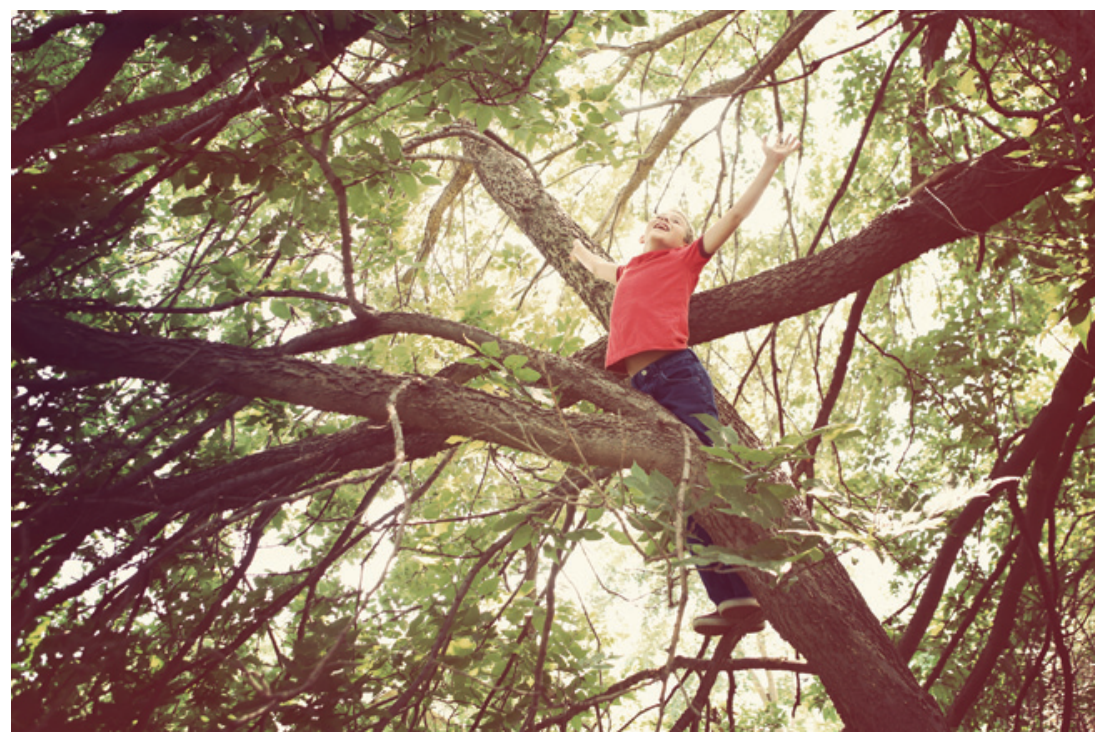

\& Butte, 2008), Intelligent Device for Energy Expenditure and Activity MiniSun (LLC, Fresno, CA) combine five accelerometers which are worn on chest, thighs and feet (Zhang, 2003) and SenseWear Armband (Bodymedia, Inc., Pittsburg, PA) combines triaxial accelerometry, skin temperature, heat flux and galvanic skin response in a single device, worn on the upper arm. These devices collect data on physiological and mechanical variables (Hills, Mokhtar, \& Byrne, 2014). There is no gold standard for objective measurements of physical activity, the choice is complex and it depends on many factors such as time, expertise, desired outcomes and desired physical activity outcomes (Ainsworth, Cahalin, Buman, \& Ross, 2015).

\section{Subjective Methods}

Subjective assessment of physical activity relies on a child remembering activities they participated in or recalling their perception of the intensity of the movement. Subjective assessment of physical activity is useful for measuring the activity of large groups since subjective methods are cheaper than objective. Subjective methods or self-report of assessing physical activity involves qualitative or descriptive recall of behaviours, logbooks, self-reports, proxy reports 
and diaries (Armstrong \& Welsman, 2006; Laggeros \& Lagiou, 2007).

Subjective instruments are the most widely used type of physical activity assessment. It is very important to identify strength and limitations of their use before using them. The recognized benefit of self-report is collected data from a large number of children at low cost. Self-reports have been used in different age ranges and measures can be adapted to fit the need of particular research and population (Sallis \& Saelens, 2000).

Questionnaires are the most common used tools for measuring physical activity with children and adolescents. There are generally two types of questionnaires, the self-report type where the older children and adolescents report on their PA on their own, and the proxy-report where physical activity of young children is reported by parents or teachers (Sallis \& Saelens, 2000). Self-reports have been used in a range of ages, and can be either intervieweradministered or self-administered. In self-report, participants are normally asked to obtain activity participation during a recent period of time (1 hour, 1 day, 7 days, 1 month) (Kohl et al., 2000). Disadvantage of self-report is validity and reliability of results (Shephard, 2003) due to over-reporting of physical activity (Warnecke et al., 1997), since recalling physical activity is very complex cognitive task (Baranowski, 1988). Disadvantage of proxy-report is reporter's ability to observe the physical activity of the subject (Sallis \& Saelenes, 2000). Benefits of questionnaires are simple compilation of the results and addressing a wide range of parameters such as type, method, duration and frequency of exercise (Planinšec, 2003). It has been suggested that children younger than 12 years are unable to reliably estimate their activity and quantify the time of their activity (Pate, 1993). The main advantage of the questionnaires is simplicity, but they most often provide only minimal information about activity. Objectivity of the data collected with questionnaires is low, but they can be a very useful tool when we need quick and essential information about children's physical activity (Volmut, 2014). Questionnaires are a very good supplement to objective methods of measuring in order to assess the context and type of physical activity. 
Physical activity diaries contain detailed information about various aspects of physical activity and may include information about intensity, duration, type and body position during physical activity (Ainsworth et al., 2013). Physical activity diaries are superior to retrospective questionnaires (Baranowski et al., 1984), but their use is unsuitable for children younger than 15 years of age (Saris, 1986). Physical activity can be monitored through physical activity diaries from one day to several weeks, depending on the purpose and interest of the research. Most of diaries are monitored via tablets, computers and smart-phones. Advantage of diaries is detailed information about specific activity, but on the other hand, disadvantage is that is does not contain all the activities that took place during the day.

Physical activity logs have checklist with tasks of activity that are completed in the end of the day, week, month or discrete period of time. Logs can include intensity and duration of physical activity. Physical activity can be monitored through activity logs from one day to multiple weeks, depending on the purpose of the assessment. Advantage of physical activity logs is simplicity of collecting the data and the biggest disadvantage is missing details of physical activity in the end of the day (Ainsworth et al., 2015).

\section{Physical Activity in Numbers World}

David Kirk (2010) at National Conference of the INEFC represented current status and future trends in research on physical education. He reviewed current and future trends within Europe-authorised research published between 2000 and 2009. Total number of published papers from physical education and pedagogy was 665 in 4 most influenced European peer-reviewed journals (EPER, JTPE, EJPE/PESP, SE\&S). In last two decades, physical activity and their effects on health, cognition, and academics has become hot topic in research field. Current studies indicated that majority of children and adolescents are not meeting the recommendation of 60 minutes of moderate- to vigorous physical activity per day (Gortmaker et al., 2012) and that physical activity levels are decreasing 
with age (Nader, Bradley, Houts, McRitchie, \& O’Brien, 2008). Several studies has been researching intensity of physical activity and and rate of energy expenditure. It has been shown, that moderateto vigorous physical activity is important for normal growth, development, body composition and decrease in acquiring risk factors for development of chronic disease. Moderate- to vigorous physical activity is associated with physical, social and mental health benefits (Warburton, Nicol, \& Bredin, 2006; Janssen \& Leblanc, 2010; Hallal, Victora, Azevedo, \& Wells, 2006) and is positively related to adult physical activity (Hallal et al., 2006; Telama et al., 2005) and health (Hallal et al., 2006).

Valid and reliable measures of physical activity are required (Caspersen, Nixon, \& DuRant, 1998; Trost, Loprinzi, Moore, \& Pfeiffer, 2011), therefore several studies has been made determinating objectively (Rowlands, 2007; Reilly et al., 2008; Guinhouya et al., 2006; Schneider, Crouter, Bassett, 2004; Trost et al., 2011) and subjectively measures (Sirard \& Pate, 2001; Corder, Ekelund, Steele, Wareham, \& Brage, 2008) of physical activity. Subjectively measured physical activity is more appropriate for large samples because it is much cheaper than objectively measured physical activity, although the reliability of the measured data is better when measuring with objective assessments. In physical activity research very interesting and hot topics are also (Kohl \& Cook, 2013): recess, physical education, active transport, sedentary or light- intensity physical activity, state and local policies on school-based physical activity, vigorousor moderate-intensity physical activity.

It is known very well, that school-related physical activity must be a large contributor to overall physical activity among youth (Kohl \& Cook, 2013). Overall contribution, including every segment of school day - transportation to and from school (McDonald, 2007; Bassett et al., 2013), physical education (Simons-Morton, Taylor, Snider, \& Huang, 1993; McKenzie et al., 2006), recess (Lee, Burgeon, Fulton, \& Spain, 2007; Bassett et al., 2013), classroom time - before and after school activities. Guidelines, recommendations and policies from all national, supranational levels and from various organizations, are known to influence children's and adolescent's 
school physical activity. Despite excellent research and good public health surveillance systems, current monitoring of overall physical activity and all behaviours and forms included in term physical activity, are inadequate. Differences have arisen for several reasons (Kohl \& Cook, 2013). Physical activity has only recently been acknowledged as a vital public health issue. It is a behavior difficult to measure and it is not easy to understand types and quantities of physical activity relevant to health and health outcomes (Kohl \& Cook, 2013). Recommendations for types and amounts of physical activity for children have changed for many times in the last two decades and the schools - as the most suitable institution for the maintenance of the recommended amount of physical activity, vary considerably in size, resources, urbanization, traditions, and policies.

Very detailed and reliable overview of physical activity for children and youth, based mostly on nationally measured data is 'Report Card on Physical Activity for Children and Youth,' which falls under cover of Active Healthy Kids Global Alliance (Tremblay et al., 2014; Tremblay, Barnes, \& Cowie, 2014; Tremblay, Brownrigg, \& Deans, 2008) and Health Behavior in School-aged Children (HBSC), which is a cross-national study gaining insight into young people's well-being, health behaviours and their social context (see http://www.hbsc.org).

\section{Slovenia}

Findings show that in 2003 in Slovenia, $18 \%$ of boys and $19 \%$ of girls were overweight, and $6 \%$ of boys and $8 \%$ of girls were classified as obese (Bučar Pajek, Strel, Kovač, \& Pajek, 2004). This proportion is still on the rise. Starc, Strel, and Kovač (2010) found that changes in motor dimensions are gigantic, diverse and surprising. In this study, they were comparing generations from school year 2007/2008 with previous generations. They found negative changes in motor abilities are on the average (for all eight movement skills measured in for SLOFIT data), or boys $0,43 \%$ and for girls $0,22 \%$ lower motor abilities than the previous generation. With body weight measurements, there is also a noticeable downward trend in primary

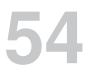




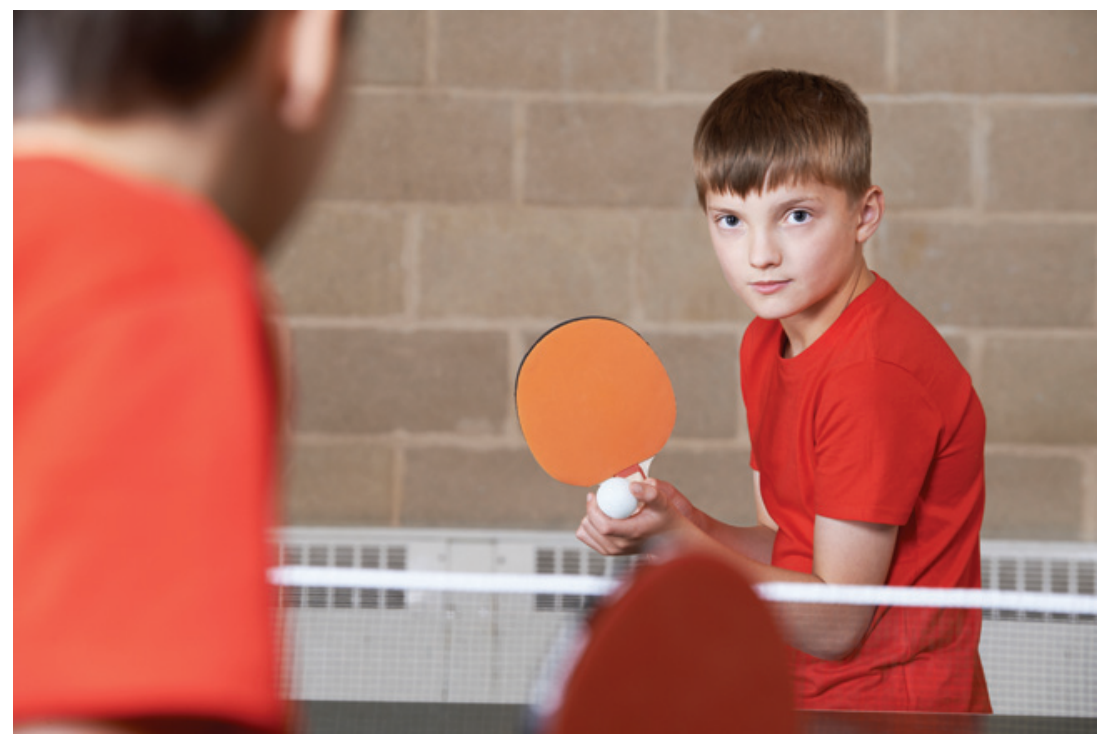

school children, when comparing to the previous generations. The greatest negative trend was noticeable with pupils between 9 and 11 years old, which gain over $1 \%$ weight compared to the previous generations. The largest increase in body weight is noticeable in 15 years old girls. Despite a sufficient number of physical education hours (3 school hours/week), and extracurricular activities connected to physical activity, there is still a negative trend, particularly when motor abilities are taken into concern. It is necessary to radically change this trend for the low-quality way of life, and promote awareness that physical activity is important- not only because of its positive effects on health but also with positive effects on academic performance. According to the ACDSi data, $97 \%$ of boys and $95 \%$ girls (ages: 6-11 years) from Ljubljana are meeting WHO recommendations for daily physical activity (2010), $86 \%$ of boys and $76 \%$ of girls aged 6-18 years) meet physical activity guidelines. On weekends, $81 \%$ boys and $72 \%$ girls meeting recommendation guidelines (Sember et al., 2016).

There is no centralized registry of sports practice or participation in organized clubs for children and youth outside of the school system in Slovenia; although $60 \%$ boys and $47 \%$ of girls aged $6-19$ years 
are engaged in extracurricular sport or clubs (Sember et al., 2016). On school days only $16 \%$ of Slovenian boys and $19 \%$ of Slovenian girls play actively more than 2 hours per day, on weekends $57 \%$ boys and $59 \%$ of girls (Sember et al., 2016). Only 3\% of Slovenian children uses bike and $26 \%$ walk to the school. The ACDSi nationallyrepresentative data (Jurak, Kovač, \& Starc, 2013; Starc et al., 2015) indicates that active commuting to school remains relatively stable with age with about $52 \%$ of boys and about $50 \%$ girls from age 5 to 18 y actively commuting to school (Sember et al., 2016). In Slovenia, $90 \%$ of boys and girls meet the recommendation of fewer than 2 hours of screen time per day. During weekends this percentage decreases to 37 and $45 \%$ of boys and girls, respectively. Weekend and weekday combined, $74 \%$ of boys and $79 \%$ of girls aged $6-19$ years meet the recommendations for screen time (Sember et al., 2016). In Slovenia $75 \%$ of parents encourage their children between 11 and 19 $y$ to be physically active. Almost $90 \%$ of parents indicate they support opportunities for physical activity by buying sports equipment, driving kids to practice, etc. When asked about their parent's physical activity levels, children perceived their fathers to be 'very active' in $\sim 30 \%$ of cases and 'moderately active' in $35 \%$ of cases. In Slovenia, physical education (PE) is a compulsory subject in all primary and secondary schools and they all follow the same PE curriculum. PE minutes vary by grade such that primary school (grades $1-5$ ) receive a minimum of 105 hours per year, grades $7-8$ receive 70 hours, and grade 9 students receive 62 hours per year. Grades 7-9 have opportunities to select an additional 35 hours of elective sport classes, and 35 hours of elective dance class. Grades 4-6 may also select an additional 35 hours of elective, health-oriented sport classes (Kovač et al., 2015). In addition to regular PE classes, primary school children have 5 sport days in each grade, each lasting 5 hours, together 25 hours of school-based physical activity in a school year. Some primary schools in Slovenia organise enhanced PE curriculum, during which children receive supplementary lessons (Jurak, Cooper, Leskošek, \& Kovač, 2013). Additionally, primary schools in Slovenia are allowed to have more than the prescribed minimum of 2 or 3 PE lessons per week if the school board decides so, although less 
than $10 \%$ of schools actually do. All primary schools are obliged to offer extracurricular sport programs, which are free of charge for all children. In the best case scenario, a 10-year old in Slovenia can receive 131 hours (or 7875 minutes) of regular PE lessons, plus 25 hours in school sport days, 35 hours of elective sport courses, and at least 35 hours of extracurricular school-based sport practice, summing to a total of 226 hours of school-based PE. Thus, Slovenian primary schools offer access to $77 \mathrm{~min}$ of daily in-school, professionally guided PA. In the (worst-case) event that a 10-year-old would participate in only the compulsory 3-weekly lessons of PE and obligatory school days, this number would drop to $\sim 39$ min per school day, still more than half the $60 \mathrm{~min}$ of recommended daily physical activity (Sember et al., 2016).

In the past two decades, the national government and municipalities have invested in the reconstruction of old, and the building of new, school sports halls including other sport infrastructure. For example, from 2001-2008 public funding of sport infrastructure exceeded $€ 300$ million euros (Jurak, 2012). The policy of the Ministry of Education, Science and Sport also enforces rules related to the professional competencies of teachers and trainers in PE and youth sport, which require people to have a university degree in PE to work with young athletes (Zakon o športu, 2017). In addition, the Ministry currently develops strategies to implement compulsory, joint teaching of regular classroom teachers and PE teachers within the first 5 years of primary school to raise the quality and effectiveness of PE. Finally, more than 25 years ago, the government of Slovenia established the Centre for School and Outdoor Education programme which has 23 learning centres scattered throughout the country. Each of these centres employs at least one PE specialist, and offers various outdoor activities that are not available within regular school settings (Sember et al., 2016).

A key reason for the past effectiveness of government policies related to schools, sport infrastructure, $\mathrm{PE}$, and its curriculum in Slovenia is the evidence-based policy planning of the Ministry of Education, Science and Sports (Kovač et al., 2015). The Ministry has continuously supported the SLOfit monitoring system and has been 
using evidence on secular trends in physical and motor development of children and youth to plan its future activities and interventions, as well as evaluate their effectiveness. To wit, the Ministry introduced a health-oriented physical activity intervention program 'Healthy Lifestyle' to combat growing childhood obesity and declining physical fitness (Strel, 2013). Current evidence from SLOfit data suggest that these state-wide interventions are effective at influencing population movements (Strel, 2013), since obesity trends have been in decline since 2011, and the physical fitness of primary school children has improved significantly (Strel, 2013). Government strategies, policies and investments was graded B+ (Sember et al., 2016).

\section{School Settings}

Physical activity is important for children and adolescents. Schools and community settings are necessary for promoting physical activity (Stone, McKenzie, Welk, \& Booth, 1998), since children and adolescents are most of the day in the school environment. In public health and biomedical research, study design plays a major role in interpretation (Rothman, 2012). Research studies are nowadays divided into interventional and observational studies.

Interventional Studies. The interventional study design is also called experimental study design. Interventional studies are studies where investigator is acting on participants and changing their normal behavior. Interventional/experimental study designs are: randomized controlled trial study design, crossover randomized controlled trial study design, pre-post study design, non-randomised trial study design (Thiese, 2014). Since schools have major influence on children during their childhood and adolescent time, schools are the best environment for physical activity interventions (Story, Nanney, \& Schwartz, 2009). Physical activity has been shown to be indirectly associated with academic performance, including better classroom behavior, self-esteem, engagement in school, on-task behavior and lower drop rate (Trudeau \& Shephard, 2008). Van Sluijs, McMinn, and Griffin (2007) reviewed 57 studies on the effectiveness of inter- 
ventions among children and adolescents. Thirty-eight studies reported positive effect (67\%) and statistical signification in 27 studies (47\%) of physical activity interventions. Significant result ranged up to $42 \%$ increase in participation in regular physical activity and increase of 83 minutes of moderate-to-vigorous physical activity per week. Kahn et al. (2002) evaluated the effectiveness of various interventions to increasing physical activity; informational, behavioral, social, environmental and policy approaches. Effective interventions were: 'point-of-decision' prompts to use stairs intervention and community-wide campaigns of informational interventions; school-based physical education, social support in community settings and individually-adapted health behaviour change from field behavioural and social interventions; and creation of or enhanced access to places for physical activity combined with informational outreach activities from field environmental and policy interventions.

Randomised Controlled Trial Study Design. Randomized controlled trial study design is the most used type of interventional studies (Machin \& Fayers, 2010). This study design randomly divides a homogenous group of participants and implements intervention on only one group. The only difference between groups should be intervention (Thiese, 2014). Dwyer, Coonan, Leitch, Hetzel, and Baghurst (1983) investigated effects of daily physical activity on health in primary schools in South Australia, using randomized control trial research design. Results for students after two years of intervention in 1980 were compared against cross-sectional measures of 1978. Findings of South Australia research suggested beneficial effects on health and no loss of academic performance in spite of 45 to 60 minutes loss of teaching time every day. Metcalf, Henley, and Wilkin (2012) reviewed 30 peer-reviewed studies, whether physical activity interventions affect overall activity of children. Studies had to meet the following inclusion criteria: children and adolescents younger than 16 years, studies had to be randomized controlled trials; physical activity had to be objectively measured, expressed in mean accelerometer counts/minute and intervention 
must have incorporated a component that aimed to increase physical activity. Thereview provided strong evidence that randomized controlled trial - physical activity interventions have had only a small effect on overall physical activity level. Intervention children had been only 4 minutes per day more active compared to control children, which may explain why such interventions have had a limited effect on body mass index or body fat.

Crossover Randomised Controlled Trial Study Design. Crossover randomized controlled trial study design at first phase divides participants the same as in the randomized controlled trial study, but at the end of first treatment intervention, participants are relocated to another treatment arm. Between treatments are often wash-out periods (Thiese, 2014). Thirty-five German adolescents between 13 and 14 years of age participated in crossover study design. They were divided into higher-fit $(n=17)$ and lower-fit $(n=16)$ subgroups. Participants were assigned to the event-related potential (ERP) study with two recording sessions, one following 20 minutes of exercise and one following 20 minutes of rest. They participated in both conditions in a random order within an exact seven days interval at the same day of the week and same time of the day. Results indicated that higher fit-individuals showed significantly greater contingent negative variation of the event-related potential amplitudes. The research team did not found the reliable effect of acute exercise on inattention or impulsivity; however, higher-fit individuals did perform better (Stroth et al., 2009). Researchers from Scotland used a crossover design trial and randomized 552 children into two groups. One group received a classroom-based program of physical exercise on week 1 and no physical exercise program in week 2; other group received a classroom-based program of physical exercise in week 2 and no physical exercise program in week 1. Each week all participants completed cognitive test battery. Benefits occurred only for participants who exercised during the second week. The research team interpreted that exercise intervention has a positive effect on cognitive performance possibly by facilitating practice effects, which are not moderated by sex, ADHD symptom 
level or BMI (Hill, Williams, Aucott, Thomson, \& Mon-Williams, 2011).

Non-Randomised Trial Study Design. The non-randomised trial study design is not considered as strong study design and is often subject to many types of bias and error. The non-randomised trial study compares a group where intervention was performed and a group where intervention was not performed (Thiese, 2014). Alexandrov et al. (1992) performed the non-randomized trial study. The three-year intervention consisted in primary prevention. All intervention children received counseling and lectures on prevention, and secondary prevention, where children with risk factors were invited to a single counseling session. Follow-up examinations were carried out at one and three years following baseline. After one-year intervention children had attained a greater reduction in their levels of total cholesterol, triglycerides, and systolic blood pressure.

Pre-Post Study Design. Pre-post study design measures outcome before and after intervention has been implemented. Pre-post study has the strength to suggest that outcome is impacted by intervention; however, pre-post studies do not have control over other elements which have changed during the intervention (Thiese, 2014). Ridgers, Stratton, Fairclough, and Twisk (2007) selected 297 schoolchildren from 26 elementary schools to wear uni-axial accelerometers during recess. Research has investigated the effects of the recess-based intervention on physical activity, investigating shortterm effects of playground markings and physical structures on recess physical activity and effects of covariates on the intervention. Following legalities of pre-post study design, data were collected at baseline and 6-weeks following playground intervention. Schools were visited twice, once before the playground redesign (pre-test), and once six weeks after playground redesign (post-test). After interventions, positive but non-significant effects had been found for moderate-to-vigorous physical activity and vigorous physical activity and boys were significantly more engaged in moderate-tovigorous and vigorous physical activity than girls. 


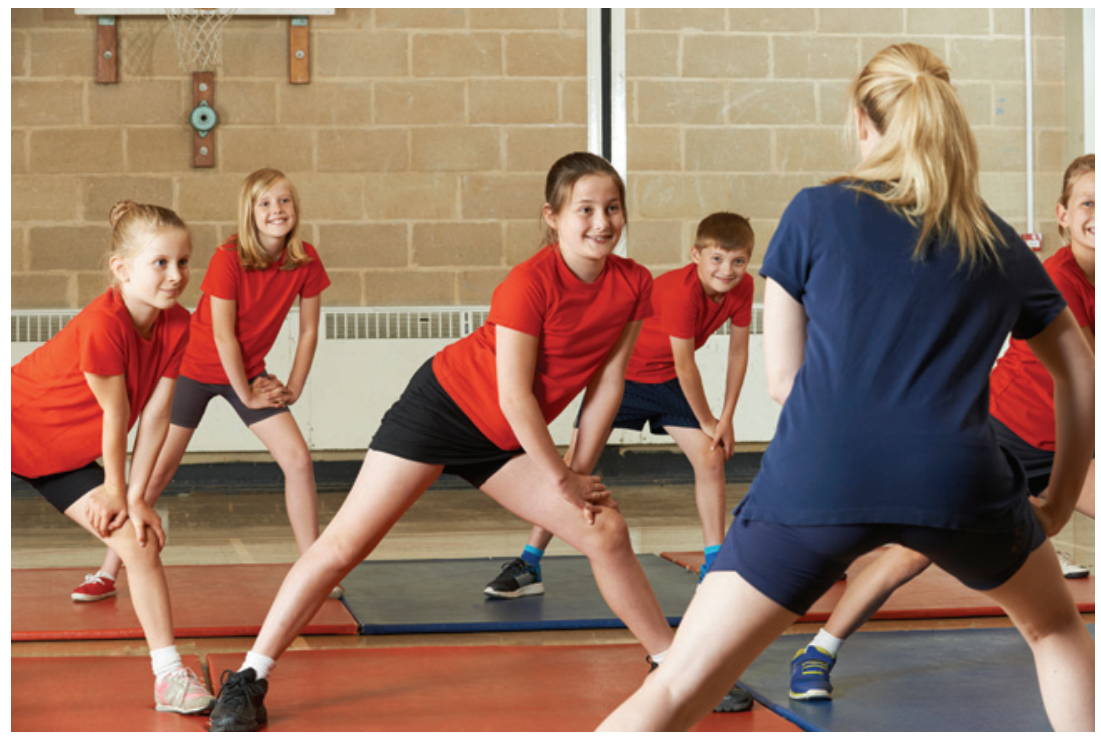

Observational Studies. Observational or epidemiological studies are those where the investigator is not acting on participants and changing their normal behavior but is observing the natural relationship between factors and outcomes. Observational studies are often retrospective (Thiese, 2014) and make decisions where the independent variable is not under investigator's control because of ethical or logistical concerns (Porta, 2008). Observational studies are ecological study design, proportional mortality ratio study design, crosssectional study design, case-control study design, case-crossover study design, retrospective and prospective cohort study design, diagnostic testing and evaluation study designs.

Ecological Study. The most basic observational study is ecological study, which compares clusters of people, mostly based on their geographical location (Breslow, 2014). Ecological studies are usually retrospective, and the data is derived from big databases, which is their weakness, since big databases are typically created for other purposes, not research (Friis \& Sellers, 2013). The advantage of ecological study is cost effectiveness and starting point for hypotheses generation (Thiese, 2014). Joens-Matre et al. (2008) looked for for rural-urban differences in physical activity, physical fitness 
and overweight prevalence of children. The sample included 3416 Iowa children from grades 4,5 and 6 with main age $10.6+0.96$. Data were obtained from the Physical Activity and Nutrition Among Rural Youth (PANARY) project and level of urbanization was determined by 1993 Rural-Urban Continuum Codes (RUCC), which distinguish metropolitan counties by size and degree of urbanization and proximity to metro areas (Joens-Matre et al., 2008). Physical activity was assessed using the Physical Activity Questionnaire for Children-PAQ-C (Joens-Matre et al., 2008) and body mass index was measured by trained physical education teachers. Prevalence of overweight was higher among rural children $(25 \% ; p<0.001)$ than children from urban areas (19\%) and small cities (17\%). Urban children were the least active overall (Cohen's $d=0.4$ ).

Proportional Mortality Ratio Study Design. Proportional mortality ratio studies design is used in occupational epidemiology (Delgado, Sillero, \& Gálvez, 1994) and equals the cause-specific standardized mortality ratio divided by overall proportionate mortality ratio (Hansen, 1990). These type of studies are limited to death (Stolley \& Lasky, 1995) as an outcome and give us cause-specific information between exposure categories (Monson, 1974).

Cross-Sectional Study Design. Cross-sectional study design or transversal is a type of observational study that involves the analysis of a representative data at one specific point in time. Cross-sectional study is also called prevalence study because one of the main variables is population prevalence (Woodward, 2013). The advantage of this study design is low cost and major disadvantage that investigators cannot normally answer the causation of the effect. Robinson et al. (1993) conducted a cohort study among female adolescents ( $n=971$, sixth and seventh-grade) with follow-up assessments 7, 14 and 24 months after baseline, where 671 girls had sufficient data for baseline cross-sectional analyses. Hours of television watching, physical activity and stage of sexual maturation were assessed with self-report instruments; height, weight and triceps skinfold were measured and body mass index was calculated. Among adolescent girls, television viewing time had weak associations with 
adiposity and physical activity. Andersen et al. (2006) assessed the associations of objectively measured physical activity (accelerometer Actigraph) with clustering of cardiovascular disease risk factors in children. Researchers did a cross-sectional study of 1732 randomly selected 9-year old and 15-year old school children from Denmark, Estonia and Portugal. The primary sampling units were schools; secondary sampling units were children on the school register. Key findings of this study were graded with negative association between clustering of risk factors and physical activity. The first to the third quintile of physical activity has had a raised risk in all analyses.

Case-Control Study Design was originally developed in epidemiology and compares people with an outcome of interest (case) with people without the specific outcome of interest (control). The outcome is measured before exposure and controls are selected by not having the outcome. The disadvantage of this study is increased risk for bias due to known case study of participants. Advantages of this type of study are low cost, fast execution of data compared to cohort studies, collection of individual participants' data, control for multiple confounders and access to multiple exposures of interest (Thiese, 2014). This study design is the most efficient when researching rare diseases. Case-control studies increased the risk for bias, particularly recall bias (Rothman, Greenland, \& Lash, 2008; Wacholder, Silverman, McLaughlin, \& Mandel, 1992). The strength of case-control studies is that study is most efficient for rare diseases, its low cost, fast execution compared to cohort studies and ability to assess multiple exposures of interest (Mann, 2003; Thiese, 2014). Da Costa Ribeiro, Taddei, and Colugnatti (2003) researched obesity among children attending elementary public schools in Sao Paulo, Brazil. They measured 223 obese and 223 eutrophic schoolchildren, aged 7-10 years. Parents of 446 schoolchildren all together were interviewed about children's eating behaviors and habits. They concluded that children with a birth weight of $3500 \mathrm{~g}$ or more or whose parents are obese should receive special attention in the prevention of obesity. 
Case-Crossover Study Design. Case-crossover studies are retrospective and the case serves as his/her own control for some comparison issues (Woodward, 2013). These studies are good where the outcome is acute and well defined (Rothman et al., 2008). The disadvantage of case-crossover studies is risk for having recall bias. Case-crossover studies require careful selection of period and careful selection of timing and the length of the windows. Experience has shown that case-crossover design applies best if the exposure is intermittent (Maclure \& Mittleman, 2000). Broderick et al. (2012) searched associations between physical activity and risk of bleeding in children with hemophilia. A case-crossover study nested within prospective cohort study design was conducted on 104 schoolchildren. Children with hemophilia were monitored for bleeds up to 1 year. Physical activity was assessed according to expected frequency and severity of collisions. The risk of bleeds associated with physical activity was estimated 8 hours before the bleed and two times for 8hour control window. Children with hemophilia were more exposed to the risk of bleeding in vigorous physical activity.

Cohort Studies identify a group of people and follow them for some time with a desire to see how their exposures affect their outcomes and are normally used in cases that cannot be controlled experimentally. Cohort studies are the only ones of observational studies that can calculate cumulative incidence and an incidence rate (Rothman et al., 2008; Ahrens \& Pigeot, 2005; Aschengrau \& Seage, 2013) between prospective and retrospective studies. Prospective study design watches for outcome during the period of study and involves observation of subjects over a long period and is considered as a gold standard of observational research (Aschengrau \& Seage, 2013). Maffeis, Talamini, and Tato (1998) researched the influence of diet, physical activity and parents' obesity on children's adiposity. Anthropometric measures of 112 prepubertal children were initiated in 1992 and follow-up measurements in 1996. Obesity was defined as relative body mass index $>120 \%$. Parents' obesity was the main risk factor for childrens' obesity and sedentary behavior was independently associated with overweight at the age of 
8 years. Retrospective study watches for outcome backward and examines exposures about an outcome that is established at the beginning of the study (Mann, 2003; LaMorte, 2015). Retrospective study or historic cohort study is a longitudinal cohort study that researches a cohort of individuals with common exposure in determining influence and is compared to another group, which was not exposed to exposure factor (Doll, 1980). A retrospective study looks backward and examines exposures to suspected risk about an outcome, established at the beginning of the survey. In retrospective studies there is a higher risk for obtaining bias than in prospective studies, this is why retrospective studies are often criticized. Data from the Cardiovascular Risk in Young Finns Study ( $n=2309$ ); longitudinal research project from the beginning of 1980 (Telama et al., 2005) were used for investigation of stability of physical activity from childhood and adolescence to adulthood and how physical activity in adulthood could be predicted from variables measured in childhood and adolescence. Physical activity was assessed with selfreport, and medical examinations were made. It was concluded that high level of physical activity in childhood affects physical activity in adulthood (Telama et al., 2005). 


\section{Physical Fitness}

Physical fitness is a general state of health and well-being and capacity to perform in physical activity, daily activities and sports and refers to a full range of physiological and psychological qualities. It is defined as the quality or state of being fit (see https: / www.merriam -webster.com/dictionary/fitness). Physical fitness is set of attributes associated with the capacity to perform physical activities (Ortega, Ruiz, Castillo, \& Sjostrom, 2008), which consisted of three components: muscle strength, endurance and motor skills (Malina \& Katzmarzyk, 2006). Physical fitness could also be thought as an integrated measure of almost all body functions (cardiorespiratory, hemato- circulatory, psychoneurological and endocrine-metabolic) involved in daily physical activity and exercise (Ortega et al., 2008). The cardiorespiratory function is assessed using maximal oxygen consumption (VO2max). Principal components of muscle strength are maximum power (static and dynamic), explosive strength, durability, power and isokinetic strength. Most appropriate tests for the assessment of muscle strength are shaking fists, Standing Long Jump and Bent Arm Hang. Speed is the ability to move the body or body parts as quickly as possible and agility is a combination of speed, balance, strength and coordination (Ortega et al., 2008). It has been shown that physical fitness is strongly correlated with total adiposity (Ruiz et al., 2006; Ara, Vicente-Rodriguez, JimenezRamirez et al., 2004; Lee \& Arslanian, 2007), abdominal adiposity (Ortega et al., 2007; Hussey, Bell, Bennett, O’Dwyer, \& Gormley, 2007), cardiovascular disease (Hurtig-Wennlof, Ruiz, Harro, \& 
Sjostrom, 2007; Chomistek, Chasman, Cook, Rimm, \& Lee, 2013; Berry et al., 2013), skeletal health (Ginty et al., 2005), and mental health (DiLorenzo et al., 1999; Castelli et al., 2007). Ortega et al. (2008) found out that physical efficiency during childhood and adolescence is a good indicator of health. Several health benefits are associated with physical fitness. Better physical fitness reduces the risk of cardiovascular disease, colon cancer, diabetes, dying prematurely and obesity (US Department of Health and Human Services, 1996), improves bone function, musculoskeletal function and psychological variables such as depression, anxiety, stress and selfconfidence (American College of Sports Medicine, 2006).

\section{Quantifying Physical Fitness}

The assessment of physical fitness has a longer history than of physical activity (Malina \& Katzmarzyk, 2006). Over the past 50 to 60 years the concept of physical fitness has evolved from a primary focus on motor and strength components to more emphasis on health in the 1970s (AAHPERD, 1980) and morphological and metabolic components have been added to the more traditional muscular strength and endurance, motor, and cardiovascular components (Bouchard \& Shephard, 1994). Caspersen et al. (1985) identified the differences between physical activity, exercise and physical fitness and their importance in health research. Physical activity is any bodily movement produced by skeletal muscles that result in energy expenditure and could be measured in kilocalories. Components of physical fitness include strength, endurance, speed, power, agility, flexibility, coordination, morphological and metabolic components (Malina \& Katzmarzyk, 2006), overall physical fitness is set of attributes that people have or achieve (Caspersen et al., 1985). The ability to carry out daily tasks with vigor and alertness, without undue fatigue and with ample energy to enjoy in activity means being physically fit. Things such as vigor, alertness, fatigue and enjoyment are hard to measure, on the other hand, health-related physical fitness is easier to measure (Caspersen et al., 1985). Definition of exercise is more restrictive than definitions physical activity and physical fitness. An exercise intended to improve or maintain an established 
level of physical fitness (Caspersen et al., 1985). From 1980 several physical fitness tests have been used (Table 6). Caspersen, Powell, and Christenson (1985) divided physicalfitness on capabilities related to health and capacity related to skills. Health-related capabilities are cardiorespiratory durability, muscle durability, muscular strength, body composition and flexibility. Skills related capabilities are agility, coordination, balance, reaction time, power and speed.

Bös (1994) made clear and transparent model of motor abilities, which represents the links between different impairments and their interdependence. Motor abilities are under different influences as the features of energy and information components of movement are intertwined. Model of motor abilities (Bös, 1994) distinguishes between fitness (power, durability) and information capabilities (speed, coordination). Physical abilities are organized at different levels (Magill, 1998) and different categories (Fleishman, 1972). In the first category are perceptive-motor abilities, while others are skills that relate to the capacity of the body. The group of perceptivemotor abilities includes: coordination of movement, control precision, choice of response, reaction time, coordination, hand movement, control the speed and direction of movement, dexterity, finger dexterity, precision movements with your hands, wrists and fingers speed and targeting. The group of abilities that define the capacity of the body includes static power, dynamic power (repetitive power), explosive strength, and the strength of the hull, flexibility, coordination of movement of the whole body, the whole body balance and endurance. Magill (1998) added the following capabilities: static balance, dynamic balance, movement coordination of eyehand coordination and eye-foot movement.

Pišot and Planinšec (2005) investigated the physical structure of the early childhood population on five-, five- and a half and six- year old children. In the group of five-year children, using PB-criterion (Štalec \& Momirovič, 1971), four latent motor dimensions were isolated and appointed: coordination of movement, the speed of the reciprocating movement, static balance and coordination of movements of the extremities. In the group of six- and a half-year-old children and using GK-criterion, seven factorswere isolated: co- 
Table 6.1 Chosen Fitness Test and Associated Physical Fitness Indicator, Test Label and Units in Which Physical Fitness Indicator is Expressed

\begin{tabular}{|c|c|c|c|c|}
\hline $\begin{array}{l}\text { Physical fit- } \\
\text { ness indicator }\end{array}$ & $\begin{array}{l}\text { Physical fit- } \\
\text { ness type }\end{array}$ & Physical test & Test label & Units \\
\hline $\begin{array}{l}\text { Aerobic } \\
\text { strength }\end{array}$ & $\begin{array}{l}\text { Health-related } \\
\text { indicator }\end{array}$ & Shuttle run & SHUTTLE & $\begin{array}{l}\text { Nr. of repeti- } \\
\text { tions }\end{array}$ \\
\hline $\begin{array}{l}\text { Muscle } \\
\text { strength }\end{array}$ & $\begin{array}{l}\text { Health-related } \\
\text { indicator }\end{array}$ & Hand grip & GRIP & Kilograms \\
\hline $\begin{array}{l}\text { Repetitive } \\
\text { strength }\end{array}$ & $\begin{array}{l}\text { Health-related } \\
\text { indicator }\end{array}$ & Situps & SITUP & $\begin{array}{l}\text { Nr. of repeti- } \\
\text { tions }\end{array}$ \\
\hline $\begin{array}{l}\text { Explosive } \\
\text { strength }\end{array}$ & $\begin{array}{l}\text { Physical per- } \\
\text { formance in- } \\
\text { dicator }\end{array}$ & $\begin{array}{l}\text { Standing long } \\
\text { jump }\end{array}$ & SLJ & Centimeters \\
\hline Coordination & $\begin{array}{l}\text { Physical per- } \\
\text { formance in- } \\
\text { dicator }\end{array}$ & $\begin{array}{l}\text { Polygon back- } \\
\text { wards }\end{array}$ & POLYGON & Decisecond \\
\hline Balance & $\begin{array}{l}\text { Health-related } \\
\text { indicator }\end{array}$ & Flamingo test & FLAMINGO & $\begin{array}{l}\text { Nr. of repeti- } \\
\text { tions }\end{array}$ \\
\hline Flexibility & $\begin{array}{l}\text { Health-related } \\
\text { indicator }\end{array}$ & Sit and reach & SAR & Centimeters \\
\hline $\begin{array}{l}\text { Rhythmic im- } \\
\text { plementation } \\
\text { of movement } \\
\text { structures }\end{array}$ & $\begin{array}{l}\text { Physical per- } \\
\text { formance in- } \\
\text { dicator }\end{array}$ & Hand tapping & HAND_TAP & $\begin{array}{l}\text { Nr. of repeti- } \\
\text { tions }\end{array}$ \\
\hline
\end{tabular}

ordination of movements, the realization of rhythmic structures, static balance, explosive leg strength, and coordination of hand movement, speed of simple movements, precision and balance. In the group of five and a half children they found that the structure of motor abilities identified eight factors. Comparison between sexes shows that the factor structures are partially similar, as were the female and male sex equally defined balance, explosive power and agility.

The area of motor abilities is organized hierarchically. It is possible to identify two regulatory dimensions that define the structure of a wide area of motor abilities. The first dimension is related to the mechanisms for receiving and processing information and is crucial for motor tasks, where structuring movement, movement control 
and central control of movement is essential for their implementation. The second dimension is related to mechanisms that regulate energy and is critical for tasks where physical experience is associated with control of intensity of excitation (Matejek, 2013).

\section{Physical Fitness in Numbers}

In Slovenia physical and motor development of children and youth has been monitored (Strel, 1996) for more than 30 years (Sember et al., 2016). Every April there are physical fitness benchmarks which are evaluated together; this initiative is called 'Športno-vzgojni karton' - the SLOFIT card. SLOFIT or the National System for Monitoring Physical and Motor Development of children and youth includes all Slovenian primary and secondary schools. For more than 30 years, this system has given teachers, researchers, and policymakers access to high-quality, standardized data on physical fitness, which in turn allows for relatively responsive evidence-based policy adjustments when needed. For example, based on more recent evidence of declining physical fitness from the SLOfit database, Slovenia introduced a health-oriented physical activity intervention program called Healthy Lifestyle in the school year 2010/2011, offering children 2 optional, additional hours of physical activity per week. Healthy Lifestyle is considered part of a school's regular extracurricular health-oriented physical activity program. This project currently includes more than $30 \%$ of the entire primary school population. Before this initiative, Slovenian children had been experiencing negative trends in motor and physical fitness for over two decades, but since 2011, physical fitness in 6- to 14-year-olds has been steadily improving (Sember et al., 2016). In 2015, Slovenia also started new tests among the student population. Indeed, with such a massive, state-sponsored program, Slovenian children have better physical characteristics compared to most European countries (see http://www.slofit.org). Nevertheless, the Slovenian youth population is not immune to changes in lifestyle, and with access to this longitudinal data, Slovenian researchers are now also seeing negative trends in child motor development. SLOfit card provide children, teachers, youth, and others with the following (Strel, 1996): in- 
formation on their achievements in sports education, graphical representation of physical and motor development of a child or a young person for the entire period of schooling, advice on which sport activity a child should take part and usefully spent his or her leisure time, advice on problems on physical or motor development, advice on what sport equipment to buy for schools and parents.

Establishment, evaluation and monitoring of physical characteristics and motor abilities are carries out by means of the following measuring procedures (Strel, 1996): body height, body weight, triceps skinfold, arm plate tapping, standing long jump, polygon backwards, sit-ups, forward bend and touch on the bench, bent arm hang, 60-m run, 600-m run. The SLOfit system measures physical development, motor development, and motor abilities. Physical development is measured through physical growth, defined by body height, weight and skinfold of the upper arm. Body Mass Index is calculated using height and weight and is used to assess nutritional status. Triceps skinfold is the anthropometric indicator of peripheral fat distribution. Motor development in system SLOfit is monitored through the development of various motor abilities, which are divided on health-related fitness indicators and physical performance indicators. Indicators of health-related fitness are aerobic power, muscular strength, muscular endurance and flexibility. Highly developed aerobic abilities reduces the risk of heart disease, diabetes and stroke. Properly developed flexibility, muscular strength and muscular endurance are important for injury prevention, proper posture and overall functioning of the body. Indicators of physical performance are speed, explosive strength and body coordination. Measurement procedure from SLOfit are the same throughout primary and secondary school period, what allows direct comparison of individual outcomes of physical and motor development from 6 to 18 years of age. Selection of appropriate tests based on several pilots and experimental studies. In last 30 years, SLOfit system measured more than 1 million children and youth. Slovenian children between 1995 and 2015 became higher for $0.8 \%$, heavier by $4.6 \%$ and their triceps skinfold increased for $14 \%$ (see http://www.slofit.org). 


\section{7 \\ Body-Mind Connection}

Many experts note that additional hours of physical education have a positive impact on the academic success (Shephard, 1997) since learning of complex movements stimulates the frontal cortex in the brain, which is also active in learning and problem solving (Jensen, 2005). The results of studies suggest a positive relationship between physical and academic achievement (Singh, Uitjtdewilligen, Twisk, Van Mechelen, \& Chinapaw, 2012). More physically active children are also more efficient at learning, compared to less active children (Kirkendall, 1985). However, researchers are aware that the increased volume of physical education in school alone cannot compensate the lack of physical activity in daily life.

Educational experts intuitively believe that individuals who are physically active perform better in school. Some studies have found positive relationships between physical activity and academic performance (Dwyer et al., 1983; Hollar et al., 2010; Donnelly, McKiel, \& Hwang, 2009; Shephard, 1997), whereas other studies found no difference, or even negative outcomes between physical activity and academic performance (Ahamed et al., 2006; Sallis et al., 1997). Many experts from the field of physical activity and physical education have found positive effects on health, musculoskeletal development, behavior and increased motivation to learn. In addition to adverse conditions correlated with physical inactivity (i.e. high blood pressure, anxiety, depression, risk of certain type of cancer, coronary heart disease ...); there are also positive outcomes of physical movement in the school environment. Advocates of quality 
daily physical education for prepubescent children frequently encounter the argument that such initiatives will harm academic progress (Shephard, 1997).

It was found that physical education affects some factors which are predictors to raising academic performance in children. Some of these factors are higher self-esteem, body image, concentration and better behavior in the classroom. Caterino and Polak (1999) were interested in the effects of physical activity on concentration. They made a comparison between passive and directed physical education activities. They used the Woodcock-Johnson Test of Concentration. Children from 4 th grade were significantly more concentrated in school after engaging in physical activity (Caterino \& Polak, 1999). Evans, Evans, Schmid, and Pennypacker (1985) reported a lower rate of inappropriate behavior of children, who were a part of physically active programs (football and jogging). Using a meta-analysis, they came to the conclusion that the most physically active interventions led to significantly reduced disruptive behavior (Allison, Faith, \& Franklin, 1985). Raising academic achievement can be as a result of the better classroom climate, or better attitudes of teachers towards students. For example, in an Australian quasi-experimental study, and in a separate Trois-Rivieres study, academic achievement was a result of a better classroom environment. Improved self-esteem and body image (Nelson \& Gordon-Larsen, 2006) are often associated with high levels of physical education. Investigators have found links between school physical education and psychosocial factors such as satisfaction, integration of students in the classroom and self-esteem. These psychological factors should also prevent dropout from school and help raise learning abilities (Libbey, 2004).

Additional physical activity in school curricula does not adversely affect children's academic achievement in the elementary school; on the contrary, there is a positive trend between increased physical activity and academic performance. There are some excellent studies which have investigated this connection, and some are summarized herein. To begin, in the suburb of San Diego, California, researchers looked at the effects of a 2-year Physical Education Program (SPARK) in Elementary Schools. In the Spark study, there 


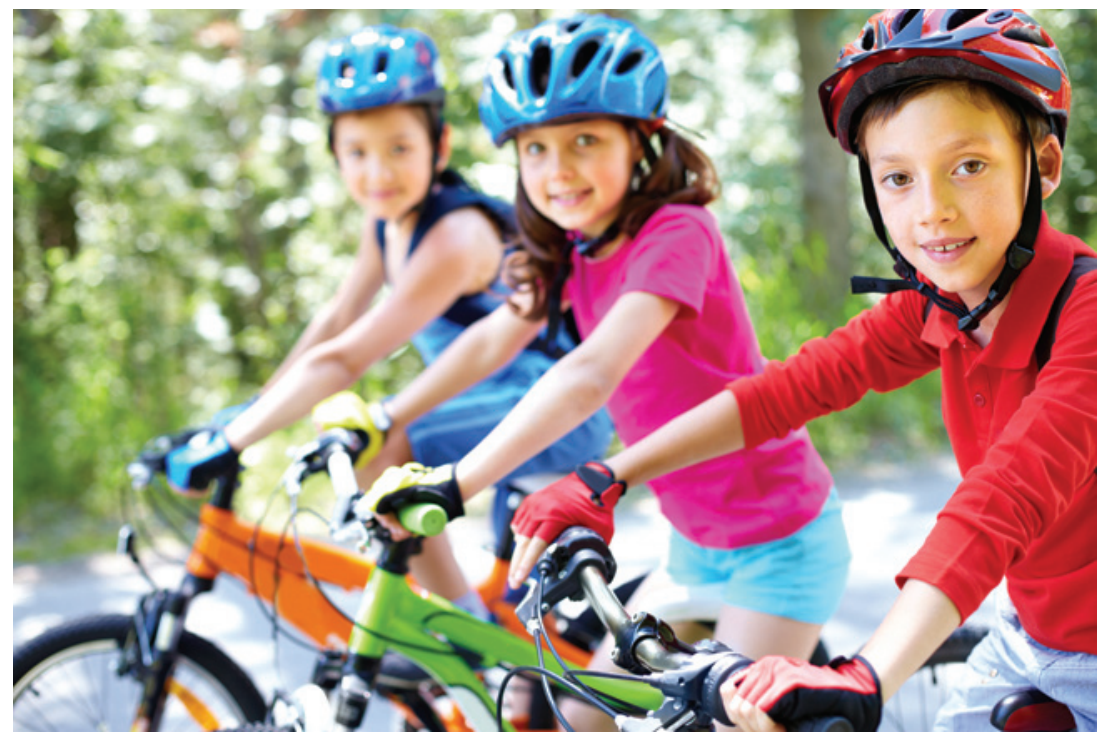

were seven elementary schools which participated. Pupils who took part in the SPARK program ( $n=759$, 5th and grade-6rs), were divided into three different groups which were assigned to one of three conditions. In the first condition, kids were taught by a physical educator ( $80 \mathrm{~min} /$ week of $\mathrm{PE}$ ), in the second condition, by a classroom teacher (65 min/week), and in the third condition, by an untrained classroom teacher (control group, $38 \mathrm{~min} /$ week). The group taught by the physical educator achieved greater cardiovascular and muscle endurance, slight declines in academic performance, but no negative effects on academic achievement. The decline in academic performance and achievement was smaller in the other two groups (Sallis et al., 1997). Similarly, in British Columbia, experts made an intervention called Action Schools! BC (AS! BC) with the desire to raise student physical activity levels, to determine the gender differences in academic performance and to maintain academic performance despite a corresponding decrease in overall academic time, which was partially replaced with physical activity. Finally, another Canadian study lasted 16 months and included 10 Canadian elementary schools. Two of the schools did not carry out the research properly, so they were excluded. In the end, the inter- 
vention study had a sample of 143 girls and 144 boys in the 4 th and 5th grade. Physical activity in intervention schools was increased by 47 minutes per week, and it was determined with the Physical Activity Questionnaire for Children (PAQ-C). Academic performance, evaluated by Canadian Achievement Test (CAT-3), remained unchanged.

Despite an overall reduction of academic time, the researchers indicated a positive trend towards an enhanced academic performance (Ahamed et al., 2007). Similarly, in the Australian longitudinal study SHAPE (School Health; Academic Performance and Exercise), researchers came to the conclusion that school kids who were given almost 60 minutes of physical activity/day, had after 14 weeks of study better ability to work and reduce body fat. Although curriculum hours of Mathematics and Reading were transferred to Physical Education, experts found positive trends in improving knowledge of mathematics and reading, body composition and positive changes in behavior after two years (Dwyer et al., 1983). The PASS \& CATCH study examined 932 children from eight elementary schools from Texas. Experts were interested in the correlation between increased school physical activity during the school day and academic performance (Murray et al., 2008). Children from experimental group significantly improved math and reading scores. From baseline to three years of study, classroom realized significant improvements in academic performance (Donnelly et al., 2009), measured with Wechsler Individual Achievement Test (Wechsler, 2001). Pupils from sports classes achieved statistically higher GPA and higher scores in mathematics and foreign languages. Finally, the HOPS (Healthier Options for Public Schoolchildren) project was an obesity prevention intervention, conducted in Florida, USA. This project examined the results of 1197 students, divided into experimental and control group. The intervention components included: integrated and replicable nutrition, physical activity and lifestyle educational curricula, matched to the state curricula standard. Examinees took Florida Comprehensive Achievement Test (FCAT). Intervention children had significantly higher FCAT scores in mathematics than children from the control group (Hollar et al., 2010). 
In many studies, it was found that physical education affects some elements which are supposed to be the effects that raise academic performance of children. These factors are higher self-esteem, body image, concentration and better behavior in the classroom. Factors that lead to better academic performance are reflected in Grade point average (GPA).

Modern, fast lifestyle, unhealthy food choices and lack of exercise are increasingly destroying the health of the younger population worldwide. With increases in sedentary activities (watching television, use of computer, learning), there is a corresponding decrease in overall physical activity. Because of large academic breadth of school curricula in many school environments, there remains less time dedicated to children's physical activity. A satisfactory amount of physical activity does not only make a positive effect on children's health but also affects elements (self-esteem, body-image, concentration and better behavior in the classroom) which lead to better academic performance. Physical activity in elementary schools as a part of physical education (Sallis et al., 1999), afternoon sports related activities (Marsh, 1993), extracurricular activities (Eccles, Barber, Stone, \& Hunt, 2003), physical exertion in school curriculum and recess periods (Verstraete, Greet, Dirk, Ilse \& Bourdeaudhuij, 2006) have a significant impact on classroom behavior, self-esteem, self-image, body image and cognitive function in elementary school children. All these factors have an impact on learning outcomes, which lead to better academic performance.

Parents are often concerned that increased physical activity and participation in sport affect academic achievement negatively because not enough time is perceived to be devoted to the reading material and homework. In addition to the negative effects of watching TV, there is also a greater decline in academic performance (Sharif \& Sargent, 2006). In primary education, it should be imparted to children that body movement is part of everyday life. A successful way to achieve sufficient daily movement is by adding extracurricular minutes to physical education in school, or by adding some extracurricular physical activities before or after school. 



\section{Summary}

This monograph was hoping to investigate and explain the relationship between physical activity and academic performance in elementary school children. It provides a summary of assessing physical activity using different methods; for example, objectively, using two types of physical activity monitors, and subjectively, using school records of achieved physical activity and self-reported questionnaires.

Whether children live in urban or rural areas were found to be sometimes different regarding the link between physical activity and academic performance. There is also often not sufficient attention to rural and poorer areas of countries, including Slovenia, who sometimes do not give attention devoted to older children finishing elementary school.

When looking at Slovenia specifically, the country reportes the highest grade for overall physical activity in comparison with 38 countries (Tremblay et al., 2016; Sember et al., 2016), since the majority of Slovenian schoolchildren meet the recommendation of at least of 60 minutes of moderate-to-vigorous physical activity per day (World Health Organisation, 2010). The Republic of Slovenia has the most active schoolchildren and great school system (Tremblay et al., 2016), compared to the other countries in the world. However, the sobering fact is that despite these high levels of overall physical activity and a robust school system, Slovenia has room to improve further, and give children more physically-narrated classes in the school system, as it was in 2004. The situation elsewhere in the 
world is more frightening compared to Slovenia, so it is necessary to inform policy makers that physical activity programs in the school system are beneficial to academic performance, and lead as an example to ensure proper physical and psychological development of the children around the world. Whereas there are links between academic performance and physical activity, we can not ignore the fact that many cofactors are responsible for such positive links between these two variables, such as parental education, place of residence and children's maturity levels.

Education will be ineffective unless children's health is made a priority and school may be the only place where health inequities can be addressed (Basch, 2011). Children are nowadays extremely sedentary (Tremblay et al., 2016) and unfit, what is related to an earlier onset of several chronic diseases such as diabetes type II and obesity. Not only health benefits of physical activity are important, the academic performance which is affected by many factors such as socioeconomic status, parental involvement, and participation is also influenced by physical activity. Following literature review and results of the thesis, academic performance is a mixture of interrelated factors, which are closely intertwined and interdependent one of another. 


\section{References}

AAPHPERD. (1980). Health related physical fitness test manual. Reston, VA: Author.

Abel, M. G., Hannon, J. C., Eisenman, P. A., Ransdell, L. B., Pett, M., \& Williams, D. P. (2009). Waist circumference, pedometer placement, and stepcounting accuracy in youth. Research Quarterly for Exercise and Sport, 80(3), 434-444.

Abel, M. G., Peritore, N., Shapiro, R., Mullineaux, D. R., Rodriguez, K., \& Hannon, J. C. (2011). A comprehensive evaluation of motion sensor stepcounting error. Applied Physiology, Nutrition, and Metabolism, 36(1), $166-170$.

Adkins, S., Sherwood, N. E., Story, M., \& Davis, M. (2004). Physical activity among African-American girls: The role of parents and the home environment. Obesity Research, 12(1), 38-45.

Ahamed, Y., Macdonald, H., Reed, K., Naylor, P. J., Liu-Ambrose, T., \& McKay, H. (2007). School-based physical activity does not compromise children's academic performance. Medicine and Science in Sports and Exercise, 39(2), 371-376.

Ahrens, W., \& Pigeot, I. (Eds.). (2005). Handbook of epidemiology. New York, NY: Springer.

Ainsworth, B. E., Cahalin, L., Buman, M., \& Ross, R. (2015). The current state of physical activity assessment tools. Progress in Cardiovascular Diseases, 57, 387-395.

Ainsworth, B. E., Keller, C., Herrmann, S., Belyea, M., Records, K., NagleWilliams, A., Vega-López, S., Permana, P., ... Coonrod, D. V. (2013). Physical activity and sedentary behaviors in postpartum Latinas: Madres para la Salud. Medicine and Science in Sports and Exercise, 45(7), 12981306. 
Al-Hazzaa, H. M., Sulaiman, M. A., Al-Matar, A. J., \& Al-Mobaireek, K. F. (1994). Cardiorespiratory fitness, physical activity patterns and coronary risk factors in preadolescent boys. International Journal of Sports Medicine, 15(05), 267-272.

Alexandrov, A. A., Maslennikova, G. Y., Kulikov, S. M., Propirnu, G. A., \& Perova, N. V. (1992). Primary prevention of cardiovascular disease: 3-year intervention results in boys of 12 years of age. Preventive Medicine, 21(1), 53-62.

Allison, D. B., Faith, M. S., \& Franklin, R. D. (1995). Antecedent exercise in the treatment of disruptive behavior: A meta-analytic review. Clinical Psychology: Science and Practice, 2(3), 279-303.

American College of Sports Medicine. (2006). ACSM's guideliness for exercise testing and prescription (7th ed.). Philadelphia, PA: Lippincott, Williams \& Wilkins.

Andersen, L. B., Harro, M., Sardinha, L. B., Froberg, K., Ekelund, U., Brage, S., \& Anderssen, S. A. (2006). Physical activity and clustered cardiovascular risk in children: A cross-sectional study. The Lancet, 368(9532), 299-304.

Ara, I., Vicente-Rodriguez, G., Jimenez-Ramirez, J., Dorado, C., SerranoSanchez, J. A., \& Calbet, J. A. L. (2004). Regular participation in sports is associated with enhanced physical fitness and lower fat mass in prepubertal boys. International Journal of Obesity, 28(12), 1585-1593.

Armstrong, N., \& Simons-Morton, B. (1994). Physical activity and blood lipids in adolescents. Pediatric Exercise Science, 6(4), 381-405.

Armstrong, N., \& Welsman, J. R. (2006). The physical activity patterns of european youth with reference to methods of assessment. Sports Medicine, 36(12), 1067-1086.

Aron, A. R., Poldrack, R. A., \& Wise, S. P. (2009). Cognition: Basal ganglia role. In L. R. Squire (Ed.), Encyclopedia of Neuroscience (2, 1069-1077). Cambridge, MA: Academic Press.

Aschengrau, A., \& Seage, G. R. (2013). Essentials of Epidemiology in Public Health. Sudbury, MA: Jones \& Bartlett Publishers.

Bailey, D. A., Faulkner, R. A., \& McKay, H. A. (1996). Growth, physical activity, and bone mineral acquisition. Exercise and Sport Sciences Reviews, 24(1), 233-266.

Bailey, D. A., McKay, H. A., Mirwald, R. L., Crocker, P. R. E., \& Faulkner, R. A. (1999). A six-year longitudinal study of the relationship of physical activity to bone mineral accrual in growing children: The University of Saskatchewan Bone Mineral Accrual Study. Journal of Bone and Mineral Research, 14(10), 1672-1679. 
Baranowski, T. (1988). Validity and reliability of self report measures of physical activity: An information-processing perspective. Research Quarterly for Exercise and Sport, 59(4), 314-327.

Baranowski, T., Dworkin, R. J., Cieslik, C. J., Hooks, P., Clearman, D. R., Ray, L., ... \& Nader, P. R. (1984). Reliability and validity of self report of aerobic activity: Family Health Project. Research Quarterly for Exercise and Sport, 55(4), 309-317.

Basch, C. E. (2011). Healthier students are better learners: A missing link in school reforms to close the achievement gap. Journal of School Health, 81(10), 593-598.

Bassett, D. R., Fitzhugh, E. C., Heath, G. W., Erwin, P. C., Frederick, G. M., Wolff, D. L., ... \& Stout, A. B. (2013). Estimated energy expenditures for school-based policies and active living. American Journal of Preventive Medicine, 44(2), 108-113.

Batty, D., \& Lee, I. M. (2004). Physical activity and coronary heart disease. British Medical Journal, 328, 1089-1890.

Batty, D., \& Thune, I. (2000). Does physical activity prevent cancer? British Medical Journal, 321, 1424-1425.

Baxter-Jones, A., Maffulli, N., \& Helms, P. (1993). Low injury rates in elite athletes. Archives of Disease in Childhood, 68, 130-132.

Berry, J. D., Pandey, A., Gao, A., Leonard, D., Farzaneh-Far, R., Ayers, C., ... \& Willis, B. (2013). Physical fitness and risk for heart failure and coronary artery disease. Circulation: Heart Failure, 6(4), 627-634.

Biddle, S. J., \& Asate, M. (2011). Physical activity and mental health in children and adolescents: A review of reviews. British Journal of Sports Medicine, 45, 886-895.

Bistritzer, T., Rosenzweig, L., Barr, J., Mayer, S., Lahat, E., Faibel, H., . . \& \& Aladjem, M. (1995). Lipid profile with paternal history of coronary heart disease before age 40. Archives of Disease in Childhood, 73(1), 62-65.

Boreham, C., \& Riddoch, C. (2001). The physical activity, fitness and health of children. Journal of Sports Sciences, 19(12), 915-929.

Boreham, C. A., Twisk, J., Savage, M. J., Cran, G. W., \& Strain, J. J. (1997). Physical activity, sports participation, and risk factors in adolescents. Medicine and Science in Sports and Exercise, 29(6), 788-793.

Bose, K. (2007). Concept of human physical growth and development (Unpublished doctoral dissertation). Vidyasagar University, Midnapore, India.

Bouchard, C., \& Sheppard, R. J. (1994). Physical activity, fitness, and health: The model and key concepts. In C. Bouchard, R. J. Shephard, and T. 
Stephens (Eds.), Physical activity, fitness, and health (pp. 77-88). Champaign, IL: Human Kinetics Books.

Bouchard, C., Tremblay, A., Nadeau, A., Dussault, J., Despres, J. P., Theriault, G., ... \& Fournier, G. (1990). Long-term exercise training with constant energy-intake: 1. Effect on body-composition and selected metabolic variables. International Journal of Obesity, 14, 1, 57-73.

Bouten, C. V., Westerterp, K. R., Verduin, M., \& Janssen, J. D. (1994). Assessment of energy expenditure for physical activity using a triaxial accelerometer. Medicine \& Science in Sports \& Exercise, 26, 1516-1552.

Bös, K. (1994). Differentielle Aspekte der Entwicklung motorischer Fähigkeiten. In J. Baur, K. Bös \& R. Singer (Eds.), Motorische Entwicklung: Ein Handbuch (pp. 238-254). Schorndorf, Germany: Verlag Hofmann.

Bradney, M., Pearce, G., Naughton, G., Sullivan, C., Bass, S., Beck, T., ... \& Seeman, E. (1998). Moderate exercise during growth in prepubertal boys: Changes in bone mass, size, volumetric density, and bone strength; A controlled prospective study. Journal of Bone and Mineral Research, 13(12), 1814-1821.

Brage, S., Wedderkopp, N., Ekelund, U., Franks, P. W., Wareham, N. J., Andersen, L. B., \& Froberg, K. (2004). Features of the Metabolic Syndrome are associated with objectively measured physical activity and fitness in Danish children the European Youth Heart Study (EYHS). Diabetes care, 27(9), 2141-2148.

Bratina, N., Hadžić, V., Battelino, T., Pistotnik, B., Dolenc, M., Šajber, D., ... \& Dervišević, E. (2013). Slovenian guidelines for physical activity in children and adolescents in the age group 2-18 years. Zdravniški vestnik, 80(12), 885-896.

Breslow, N. E. (2014). Case-control studies. In W. Ahrens and I. Pigeot (Eds.), Handbook of epidemiology (pp. 293-323). New York, NY: Springer.

Broderick, C. R., Herbert, R. D., Latimer, J., Barnes, C., Curtin, J. A., Mathieu, E., ... \& Brown, S. A. (2012). Association between physical activity and risk of bleeding in children with hemophilia. Jama, 308(14), 1452-1459.

Brudvik, C., \& Hove, L. M. (2003). Childhood fractures in Bergen, Norway: Identifying high-risk groups and activities. Journal of Pediatric Orthopaedics, 23(5), 629-634.

Buckworth, J., Lee, R. E., Regan, G., Schneider, L. K., \& DiClemente, C. C. (2007). Decomposing intrinsic and extrinsic motivation for exercise: Application to stages of motivational readiness. Psychology of Sport and Exercise, 8(4), 441-461.

Bučar Pajek, M., Strel, J., Kovač, M., \& Pajek, J. (2004). Naraščanje prekomerne

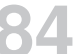


telesne teže in debelosti šoloobveznih otrok v starosti od 7 do 10 let: nova epidemija dejavnika tveganja. In V Štemberger, J. Zurc, in A. Obid (Eds.), Otrok v gibanju: zbornik prispevkov (p. 52). Koper, Slovenia: Annales.

Cain, K. L., Sallis, J. F., Conway, T. L., Van Dyck, D., \& Calhoon, L. (2013). Using accelerometers in youth physical activity studies: A review of methods. Journal of Physical Activity \& Health, 10 (3), 437-450.

Caroli, M. (2003). 13th European Childhood Obesity Group Workshop. International Journal of Obesity and Related Metabolic Disorders, 27(S2), $1-30$.

Carson, V., Ridgers, N. D., Howard, B. J., Winkler, E. A., Healy, G. N., Owen, N, .. \& Salmon, J. (2013). Light-intensity physical activity and cardiometabolic biomarkers in US adolescents. PLoS One, 8(8), e71417.

Caspersen, C. J., Powell, K. E., \& Christenson, G. M. (1985). Physical activity, exercise, and physical fitness: Definitions and distinctions for healthrelated research. Public Health Reports, 100, 126-131.

Caspersen, C. J., Nixon, P. A., \& DuRant, R. H. (1997). Physical activity epidemiology applied to children and adolescents. Exercise and Sport Sciences Reviews, 26, 341-403.

Castelli, D. M., Hillman, C. H., Buck, S. M., \& Erwin, H. E. (2007). Physical fitness and academic achievement in third- and fifth-grade students. Journal of Sport \& Exercise Psychology, 29, 239-252.

Catellier, D. J., Hannan, P. J., Murray, D. M., Addy, C. L., Conway, T. L., Yang, S., \& Rice, J. C. (2005). Imputation of missing data when measuring physical activity by accelerometry. Medicine and Science in Sports and Exercise, 37(11), 555-562.

Caterino, M. C., \& Polak, E. D. (1999). Effects of two types of activity on the performance of second-, third-, and fourth-grade students on a test of concentration. Perceptual and Motor Skills, 89(1), 245-248.

Centers for Disease Control. (1997). Promote lifelong physical activity among young people, risk behavior surveillance - United States. Morbidity and Mortality Weekly Report, 46(6), 1-36.

Centers for Disease Control. (2013). Make a difference at your school (Chronic Disease Paper 31). Retrieved from http://digitalcommons.hsc.unt.edu/ disease/31

Chaddock, L., Erickson, K. I., Prakash, R. S., VanPatter, M., Voss, M. W., Pontifex, M. B., \& Kramer, A. F. (2010). Basal ganglia volume is associated with aerobic fitness in preadolescent children. Developmental Neuroscience, 32(3), 249-256.

Chaddock, L., Pontifex, M. B., Hillman, C. H., \& Kramer, A. F. (2011). A review 
of the relation of aerobic fitness and physical activity to brain structure and function in children. Journal of the International Neuropsychological Society, 17(6), 975-985.

Chaddock-Heyman, L., Erickson, K. I., Holtrop, J. L., Voss, M. W., Pontifex, M. B., Raine, L. B., ... \& Kramer, A. F. (2014). Aerobic fitness is associated with greater white matter integrity in children. Frontiers in Human Neuroscience, 8, 584.

Chen, K. Y., \& Bassett, D. R. (2005). The technology of accelerometry-based activity monitors: Current and future. Medicine and Science in Sports and Exercise, 37(11), S490.

Cheng, G., Buyken, A. E., Shi, L., Karaolis-Danckert, N., Kroke, A., Wudy, S. A., ... \& Remer, T. (2012). Beyond overweight: Nutrition as an important lifestyle factor influencing timing of puberty. Nutrition Reviews, 70(3), 133-152.

Chomistek, A. K., Chasman, D. I., Cook, N. R., Rimm, E. B., \& Lee, I. M. (2013). Physical activity, genes for physical fitness, and risk of coronary heart disease. Medicine and Science in Sports and Exercise, 45(4), 691.

Colcombe, S., \& Kramer, A. F. (2003). Fitness effects on the cognitive function of older adults a meta-analytic study. Psychological science, 14(2), 125130.

Committee on Physical Activity and Physical Education in the School Environment. (2013). Educating the student body. Washington, DC: Academic Press.

Cook, S., Weitzman, M., Auinger, P., Nguyen, M., \& Dietz, W. H. (2003). Prevalence of a metabolic syndrome phenotype in adolescents: Findings from the third National Health and Nutrition Examination Survey, 1988-1994. Archives of Pediatrics \& Adolescent Medicine, 157(8), 821-827.

Corder, K., Ekelund, U., Steele, R. M., Wareham, N. J., \& Brage, S. (2008). Assessment of physical activity in youth. Journal of Applied Physiology, 105(3), 977-987.

Craft, L. L., \& Landers, D. M. (1998). The effect of exercise on clinical depression and depression resulting from mental illness: A meta-analysis. Journal of Sport and Exercise Psychology, 20, 339-357.

Craig, S. B., Bandini, L. G., Lichtenstein, A. H., Schaefer, E. J., \& Dietz, W. H. (1996). The impact of physical activity on lipids, lipoproteins, and blood pressure in preadolescent girls. Pediatrics, 98(3), 389-395.

da Costa Ribeiro, I., Taddei, J. A. A., \& Colugnatti, F. (2003). Obesity among children attending elementary public schools in Sao Paulo, Brazil: A case-control study. Public Health Nutrition, 6(7), 659-663. 
de Visser, D. C., van Hooft, I. M., van Doornen, L. J., Hofman, A., Orlebeke, J. F., \& Grobbee, D. E. (1994). Anthropometric measures, fitness and habitual physical activity in offspring of hypertensive parents: Dutch hypertension and offspring study. American Journal of Hypertension, 7(3), 242-248.

Delgado, R. M., Sillero, A. M., \& Gálvez, V. R. (1993). Proportional mortality studies: Criteria for the selection of participant groups. Gaceta sanitaria/SESPAS, 8(41), 85-93.

Department of Health. (2011). Stay active: A report in physical activity from the four home countries' Chief Medical Officers. London, England: Author.

Department of Health and Children, Health Service executive. (2009). The national guidelines on physical activity for Ireland. Dublin, England: Author.

DiLorenzo, T. M., Bargman, E. P., Stucky-Ropp, R., Brassington, G. S., Frensch, P. A., \& LaFontaine, T. (1999). Long-term effects of aerobic exercise on psychological outcomes. Preventive Medicine, 28(1), 75-85.

Dishman, R. K., Washburn, R. A., \& Schoeller, D. A. (2001). Measurement of physical activity. Quest, 53, 295-309.

Dishman, R. K., Motl, R. K., Saunders, R., Felton, G., Ward, D. S., \& Dowda, M. (2004). Self-efficacy partially mediates the effect of a school-based physical-activity intervention among adolescent girls. Preventive Medicine, 38(5), 628-636.

Dishman, R. K., Motl, R. K., Saunders, R., Felton, G., Ward, D. S., \& Dowda, M. (2005). Enjoyment mediates effects of a school-based physical-activity intervention. Medicine \& Science in Sports \& Exercise, 37(3), 478-487.

Doll, S. R. (1980). The epidemiology of cancer. Cancer, 45(10), 2475-2485.

Donnelly, T. T., McKiel, E., \& Hwang, J. J. (2009). Challenges and motivators influencing the academic performance of English as an additional language (EAL) nursing students: The perspectives of the students. Canadian Journal of Nursing Research, 41(3), 130-150.

DuBose, K. D., Addy, C. L., Ainsworth, B. E., Hand, G. A., \& Durstine, J. L. (2005). The relationship between leisure-time physical activity and the metabolic syndrome: An examination of NHANES III, 1988-1994. Journal of Physical Activity and Health, 2(4), 470-487.

DuBose, K. D., McKune, A. J., Brophy, P., Geyer, G., \& Hickner, R. C. (2015). The relationship between physical activity and the metabolic syndrome score in children. Pediatric Exercise Science, 27(3), 364-371.

Dwyer, T., Coonan, W. E., Leitch, D. R., Hetzel, B. S., \& Baghurst, R. A. (1983). 
An investigation of the effects of daily physical activity on the health of primary school students in South Australia. International Journal of Epidemiology, 12(3), 308-313.

Dwyer, T., \& Gibbons, L. E. (1994). The Australian schools health and fitness survey: Physical fitness related to blood pressure but not lipoproteins. Circulation, 89(4), 1539-1544.

Ebbeling, C. B, Pawlak, D. B., \& Ludwig, D. S. (2002). Childhood obesity: Public-health crisis, common sense cure. Lancet, 360, 473-482.

Eccles, J. S., Barber, B. L., Stone, M., \& Hunt, J. (2003). Extracurricular activities and adolescent development. Journal of Social Issues, 59(4), 865-889.

Ekelund, U., Anderssen, S. A., Froberg, K., Sardinha, L. B., Andersen, L. B., Brage, S., \& European Youth Heart Study Group. (2007). Independent associations of physical activity and cardiorespiratory fitness with metabolic risk factors in children: The European youth heart study. Diabetologia, 50(9), 1832-1840.

Ekelund, U., Yngve, A., Sjöström, M., \&Westerterp, K. (2000). Field evaluation of the Computer Science and Applications Inc. Activity monitor during running and skating training in adolescent athletes. International Journal of Sports Medicine, 21(8), 586-592.

European Commission. 2013. Physical education and sport at school in Europe (Eurydice Report). Luxembourg: Publications Office of the European Union.

Eurydice. (2014). The structure of the European education systems 2014/15. Luxembourg: Publications Office of the European Union.

Eurydice. (2015). The Structure of the European education systems 2015/16. Luxembourg: Publications Office of the European Union.

Evans, W. H., Evans, S. S., Schmid, R. E., \& Pennypacker, H. S. (1985). The effects of exercise on selected classroom behaviors of behaviorally disordered adolescents. Behavioral Disorders, 11(1), 42-51.

Evenson, K., R., Goto, M. M., \& Furberg, R. D. (2015). Systematic review of the validity and reliability of consumer-wearable activity trackers. International Journal of Behavioral Nutrition and Physical Activity, 12(159), $1-22$.

EU Working Group 'Sport and Health.' (2008). EU physical activity guidelines. Retrieved from http://ec.europa.eu/assets/eac/sport/library/policy _documents/eu-physical-activity-guidelines-2008_en.pdf

Fernhall, B., \& Agiovlasitis, S. (2008). Arterial function in youth: Window into cardiovascular risk. Journal of Applied Physiology, 105, 325-333.

Finch, C., Valuri, G., \& Ozanne-Smith, J. (1998). Sport and active recreation 
injuries in Australia: Evidence from emergency department presentations. British Journal of Sports Medicine, 32(3), 220-225.

Finger, S. (2001). Origins of neuroscience: A history of explorations into brain function. New York, NY: Oxford University Press.

Fleishman, E. A. (1972). The structure and measurment of physical fitness. Engelwood Cliffs, NJ: Prentice-Hall.

Flodmark, C. E., Lissau, I., Moreno, L. A., Pietrobelli, A., \& Widhalm, K. (2004). New insights into the field of children and adolescents' obesity: The European perspective. International Journal of Obesity, 28(10), 11891196.

Ford, E. S., Li, C., \& Zhao, G. (2010). Prevalence and correlates of metabolic syndrome based on a harmonious definition among adults in the US. Journal of Diabetes, 2(3), 180-193.

Fras, Z., \& Poličnik, R. (2007). Nacionalni program spodbujanja telesne dejavnosti za krepitev zdravja od 2007 do 2012: povzeto po strategiji Vlade Republike Slovenije na področju telesne (gibalne) dejavnosti za krepitev zdravja od 2007 do 2012. Retrieved from http:/ / www.mz.gov.si/fileadmin /mz.gov.si/pageuploads/javno_zdravje_09/Nacionalni_program _telesna_dejavnost_slo.pdf

Freedson, P., Bowles, H. R., Troiano, R., \& Haskell, W. (2012). Assessment of physical activity using wearable monitors: Recommendations for monitor calibration and use in the field. Medicine and Science in Sports and Exercise, 44 (1), S1.

Freedson, P. S., \& Miller, K. (2000). Objective monitoring of physical activity using motion sensors and heart rate. Research Quarterly for Exercise and Sport, 71(S2), 21-29.

Friis, R. H., \& Sellers, T. (2013). Epidemiology for public health practice. Sudbury, MA: Jones \& Bartlett Publishers.

Fuchs, R. K., Bauer, J. J., \& Snow, C. M. (2001). Jumping improves hip and lumbar spine bone mass in prepubescent children: A randomized controlled trial. Journal of Bone and Mineral Research, 16(1), 148-156.

Gabriel, K. K. P., Morrow Jr, J. R., \& Woolsey, A. L. T. (2012). Framework for physical activity as a complex and multidimensional behavior. Journal of Physical Activity and Health, 9(S1), 11-18.

Garn, S. M., \& Clark, D. C. (1976). Trends in fatness and the origins ob obesity. Pediatrics, 57, 443-456.

Gillander Gadin, K., \& Hammarstrom, A. (2002). Can school-related factors predict future health behaviour among young adolescents? Public Health, 116, 22-29. 
Ginty, F., Rennie, K. L., Mills, L., Stear, S., Jones, S., \& Prentice, A. (2005). Positive, site-specific associations between bone mineral status, fitness, and time spent at high-impact activities in 16-to 18-year-old boys. Bone, 36(1), 101-110.

Grimston, S. K., Willows, N. D., \& Hanley, D. A. (1993). Mechanical loading regime and its relationship to bone mineral density in children. Medicine and Science in Sports and Exercise, 25, 1203-1210.

Grissom, J. B. (2005). Physical fitness and academic achievement. Journal of Exercise Physiology Online, 8(1), 11-25.

Goodman, E., Dolan, L. M., Morrison, J. A., \& Daniels, S. R. (2005). Factor analysis of clustered cardiovascular risks in adolescence obesity is the predominant correlate of risk among youth. Circulation, 111(15), 19701977.

Gortmaker, S. L., Lee, R., Cradock, A. L., Sobol, A. M., Duncan, D. T., \& Wang, Y. C. (2012). Disparities in youth physical activity in the United States: 2003-2006. Medicine \& Science in Sports \& Exercise, 44(5), 888-893.

Guinhouya, C. B., Hubert, H., Soubrier, S., Vilhelm, C., Lemdani, M., \& Durocher, A. (2006). Moderate-to-vigorous physical activity among children: Discrepancies in accelerometry-based cut-off points. Obesity, 14(5), 774-777.

Gunter, K. B., Almstedt, H. C., \& Janz, K. F. (2012). Physical activity in childhood may be the key to optimizing lifespan skeletal health. Exercise and Sport Sciences Reviews, 40(1), 13.

Gutin, B., Cucuzzo, N., Islam, S., Smith, C., \& Stachura, M. E. (1996). Physical training, lifestyle education, and coronary risk factors in obese girls. Medicine and Science in Sports and Exercise, 28(1), 19-23.

Hackensmith, C. W. (1966). History of physical education. New York, NY: HarperCollins Publishers.

Hallal, P. C., Victora, C. G., Azevedo, M. R., \& Wells, J. C. (2006). Adolescent physical activity and health. Sports Medicine, 36(12), 1019-1030.

Hansen, E. S. (1990). The proportionate mortality ratio and its relationship with measures of mortality. Statistics in Medicine, 9(3), 315-323.

Haque, A. K., Gadre, S., Taylor, J., Haque, S. A., Freeman, D., \& Duarte, A. (2008). Pulmonary and cardiovascular complications of obesity: An autopsy study of 76 obese subjects. Archives of Pathology \& Laboratory Medicine, 132(9), 1397-1404.

Harrell, J. S., McMurray, R. G., Bangdiwala, S. I., Frauman, A. C., Gansky, S. A., \& Bradley, C. B. (1996). Effects of a school-based intervention to reduce cardiovascular disease risk factors in elementary-school children: 
The Cardiovascular Health in Children (CHIC) study. The Journal of Pediatrics, 128(6), 797-805.

Health Canada, Canadian Society for Exercise Physiology. (2002). Canada's physical activity guide for youth. Ottawa: Minister of Public Works and Government Services Canada.

Heaney, R. P., Abrams, S., Dawson-Hughes, B., Looker, A., Marcus, R., Matkovic, V., \& Weaver, C. (2000). Peak bone mass. Osteoporosis International, 11, 985-1009.

Hermanussen, M. (2010). Tempo and amplitude in growth. Georgian Medical News, July-August, 83-88.

Hill, L. J., Williams, J. H., Aucott, L., Thomson, J., \& Mon-Williams, M. A. R. K. (2011). How does exercise benefit performance on cognitive tests in primary-school pupils? Developmental Medicine \& Child Neurology, 53(7), 630-635.

Hills, A. P., Mokhtar, N., \& Byrne, N. M. (2014). Assessment of physical activity and energy expenditure: An overview of objective measures. Frontiers in Nutrition, 1(5).

Hollar, D., Lombardo, M., Lopez-Mitnik, G., Hollar, T. L., Almon, M., Agatston, A. S., \& Messiah, S. E. (2010). Effective multi-level, multi-sector, schoolbased obesity prevention programming improves weight, blood pressure, and academic performance, especially among low-income, minority children. Journal of Health Care for the Poor and Underserved, 21(2), 93-108.

Hudson, C. E. (2008). An integrative review of obesity prevention in African American children. Issues in Comprehensive Pediatric Nursing, 31(4), 147-170.

Hurtig-Wennlöf, A., Ruiz, J. R., Harro, M., \& Sjöström, M. (2007). Cardiorespiratory fitness relates more strongly than physical activity to cardiovascular disease risk factors in healthy children and adolescents: The European Youth Heart Study. European Journal of Cardiovascular Prevention \& Rehabilitation, 14(4), 575-581.

Hussey, J., Bell, C., Bennett, K., O’Dwyer, J., \& Gormley, J. (2007). Relationship between the intensity of physical activity, inactivity, cardiorespiratory fitness and body composition in 7-10-year-old Dublin children. British Journal of Sports Medicine, 41(5), 311-316.

Institute of Medicine. (2013). Educating the student body: Taking physical activity and physical education to school. Washington, DC: The National Academies Press.

Janssen, I., Katzmarzyk, P. T., Boyce, W. F., Vereecken, C., Mulvihill, C., Roberts,

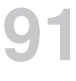


C., ... \& Pickett, W. (2005). Comparison of overweight and obesity prevalence in school-aged youth from 34 countries and their relationships with physical activity and dietary patterns. Obesity Reviews, 6(2), 123132.

Janssen, I., \& LeBlanc, A. G. (2010). Systematic review of the health benefits of physical activity and fitness in school-aged children and youth. International Journal of Behavioral Nutrition and Physical Activity, 7(40).

Jensen, E. (2005). Teaching with the brain in mind. Alexandria, VA: ASCD.

Jespersen, E., Rexen, C. T., Franz, C., Müller, N. C., Froberg, K., \& Wedderkopp, N. (2015). Musculoskeletal extremity injuries in a cohort of schoolchildren aged 6-12: A 2.5-year prospective study. Scandinavian Journal of Medicine \& Science in Sports, 25(2), 251-258.

Jiménez-Pavón, D., Konstabel, K., Bergman, P., Ahrens, W., Pohlabeln, H., Hadjigeorgiou, C., ... \& Pitsiladis, Y. (2013). Physical activity and clustered cardiovascular disease risk factors in young children: A crosssectional study (the IDEFICS study). BMC Medicine, 11(1), 310-314.

Joens-Matre, R. R., Welk, G. J., Calabro, M. A., Russell, D. W., Nicklay, E., \& Hensley, L. D. (2008). Rural-urban differences in physical activity, physical fitness, and overweight prevalence of children. The Journal of Rural Health, 24, 49-54.

Johnson, W. D., Kroon, J. J., Greenway, F. L., Bouchard, C., Ryan, D., \& Katzmarzyk, P. T. (2009). Prevalence of risk factors for metabolic syndrome in adolescents: National Health and Nutrition Examination Survey (NHANES), 2001-2006. Archives of Pediatrics \& Adolescent Medicine, 163(4), 371-377.

Jurak, G. (2012). Analiza šolskega športnega prostora s smernicami za nadaljnje investicije. https://www.fsp.uni-lj.si/COBISS/Monografije/Analiza _skupaj3.pdf

Jurak, G., Cooper, A., Leskosek, B., \& Kovac, M. (2013). Long-term effects of 4 -year longitudinal school-based physical activity intervention on the physical fitness of children and youth during 7-year follow-up assessment. Central European Journal of Public Health, 21(4), 190-194.

Jurak, G., Kovac, M., \& Starc, G. (2013). The ACDSi 2013 - The Analysis of Children's Development in Slovenia 2013: Study protocol. Anthropological Notebooks, 19(3), 123-43.

Jurak, G., Kovač, M., \& Strel, J. (2007). Utjecaj programa dodatnih sati tjelesnog odgoja na tjelesni i motorički razvoj djece u dobi od 7 do 10 godina. Kinesiology: International Journal of Fundamental and Applied Kinesiology, 38(2), 105-115.

Jurak, G., Leskošek, B., \& Strel, J. (2013). Prostorska razpršenost in starost šol- 
skih športnih dvoran ter skupine njihovih uporabnikov. Šport, 61(3/4), 130-138.

Kahn, E. B., Ramsey, L. T., Brownson, R. C., Heath, G. W., Howze, E. H., Powell, K. E., ... \& Corso, P. (2002). The effectiveness of interventions to increase physical activity: A systematic review. American Journal of Preventive Medicine, 22(4), 73-107.

Kahlmeier, S., Wijnhoven, T. M., Alpiger, P., Schweizer, C., Breda, J., \& Martin, B. W. (2015). National physical activity recommendations. BMC Public Health, 15(133), 1-14.

Kanner, K. D. (1990). High versus low-intensity exercise as part of an inpatient treatment program for childhood and adolescent depression (Unpublished doctoral dissertation). California School of Professional Psychology, Ahhambra, CA.

Kirk, D. (2010). Why research matters: Current status and future trends in physical education pedagogy. Movimento, 16(2), 11-43.

Kirkendall, D. R. (1985). Effects of physical activity on intelectual development and academic performance. In G. Stull, \& H Eckert (Eds.). Effects of physical activity on children (pp. 49-63). Champaign, IL: Human Kinetics Publishers.

Kleim, J. A., Cooper, N. R., \& VandenBerg, P. M. (2002). Exercise induces angiogenesis but does not alter movement representations within rat motor cortex. Brain Research, 934(1), 1-6.

Kohl, H. W., Fulton, J. E., \& Caspersen, C. J. (2000). Assessment of physical activity among children and adolescents: A review and synthesis. Preventive Medicine, 31(2), 54-76.

Kohl, H., W., \& Cook, H. D. (Eds.) (2013). Educating the student body: Taking physical activity and physical education to school. Washington, DC: National Academies Press.

Kovač, M., Jurak, G., Starc, G., \& Strel, J. (2011). The importance of researchbased evidence for political decisions on physical education. In K. Hardman, \& K. Green (Eds.), Contemporary issues in physical education: International perspectives (pp. 47-68). Auckland, Australia: Meyer \& Meyer.

Ministrstvo za šolstvo in šport. (2011). Program osnovna šola: športna vzgoja; učni načrt. Ljubljana, Slovenia: Author.

Kovač, M., Strel, J., Jurak, G., \& Starc, G. (2015). The importance of researchbased data for design of intervention sport programmes for children. In J. Rugelj, V. Štemberger, M. Blažiž, I. Saksida, \& M. Kovač (Eds.), Zbornik radova: istraživanja paradigm djetinstva, odgoja i obrazovanja (pp. 111). Zagreb, Croatia: Faculty of Teacher Education. 
Kramer, A. F., Hahn, S., Cohen, N. J., Banich, M. T., McAuley, E., Harrison, C. R., ... \& Colcombe, A. (1999). Ageing, fitness and neurocognitive function. Nature, 400(6743), 418-419.

Kraus, W. E., Houmard, J. A., Duscha, B. D., Knetzger, K. J., Wharton, M. B., McCartney, J. S., .. \& \& Kulkarni, K. R. (2002). Effects of the amount and intensity of exercise on plasma lipoproteins. New England Journal of Medicine, 347(19), 1483-1492.

Kromhout, D., Bloemberg, B., Seidell, J. C., Nissinen, A., \& Menotti, A. (2001). Physical activity and dietary fiber determine population body fat levels: The Seven Countries Study. International Journal of Obesity and Related Metabolic Disorders, 25, 301-306.

Kumahara, H., Tanaka, H., \& Schutz, Y. (2004). Daily physical activity assessment: What is the importance of upper limb movements vs. whole body movements? InternaInternational Journal of Obesity and Related Metabolic Disorders, 28(9), 1105-1110.

Lagerros, Y. T., \& Lagiou, P. (2007). Assessment of physical activity and energy expenditure in epidemiological research of chronic diseases. European Journal of Epidemiology, 22(6), 353-362.

LaMorte, W. W. (2015). Prospective and retrospective cohort studies. Retrieved from http://sphweb.bumc.bu.edu/otlt/MPH-Modules/EP/EP713 _AnalyticOverview/EP713_AnalyticOverview3.html

Lanciego, J. L., Luquin, N., \& Obeso, J. A. (2012). Functional neuroanatomy of the basal ganglia. Cold Spring Harbor Perspectives in Medicine, 2(12), a009621.

Lasan, M. (2004). Fiziologija športa - harmonija med delovanjem in mirovanjem. Ljubljana, Slovenia: Fakulteta za šport, Inštitut za šport.

Lee, S. M., Burgeson, C. R., Fulton, J. E., \& Spain, C. G. (2007). Physical education and physical activity. Journal of School Health, 77(8), 435-463.

Lee, S. J., \& Arslanian, S. A. (2007). Cardiorespiratory fitness and abdominal adiposity in youth. European Journal of Clinical Nutrition, 61(4), 561565.

Leon, A. S., \& Sanchez, O. A. (2001). Response of blood lipids to exercise training alone or combined with dietary intervention. Medicine \& Science in Sports \& Exercise, 33, 502-515.

Libbey, M. (2004, 22 January). Learning from 2003: Spamming trends and key insights. Paper presented at the MIT Spam Conference, Cambridge, MA.

Lindquist, C. H., Reynolds, K. D., \& Goran, M. I. (1999). Sociocultural determinants of physical activity among children. Preventive Medicine, 29(4), 305-312. 
Lissau, I. Overpeck, M. D., Ruan, W. J., Due, P., Holstein, B. E., \& Hediger, M. L. 2004. Body mass index and overweight in adolescents in 13 European countries, Israel, and the United States. Archives of Pediatrics and Adolescent Medicine, 158, 27-33.

Livingstone, M. B., Robson, P. J., Wallace, J. M., \& McKinley, M. C. (2003). How active are we? Levels of routine physical activity in children and adults. Proceedings of the Nutrition Society, 62(3), 681-701.

Lobstein, T., Baur, L., \& Uauy, R. (2004). Obesity in children and young people: A crisis in public health. Obesity Reviews, 5(S1), 4-85.

Machin, D., \& Fayers, P. M. (2010). Randomized clinical trials: Design, practice and reporting. Hoboken, NJ: Wiley.

Maclure, M., \& Mittleman, A. M. (2000). Should we use a case-crossover design? Annual Review of Public Health, 21(1), 193-221.

Maffeis, C., Talamini, G., \& Tato, L. (1998). Influence of diet, physical activity and parents' obesity on children's adiposity: A four-year longitudinal study. International Journal of Obesity \& Related Metabolic Disorders, 22(8): 758-764.

Maffeis, C. (2000). Aetiology of overweight and obesity in children and adolescents. European Journal of Pediatrics, 159(1), S35-S44.

Magill, A. (1998). Motor learning: Concepts and applications. Dubuque, IA: McGraw-Hill.

Malina, R. M., Bouchard, C., \& Bar-Or, O. (2004). Growth, maturation, and physical activity. Champaign, IL: Human Kinetics.

Malina, R. M., \& Katzmarzyk, P. T. (2006). Physical activity and fitness in an international growth standard for preadolescent and adolescent children. Food and Nutrition Bulletin, 27(4), S295-S313.

Mann, C. J. (2003). Observational research methods: Research design II; Cohort, cross sectional, and case-control studies. Emergency Medicine Journal, 20(1), 54-60.

Marsh, H. W. (1993). The multidimensional structure of physical fitness: Invariance over gender and age. Research Quarterly for Exercise and Sport, 64(3), 256-273.

Marshall, S. J., \& Ramirez, E. (2011). Reducing sedentary behavior: A new paradigm in physical activity promotion. American Journal of Lifestyle Medicine, 5(6), 518-530.

Martínez-Gómez, D., Eisenmann, J. C., Moya, J. M., Gómez-Martínez, S., Marcos, A., \& Veiga, O. L. (2009). The role of physical activity and fitness on the metabolic syndrome in adolescents: Effect of different scores; The AFINOS Study. Journal of Physiology and Biochemistry, 65(3), 277-289. 
Matejek, Č. (2013). Povezanost telesnih razsežnosti in gibalnih sposobnosti z nekaterimi okoljskimi dejavniki otrok, starih 11 in 14 let (Unpublished doctoral dissertation). University of Ljubljana, Ljubljana, Slovenia.

Mattocks, C., Ness, A., Leary, S., Tilling, K., Blair, S. N., Shield, J., ... \& Riddoch, C. (2008). Use of accelerometers in a large field-based study of children: Protocols, design issues, and effects on precision. Journal of Physical Activity \& Health Journal, 5(1), 98-111.

McArdle, W. D., Katch, F. I., \& Katch, V. L. (2006). Essentials of exercise physiology. Philadelphia, PA: Lippincott Williams \& Wilkins.

McDonald, N. C. (2007). Active transportation to school: Trends among US schoolchildren, 1969-2001. American Journal of Preventive Medicine, 32(6), 509-516.

McGill, H. C., McMahan, C. A., Herderick, E. E., Zieske, A. W., Malcom, G. T., Tracy, R. E., ... \& Pathobiological Determinants of Atherosclerosis in Youth (PDAY) Research Group. (2002). Obesity accelerates the progression of coronary atherosclerosis in young men. Circulation, 105(23), 2712-2718.

McKay, H. A., Petit, M. A., Schutz, R. W., Prior, J. C., Barr, S. I., \& Khan, K. M. (2000). Augmented trochanteric bone mineral density after modified physical education classes: A randomized school-based exercise intervention study in prepubescent and early pubescent children. The Journal of Pediatrics, 136(2), 156-162.

McKenzie, T., L. (2001). Use of direct observation to assess physical activity. In Welk, G. (Ed.), Physical activity assessments for health-related research (pp. 179-197). Champaign, IL: Human Kinetics.

McKenzie, T. L., Catellier, D. J., Conway, T., Lytle, L. A., Grieser, M., Webber, L. A., ... \& Elder, J. P. (2006). Girls' activity levels and lesson contexts in middle school PE: TAAG baseline. Medicine and Science in Sports and Exercise, 38(7), 1229-1235.

McPhie, M. L., \& Rawana, J. S. (2015). The effect of physical activity on depression in adolescence and emerging adulthood: A growth-curve analysis. Journal of Adolescence, 40, 83-92.

Menschik, D., Ahmed, S., Alexander, M. H., \& Blum, R. W. (2008). Adolescent physical activities as predictors of young adult weight. Archives of Pediatrics \& Adolescent Medicine, 162(1), 29-33.

Metcalf, B., Henley, W., \& Wilkin, T. (2012). Effectiveness of intervention on physical activity of children: Systematic review and meta-analysis of controlled trials with objectively measured outcomes (EarlyBird 54). $B M J, 345(\mathrm{e} 5888)$. 
Ministry of Health, Welfare and Sport. (2005). The power of sport. The Hague, The Netherlands: Author.

Monson, R. R. (1974). Analysis of relative survival and proportional mortality. Computers and Biomedical Research, 7, 325-332.

Montoye, H. J., Kemper, H. C. G., Saris, W. H. M., \& Washburn, R. A. (1996). Measuring physical activity and energy expenditure. Champaign, IL: Human Kinetics.

Morris, F. L., Naughton, G. A., Gibbs, J. L., Carlson, J. S., \& Wark, J. D. (1997). Prospective ten-month exercise intervention in premenarcheal girls. Journal of Bone and Mineral Research, 12(9), 1453-1462.

Murray, N. G., Garza, J. C., Diamond, P. M., Hoelscher, D. M., Kelder, S., \& Ward, J. L. (2008). Fitness and academic achievement among 3rd and 4 th grade students in Texas. Medicine \& Science in Sports \& Exercise, 40(5), S96.

Nader, P. R., Bradley, R. H., Houts, R. M., McRitchie, S. L., \& O’Brien, M. (2008). Moderate-to-vigorous physical activity from ages 9 to 15 years. Jama, 300(3), 295-305.

National Association for Sport and Physical Education. (2004). Moving into the future: National Physical Education Content Standards. Reston, VA: Author.

National Association for Sport and Physical Education. (2010). Shape of the nation report: Status of physical education in the USA. Reston, VA: Author.

Nelson, M. C., \& Gordon-Larsen, P. (2006). Physical activity and sedentary behavior patterns are associated with selected adolescent health risk behaviors. Pediatrics, 117(4), 1281-1290.

North, T. C., McCullagh, P., \& Tran, Z. V. (1990). Effect of exercise on depression. Exercise and Sport Sciences Reviews, 18, 379.

OECD. (2012). Health at a glance: Europe 2012. Paris: Author.

Ogden, C. L., Carroll, M. D., Curtin, L. R., McDowell, M. A., Tabak, C. J., Flegal, K. M. (2006). Prevalence of overweight and obesity in the United States, 1999-2004. Journal of the American Medical Association, 295(13), 15491555.

Ogden, C. L., Flegal, K. M., Carroll, M. D., \& Johnson, C. L. (2002). Prevalence and trends in overweight among US children and adolescents 19992000. Jama, 288, 1728-1732.

Ortega, F. B., Ruiz, J. R., Castillo, M. J., \& Sjöström, M. (2008). Physical fitness in childhood and adolescence: A powerful marker of health. International Journal of Obesity, 32(1), 1-11. 
Ortega, F. B., Tresaco, B., Ruiz, J. R., Moreno, L. A., Martin-Matillas, M., Mesa, J. L., ... \& Castillo, M. J. (2007). Cardiorespiratory fitness and sedentary activities are associated with adiposity in adolescents. Obesity, 15(6), 1589-1599.

Papalia, D. E., Olds, S. W., \& Feldman, R. D. (2003). Human development. New York, NY: McGraw-Hill.

Pate, R. R. (1993). Physical activity assessment in children and adolescents. Critical Reviews in Food Science and Nutrition, 33, 321-316.

Pate, R. R., McIver, K. L., Colabianchi, N., Troiano, R. P., Reis, J. P., Carroll, D. D., \& Fulton, J. E. (2015). Physical activity measures in the healthy communities study. American Journal of Preventive Medicine, 49(4), 653-659.

Pišot, R., \& Planinšec, J. (2005). Struktura motorike v zgodnjem otroštvu. Koper, Slovenia: Annales.

Planinšec, J. (2003). Ugotavljanje gibalne dejavnosti mlajših otrok. Zdravstveno varstvo, 42(2), 58-65.

Plasqui, G., \& Westerterp, K. R. (2006). Accelerometry and heart rate as a measure of physical fitness: Cross-validation. Medicine and science in sports and exercise, 38(8), 1510-1514.

Plasqui, G., \& Westerterp, K. R. (2007). Physical activity assessment with accelerometers: An evaluation against doubly labeled water. Obesity, 15(10), 2371-2379.

Porta, M. (Ed.). (2008). A dictionary of epidemiology (5th ed.). New York, NY: Oxford University Press.

Powell, K. E., \& Pratt, M. (1996). Physical activity and health. BMJ, 313(126).

Prince, S. A., Adamo, K. B., Hamel, M. E., Hardt, J., Gorber, S. C., \& Tremblay, M. (2008). A comparison of direct versus self-report measures for assessing physical activity in adults: A systematic review. International Journal of Behavioral Nutrition and Physical Activity, 5(1), 1-24.

Public Health Institute. (2008). Recommendations for physical activity. Reykjavik, Iceland: Author.

Reilly, J., Penpraze, V., Hislop, J., Davies, G., Grant, S., Paton, J. Y. (2008). Objective measurement of physical activity and sedentary behaviour: Review with new data. Archives of Disease in Childhood, 93, 614-619.

Reynolds, K. D., Killen, J. D., Bryson, S. W., Maron, D. J., Taylor, C. B., Maccoby, N., \& Farquhar, J. W. (1990). Psychosocial predictors of physical activity in adolescents. Preventive Medicine, 19(5), 541-551.

Riddoch, C. (1998). Relationships between physical activity and physical health in young people. In S. Biddle, J. Sallis, \& N. Cavill (Eds.), Young and active? Young people and healthenhancing physical activity: Evid- 
ence and implications (pp. 17-48). London: Health Education Authority.

Riddoch, C. J., Mattocks, C., Deere, K., Saunders, J., Kirkby, J., Tilling, K., ... \& Ness, A. R. (2007). Objective measurement of levels and patterns of physical activity. Archives of Disease in Childhood, 92(11), 963-969.

Ridgers, N. D., Stratton, G., Fairclough, S. J., \& Twisk, J. W. (2007). Children's physical activity levels during school recess: A quasi-experimental intervention study. International Journal of Behavioral Nutrition and Physical Activity, 4(1), 1-11.

Ridgers, N. D., \& Fairclough, S. (2011). Assessing free-living physical activity using accelerometry: Practical issues for researchers and practitioners. European Journal of Sport Science, 11(3), 205-213.

Roberts, K. C., Shields, M., de Groh, M., Aziz, A., \& Gilbert, J. A. (2012). Overweight and obesity in children and adolescents: Results from the 2009 to 2011 Canadian Health Measures Survey. Health Reports, 23(3), 37-41.

Roberts, C, Tynjälä, J., \& Komkov, A. (2004). Physical activity. In C. Currie, C. Roberts, A. Morgan, R. Smith, W. Settertobulte, O. Samdal, \& V. Barnekow Rasmussen (Eds.), Young people's health in contex: Health Bahaviour in School-Aged Children (HBSC) Study (pp. 90-97). Copenhagen, Denmark: World Health Organization.

Robinson, L. E. (2011). The relationship between perceived physical competence and fundamental motor skills in preschool children. Child: Care, Health and Development, 37(4), 589-596.

Robinson, T. N., Hammer, L. D., Wilson, D. M., Killen, J. D., Kraemer, H. C., Hayward, C., \& Taylor, C. B. (1993). Does television viewing increase obesity and reduce physical activity? Cross-sectional and longitudinal analyses among adolescent girls. Pediatrics, 91(2), 273-280.

Robinson, T. N., Killen, J. D. (1995). Ethnic and gender differences in the relationships between television viewing and obesity, physical activity, and dietary fat intake. Journal of Health Education, 26(2), 91-98.

Rothman, K. J. (2012). Epidemiology: An introduction. Oxford, England: Oxford University Press.

Rothman, K. J., Greenland, S., \& Lash, T. L. (Eds.). (2008). Modern epidemiology. Philadelphia, PA: Lippincott Williams \& Wilkins.

Rowland, T. W., Mattel, L., Vanderburgh, P., Manos, T., \& Charkoudian, N. (1996). The influence of short-term aerobic training on blood lipids in healthy 10-12 year old children. International Journal of Sports Medicine, 17(7), 487-492.

Rowlands, A. V. (2007). Accelerometer assessment of physical activity in children: An update. Pediatric Exercise Science, 3, 252-266. 
Ruiz, J. R., Rizzo, N. S., Hurtig-Wennlöf, A., Ortega, F. B., Wärnberg, J., \& Sjöström, M. (2006). Relations of total physical activity and intensity to fitness and fatness in children: The European Youth Heart Study. The American Journal of Clinical Nutrition, 84(2), 299-303.

Sandvik, L., Erikssen, J., Thaulow, E., Erikssen, G., Mundal, R., \& Aakhus, T. (1993). Heart volume and cardiovascular mortality. European Heart Journal, 14(5), 592-596.

Sallis, J. F., Alcaraz, J. E., McKenzie, T. L., Hovell, M. F., Kolody, B., \& Nader, P. R. (1992). Parental behavior in relation to physical activity and fitness in 9-year-old children. American Journal of Diseases of Children, 146(11), 1383-1388.

Sallis, J. F., McKenzie, T. L., Kolody, B., Lewis, M., Marshall, S., \& Rosengard, P. (1999). Effects of health-related physical education on academic achievement: Project SPARK. Research Quarterly for Exercise and Sport, 70(2), 127-134.

Sallis, J. F., McKenzie, T. L., Alcaraz, J. E., Kolody, B., Faucette, N., \& Hovell, M. F. (1997). The effects of a 2-year physical education program (SPARK) on physical activity and fitness in elementary school students. American Journal of Public Health, 87(8), 1328-1334.

Sallis, J. F., Patterson, T. L., Buono, M. J., Atkins, C. J., \& Nader, P. R. (1988). Aggregation of physical activity habits in Mexican-American and Anglo families. Journal of Behavioral Medicine, 11(1), 31-41.

Sallis, J. F., Prochaska, J. J., Taylor, W. C. (2000). A review of correlates of physical activity of children and adolescents. Medicine and Science in Sports and Exercise, 32(5), 963-975.

Sallis, J. F., \& Saelens, B. E. (2000). Assessment of physical activity by selfreport: Status, limitations, and future directions. Research Quarterly for Exercise and Sport, 71(2), 1-14.

Saris, W. H. M. (1986). Habitual physical activity in children: Methodology and findings in health and disease. Medicine \& Science in Sports \& Exercise, 18, 253-263.

Saris, W. H. M., \& Binkhorst, R. A. (1977). The use of pedometer and actometer in studying daily physical activity in man. Part 2: Validity of pedometer and actometer measuring the daily physical activity. European Journal of Applied Physiology and Occupational Physiology, 37(3), 229-235.

Sasaki, J., Shindo, M., Tanaka, H., Ando, M., \& Arakawa, K. (1987). A longterm aerobic exercise program decreases the obesity index and increases the high density lipoprotein cholesterol concentration in obese children. International Journal of Obesity, 11, 339-345. 
Schneider, P. L., Crouter, S. E., \& Bassett, D. R. (2004). Pedometer measures of free-living physical activity: Comparison of 13 models. Medicine and Science in Sports and Exercise, 36(2), 331-335.

Schutz, Y., Weinsier, R. L., \& Hunter, G. R. (2001). Assessment of free-living physical activity in humans: An overview of currently available and proposed new measures. Obesity Research, 9(6), 368-379.

Sember, V., Starc, G., Jurak, G., Golobič, M., Kovač, M., Samardžija, P. P., \& Morrison, S. A. (2016). Results from the Republic of Slovenia's 2016 report card on physical activity for children and youth. Journal of Physical Activity and Health, 13(11), S256-S264.

Serdula, M. K., Ivery, D., Coates, R. J., Freedman, D. S., Williamson, D. F., \& Byers, T. (1993). Do obese children become obese adults? A review of the literature. Preventive Medicine, 22(2), 167-177.

Shannonhouse, A. K. (2012). The effects of physical activity on academic achievement in kindergarten aged children (Unpublished doctoral dissertation). University of Pittsburgh, Pittsburgh, PA.

Sharif, I., \& Sargent, J. D. (2006). Association between television, movie, and video game exposure and school performance. Pediatrics, 118(4), e1061e1070.

Shephard, R. J. (1997). Curricular physical activity and academic performance. Pediatric Exercise Science, 9, 113-126

Shephard, R. J. (2003). Limits to the measurement of habitual physical activity by questionnaires. British Journal of Sports Medicine, 37, 197-206.

Sibley, B. A., \& Etnier, J. L. (2003). The relationship between physical activity and cognition in children: A meta-analysis. Pediatric Exercise Science, 15, 243-256.

Siedentop, D. L. (2009). National plan for physical activity: Education sector. Journal of Physical Activity and Health, 6(2), 168-180.

Simons-Morton, B. G., Taylor, W. C., Snider, S. A., \& Huang, I. W. (1993). The physical activity of fifth-grade students during physical education classes. American Journal of Public Health, 83(2), 262-264.

Singh, A., Uitjtdewilligen, L., Twisk, J. W. R., Van Mechelen, W., in Chinapaw, M. J. M. (2012). Physical activity and performance at school: A systematic review of the literature including a methodological quality assesment. Archives of Pediatrics Adolescent Medicine, 166(1), 49-55.

Sinha, R., Fisch, G., Teague, B., Tamborlane, W. V., Banyas, B., Allen, K., ... \& Sherwin, R. S. (2002). Prevalence of impaired glucose tolerance among children and adolescents with marked obesity. New England Journal of Medicine, 346(11), 802-810. 
Sirard, J. R., \& Pate, R. R. (2001). Physical activity assessment in children and adolescents. Sports Medicine, 31(6), 439-454.

Slemenda, C., Reister, T., Hui, S., Miller, J., Christian, J., \& Johnston, C. C. (1994). Influences on skeletal mineralization in children and adolescents: Evidence for varying effects of sexual maturation and physical activity. The Journal of Pediatrics, 125, 201-207.

Speakman, J. R. (1998). The history and theory of the doubly labeled water technique. The American Journal of Clinical Nutrition, 68(4), 932-938.

Speakman, J. R., Nair, K. S., \& Goran, M. I. (1993). Revised equations for calculating $\mathrm{CO}_{2}$ production from doubly labeled water in humans. American Journal of Physiology-Endocrinology and Metabolism, 264(6), E912E917.

Starc, G., Kovač, M., Strel, J., Golja, P., Robi, T., Grum, D. K., ... \& Pinter, S. (2015). The ACDSi 2014 - a decennial study on adolescents' somatic, motor, psycho-social development and healthy lifestyle: Study protocol. Anthropological Notebooks, 21(3), 107-123.

Starc, G., Strel, J., \& Kovač, M. (2010). Telesni in gibalni razvoj slovenskih otrok in mladine $v$ številkah: šolsko leto 2007/2008. Ljubljana, Slovenia: Fakulteta za šport.

Starling, R. D., Matthews, D. E., Ades, P. A., \& Poehlman, E. T. (1999). Assessment of physical activity in older individuals: A doubly labeled water study. Journal of Applied Physiology, 86(6), 2090-2096.

Stensel, D., Lin, F. P., Ho, T. F., \& Aw, T. C. (2001). Serum lipids, serum insulin, plasma fibrinogen and aerobic capacity in obese and non-obese Singaporean boys. International Journal of Obesity, 25(7), 984-989.

Stolley, P. D., \& Lasky, T. (1995). Investigating disease patterns: The science of epidemiology. New York, NY: Scientific American Library.

Stone, E. J., McKenzie, T. L., Welk, G. J., \& Booth, M. L. (1998). Effects of physical activity interventions in youth: Review and synthesis. American Journal of Preventive Medicine, 15(4), 298-315.

Story, M., Nanney, M. S., \& Schwartz, M. B. (2009). Schools and obesity prevention: Creating school environments and policies to promote healthy eating and physical activity. The Milbank Quarterly, 87(1), 71-100.

Strauss, R. S., Rodzilsky, D., Burack, G., \& Colin, M. (2001). Psychosocial correlates of physical activity in healthy children. Archives of Pediatrics Adolescents Medicine, 155(8), 897-902.

Strel, J. (1996). Sports educational charts. Ljubljana, Slovenia: Ministry of education and sports.

Strel, J., Kovač, M., Roglej, A., Leskošek, B., Jurak, G., Starc, G., Majerič, M., 
\& Kolenc, M. (2003). Ovrednotenje spremljave gibalnega in telesnega razvoja otrok in mladine $v$ šlskem letu 2001-2002 in primerjava nekaterih parametrov športnovzgojnega kartona s šolskim letom 2000-2001 ter z obdobjem 1999-2000. Ljubljana, Slovenia: Zavod za šport Slovenije.

Strel, J. (2013). Analiza programa 'Zdrav življenjski slog' za leti 2010/11 in 2011/12. Retrieved from https://www.zsrs-planica.si/wp-content/ uploads/2013/05/Analiza-programa-_Zdrav-\%C5\%BEivljenjski-slog _-vmesno-poro\%C4\%8Dilo.pdf

Stroth, S., Kubesch, S., Dieterle, K., Ruchsow, M., Heim, R., \& Kiefer, M. (2009). Physical fitness, but not acute exercise modulates event-related potential indices for executive control in healthy adolescents. Brain Research, 1269, 114-124.

Suter, E., \& Hawes, M. R. (1993). Relationship of physical activity, body fat, diet, and blood lipid profile in youths 10-15 yr. Medicine and Science in Sports and Exercise, 25(6), 748-754.

Škof, B. (2007). Šport po meri otrok in mladostnikov: pedagoško-psihološki in biološki vidiki kondicijske vadbe mladih. Ljubljana, Slovenia: Fakulteta za šport.

Štalec, J., \& Momirović, K. (1971). Ukupna količina valjane varijance kao osnov kriterija za određivanje broja značajnih glavnih komponenata. Kineziologija, 1(1), 77-81.

Telama, R., Yang, X., Viikari, J., Välimäki, I., Wanne, O., \& Raitakari, O. (2005). Physical activity from childhood to adulthood: A 21-year tracking study. American Journal of Preventive Medicine, 28(3), 267-273.

Telford, A., Salmon, J., Timperio, A. F., \& Crawford, D. A. (2005). Examining physical activity among 5- to 6- and 10- to 12-year-old children: The Children's Leisure Activities Study. Pediatric Exercise Science, 17(3), 266280.

Thiese, M. S. (2014). Observational and interventional study design types: An overview. Biochemia Medica, 24(2), 199-210.

Titze, S., Ring-Dimitriou, S., Schober, P. H., Halbwachs, C., Samitz, G., ... \& Arbeitsgruppe Körperliche Aktivität/Bewegung/Sport der Österreichischen Gesellschaft für Public Health. (2010). Österriche Empfehlungen fur gesundheitswirksame Bewegung. Wien: Bundesministrum fur Gesundheit.

Tremblay, M. S., Barnes, J. D., \& Cowie, B. J. (2014). Impact of the active healthy kids Canada report card: A 10-year analysis. Journal of Physical Activity \& Health, 11, S3-S20.

Tremblay, M. S., Brownrigg, M., \& Deans, R. (2008, September). 23 active 
healthy kids Canada report card on physical activity for children and youth. In Children and exercise 14: The proceedings of the 24th Pediatric Work Physiology Meeting (p. 115). London, England: Routledge.

Tremblay, M. S., Gonzalez, S. A., Katzmarzyk, P. T., Onywera, V. O., Reilly, J. J., \& Tomkinson, G. (2016). Introduction to the Global Matrix 2.0: Report card grades on the physical activity of children and youth comparing 38 countries. Journal of Physical Activity and Health, 13(11), S85-S86.

Tremblay, M. S., Gray, C. E., Akinroye, K. K., Harrington, D. M., Katzmarzyk, P. T., Lambert, E. V., ... \& Prista, A. (2014). Physical activity of children: A global matrix of grades comparing 15 countries. Journal of Physical Activity and Health, 11(S1), 113-125.

Tremblay, M. S., Warburton, D. E., Janssen, I., Paterson, D. H., Latimer, A. E., Rhodes, R. E., ... \& Murumets, K. (2011). New Canadian physical activity guidelines. Applied Physiology, Nutrition, and Metabolism, 36(1), 36-46.

Treuth, M. S., Sherwood, N. E., Butte, N. F., McClanahan, B., Obarzanek, E., Zhou, A., ... \& Rochon, J. (2003). Validity and reliability of activity measures in African-American girls for GEMS. Medicine and Science in Sports and Exercise, 35(3), 532-539.

Troiano, R. P., \& Flegal, K. M. (1998). Overweight children and adolescents: Description, epidemiology and demographics. Pediatrics, 101, 497-504.

Trost, S. G. (2007). State of the art reviews: Measurement of physical activity in children and adolescents. American Journal of Lifestyle Medicine, 1(4), 299-314.

Trost, S. G., Loprinzi, P. D., Moore, R., \& Pfeiffer, K. A. (2011). Comparison of accelerometer cut points for predicting activity intensity in youth. Medicine \& Science in Sports \& Exercise, 43(7), 1360-1368.

Trost, S. G., Pate, R. R., Saunders, R., Ward, D. S., Dowda, M., \& Felton, G. A. (1997). Prospective study of the determinants of physical activity in rural fifth-grade children. Preventive Medicine, 26(2), 257-263.

Trost, S. G., McIver, K. L., \& Pate, R. R. (2005). Conducting accelerometerbased activity assessments in field-based research. Medicine \& Science in Sports \& Exercise, 37(11), 531-553.

Trudeau, F, \& Shephard, R. J. (2008). Physical education, school physical activity, school sports and academic performance. International Journal of Behavioral Nutrition and Physical Activity, 5(1), 10.

Twisk, J. W. R., Kemper, H. C. G., Mellenbergh, G. J., Van Mechelen, W., \& Post, G. B. (1996). Relation between the longitudinal development of lipoprotein levels and lifestyle parameters during adolescence and young adulthood. Annals of Epidemiology, 6(3), 246-256. 
UNESCO Institute for Statistics. (2012). International Standard Classification of Education: ISCED 2011. Montreal, Canada: Author.

US Department of Health and Human Services. (1996). Physical activity and health: A report of the Surgeon General. Atlanta, GA: Author.

US Department of Health and Human Services. (2000). Healthy people 2010. Atlanta, GA: Author.

US Department of Health and Human Services. (2008). Physical activity guidelines for Americans. Atlanta, GA: Author.

US Department of Health and Human Services. (2014, 1 December). HHS announces the nation's new health promotion and disease prevention agenda. Retrieved from https://smhs.gwu.edu/news/hhs-announces -nation\%E2\%80\%99s-new-health-promotion-and-disease-prevention -agenda

Van Boxtel, M. P., Paas, F. G., Houx, P. J., Adam, J. J., Teeken, J. C., \& Jolles, J. (1997). Aerobic capacity and cognitive performance in a cross-sectional aging study. Medicine \& Science in Sports \& Exercise, 29(10), 1357-1364.

Van Mechelen, W. (1997). Etiology and prevention of sports injuries in youth. In K. Froberg, O. Lammert, H. Steen Hansen, \& J. R. Blimkie Children and exercise 18: Exercise and Fitness - Benefits and Risks (pp. 209-227). Odense, Denmark: Odense University Press.

Van Sluijs, E. M., McMinn, A. M., \& Griffin, S. J. (2007). Effectiveness of interventions to promote physical activity in children and adolescents: Systematic review of controlled trials. BMJ, 335(7622), 1-13.

Verstraete, S. J., Cardon, G. M., De Clercq, D. L., \& De Bourdeaudhuij, I. M. (2006). Increasing children's physical activity levels during recess periods in elementary schools: The effects of providing game equipment. European Journal of Public Health, 16(4), 415-419.

Videmšek, M., \& Pišot, R. (2007). Šport za najmlajše. Ljubljana, Slovenia: Fakulteta za šport.

Volmut, T. (2014). Z merilnikom pospeška izmerjena gibalna/športna aktivnost mlajših otrok in analiza izbranih intervencij (Unpublished doctoral dissertation). University of Primorska, Koper.

Wacholder, S., Silverman, D. T., McLaughlin, J. K., \& Mandel, J. S. (1992). Selection of controls in case-control studies: II. types of controls. American Journal of Epidemiology, 135(9), 1029-1041.

Warburton, D. E., Nicol, C. W., \& Bredin, S. S. (2006). Health benefits of physical activity: The evidence. Canadian Medical Association Journal, 174(6), 801-809.

Ward, D. S., Evenson, K. R., Vaughn, A., Rodgers, A. B., \&Troiano, R. P. (2005). 
Accelerometer use in physical activity: Best practices and research recommendations. Medicine \& Science in Sports \& Exercise, 37, 582-588.

Warnecke, R. B., Johnson, T. P., Chávez, N., Sudman, S., O’Rourke, D. P., Lacey, L., \& Horm, J. (1997). Improving question wording in surveys of culturally diverse populations. Annals of Epidemiology, 7(5), 334-342.

Wechsler, D. (2001). Wechsler Individual Achievement Test-II-Abbreviated. San Antonio, TX: The Psychological Corporation.

Welk, G. J., Corbin, C. B., \& Dale, D. (2000). Measurement issues in the assessment of physical activity in children. Research Quarterly for Exercise and Sport, 71(2), 59-73.

Welk, G. J., Morrow, J. R. J., \& Falls, H. B. E. (2002). Fitnessgram reference guide. Dallas, TX: The Cooper Institute.

Westerterp, K. (2009). Assessment of physical activity: A critical appraisal. European Journal of Applied Physiology, 105(6), 823-828.

Whelton, S. P., Chin, A., Xin, X., \& He, J. (2002). Effect of aerobic exercise on blood pressure: A meta-analysis of randomized, controlled trials. Annals of Internal Medicine, 136(7), 493-503.

Wood, T., D. (1913). The ninth yearbook of the National Society for the Study of Education (Part 1). Chicago, IL: University of Chicago Press.

Woodward, M. (2013). Epidemiology: Study design and data analysis. [Place?] CRC Press.

World Health Organisation. (1997). Obesity: Preventing and managing the global epidemic. Geneva: Author.

World Health Organisation. (2002). Move for health. Geneva: Author.

World Health Organisation. (2010). Global recommendations on physical activity for health. Geneva: Author.

Yang, Y., \& Raine, A. (2009). Prefrontal structural and functional brain imaging findings in antisocial, violent, and psychopathic individuals: A meta-analysis. Psychiatry Research: Neuroimaging, 174(2), 81-88.

Yusuf, S., Hawken, S., Ôunpuu, S., Dans, T., Avezum, A., Lanas, F., ... \& Lisheng, L. (2004). Effect of potentially modifiable risk factors associated with myocardial infarction in 52 countries (the INTERHEART study): Case-control study. The Lancet, 364(9438), 937-952.

Zaninotto, P., Wardle, H., Stamatakis, E., Mindell, J., \& Head, J. (2006). Forecasting obesity to 2010. London, England: Department of Health.

Zakarian, J. M., Hovell, M. F., Hofstetter, C. R., Sallis, J. F., \& Keating, K. J. (1994). Correlates of vigorous exercise in a predominantly low SES and minority high school population. Preventive Medicine, 23(3), 314-321. 
Zakeri, I., Adolph, A. L., Puyau, M. R., Vohra, F. A., \& Butte N. F. Application of cross-sectional time series modeling for the prediction of energy expenditure from heart rate and accelerometry. Journal of Applied Physiology, 104(6), 1665-1673.

Zakon o osnovni šoli (ZOsn-UPB3). (2006). Uradni list Republike Slovenije, No. 81.

Zakon o športu (ZSpo-1). (2017). Uradni list Republike Slovenije, No. 29.

Zhang, K., Werner, P., Sun, M., Pi-Sunyer, F. X., \& Boozer, C. N. (2003). Measurement of human daily physical activity. Obesity Research, 11(1), 33-40. 



\section{Reviews}

This is the first monograph to systematically detail the state of physical activity in school children and relate these data to how well students perform academically in school. The work in this monograph provides an excellent overview of the methodologies used to collect physical activity and physical fitness data in children, which is of great importance for physical education university students, teachers and practitioners alike. The document also includes some of the first data complied on Slovenian school children in this area, and as such, is an excellent communication tool for advocating for child physical activity in Slovenia and particularly, highlighting the Slovenian school- based physical activity and physical education system. The work is written by dr. Sember and dr. Morrison, who were each actively involved in creating the Active Healthy Kids Slovenia research group, with the purpose of systematically chronicling the physical activity of children and youth in the country over the past 4 years. This nation-wide initiative required Sember, Morrison, and colleagues to assemble a national leadership group, compile all available data related to the physical activity of children and youth, and synthesize these data according to an international framework. This monograph represents an excellent addition to the research area and will certainly be used for pedagogical, research and outreach purposes both here in Slovenia and with International colleagues as well. 
Physical activity is one of the key determinants of health in life, which can be expressed in sports, playing with friends, family, physically-active transport, dancing, and others activities. Movement and sport activity in a population is very difficult to evaluate, especially when measuring physical activity directly. The Republic of Slovenia has a lot of data on physical activity in children, but to this day it has not been possible to read an overall view of the physical and sporting activities of children and adolescents in one place. This book summarizes the best available, and most reliable data and results from the field of physical activity in children and youth, presenting a current picture of various aspects of this social phenomenon. This book will be extremely welcome for all sports teachers, researchers in the field of kinesiology, sport, public health, and all those who have sports and movement in their heart. The content of this book is also appropraite and recommended to the parents of children who are involved in organized sport activities, and to the general public, especially to policy makers in government, public health, and education.

Janko Strel 

University of Primorska Press

www.hippocampus.si 